Aus der Klinik für Unfallchirurgie, Orthopädie und Plastische Chirurgie (Prof. Dr. med. W. Lehmann)

der Medizinischen Fakultät der Universität Göttingen

\title{
Die Auswirkungen des selektiven Androgenrezeptor-Modulators Enobosarm auf die Skelettmuskulatur der orchiektomierten Ratte
}

\author{
INAUGURAL-DISSERTATION \\ zur Erlangung des Doktorgrades \\ der Medizinischen Fakultät der \\ Georg-August-Universität zu Göttingen
}

vorgelegt von

Johannes Valentin Boy Billy-Rubin Wolgast

aus

Hamburg

Göttingen 2019 
Dekan:

Referent/in

Ko-Referent/in:

Drittreferent/in:
Prof. Dr. med. W. Brück

Prof. Dr. med. S. Sehmisch

Datum der mündlichen Prüfung: 
Hiermit erkläre ich, die Dissertation mit dem Titel "Die Auswirkungen des selektiven Androgenrezeptor-Modulators Enobosarm auf die Skelettmuskulatur der orchiektomierten Ratte" eigenständig angefertigt und keine anderen als die von mir angegebenen Quellen und Hilfsmittel verwendet zu haben.

Hamburg, den 


\section{Inhaltsverzeichnis}

Abbildungsverzeichnis.......................................................................

Tabellenverzeichnis............................................................................ VII

Abkürzungsverzeichnis........................................................................

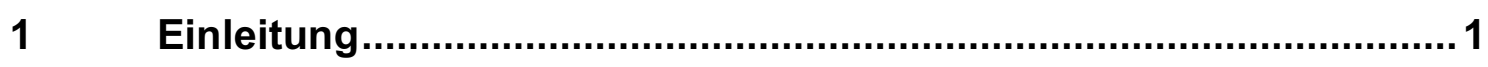

$1.1 \quad$ Kontext und Zielsetzung ........................................................ 1

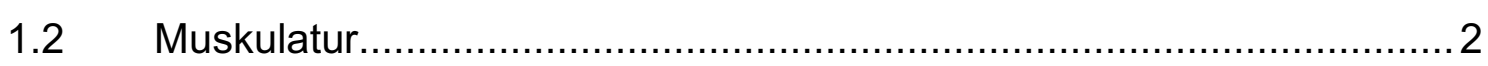

1.2.1 Anatomische und histologische Grundlagen .....................................

1.2.1.1 Embryologie der Skelettmuskulatur...............................................

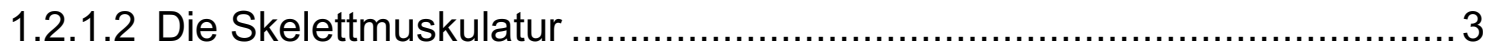

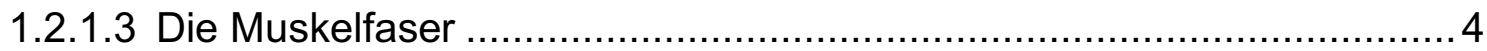

1.2.2 Physiologische und biochemische Grundlagen ............................... 5

1.2.3 Klassifizierung der Skelettmuskelzellen ......................................... 6

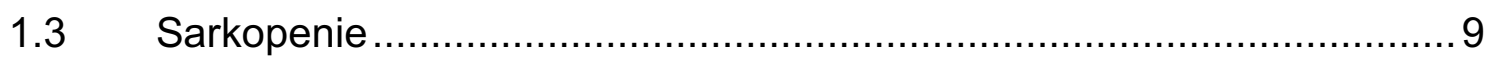

1.3.1 Zusammenhänge von Sarkopenie und Osteoporose .......................... 15

1.4 Selektive Androgenrezeptor-Modulatoren ........................................ 17

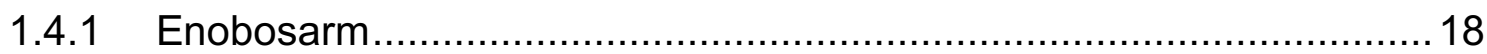

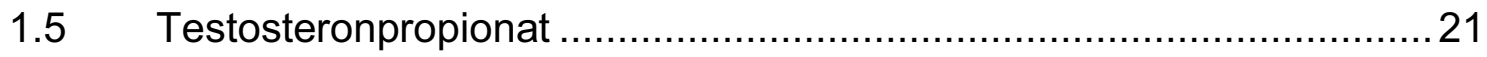

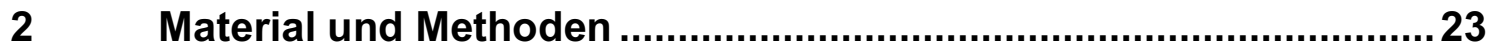

2.1 Versuchstiere und deren Haltung .................................................. 23

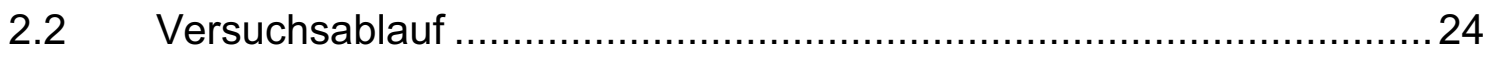

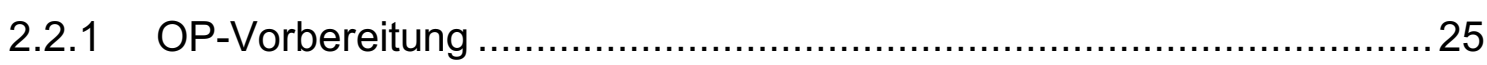

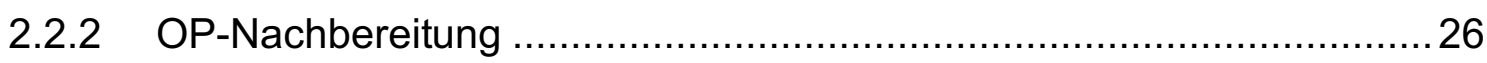

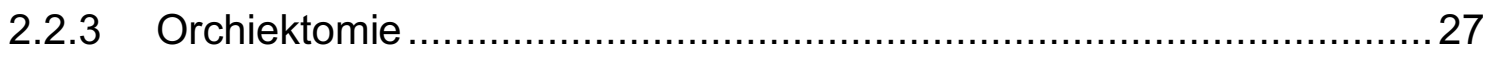

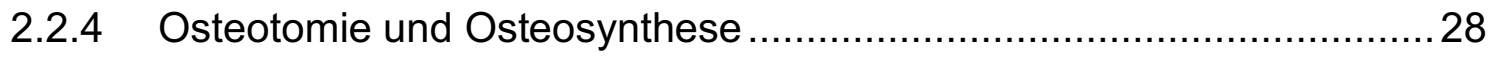

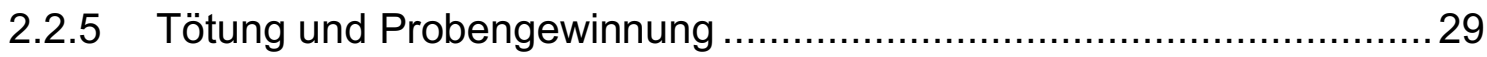

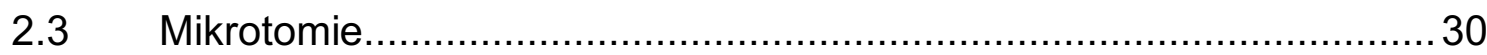

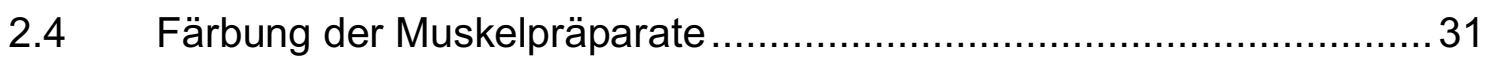

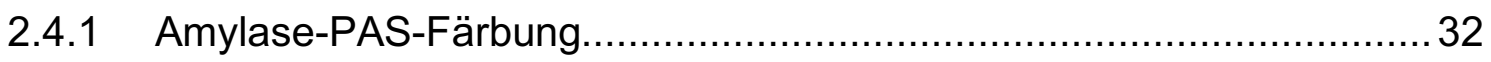

2.4.2 ATPase-Färbung mit Diaphorase …............................................... 32 


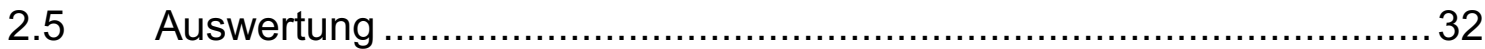

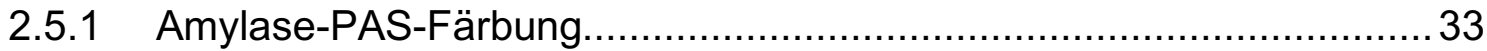

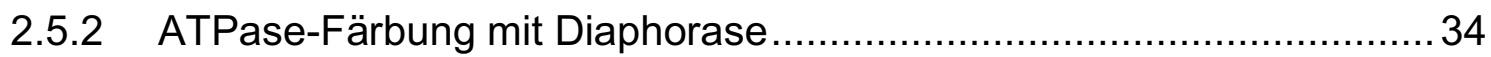

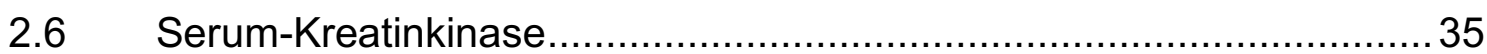

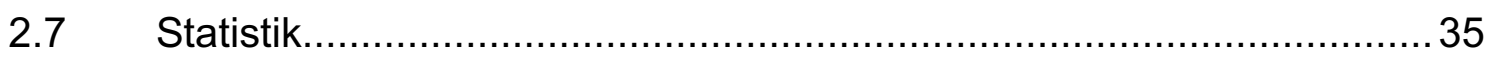

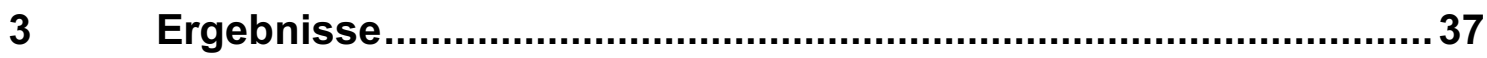

3.1 Versuchsgruppengrößen zum Versuchsende ….............................. 38

3.2 Futteraufnahme und Wirkstoffaufnahme im Versuchsverlauf................38

3.3 Körper-, Muskel- und Prostatagewichte .......................................... 41

3.3.1 Körpergewichte im Versuchsverlauf............................................ 41

3.3.2 Muskelgewichte zum Versuchsende ............................................... 44

3.3.3 Korrelation zwischen Muskel- und Körpergewichten...........................47

3.3.4 Prostatagewichte zum Versuchsende ............................................ 49

3.4 Auswertung der Amylase-PAS-Färbung........................................... 50

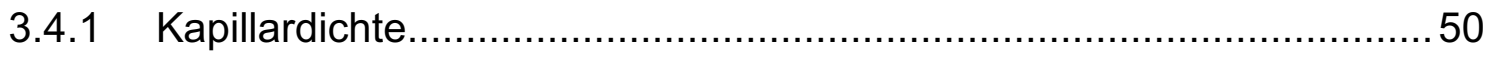

3.5 Auswertung der ATPase-Färbung mit Diaphorase .............................52

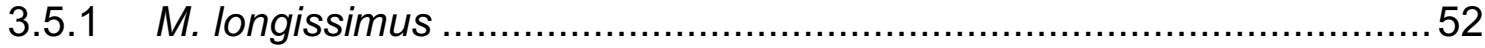

3.5.1.1 Auswertung der Muskelzellquerschnittsflächen................................52

3.5.1.2 Auswertung der Muskelzell-Äquivalentdurchmesser...........................55

3.5.1.3 Verhältnisse der Muskelzelltypen .................................................57

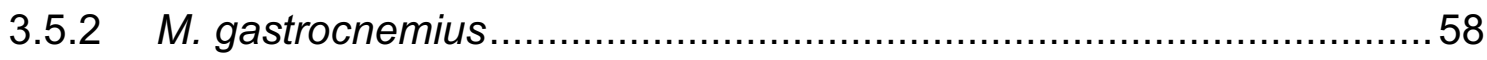

3.5.2.1 Auswertung der Muskelzellquerschnittsflächen.................................58

3.5.2.2 Auswertung der Muskelzell-Äquivalentdurchmesser..........................62

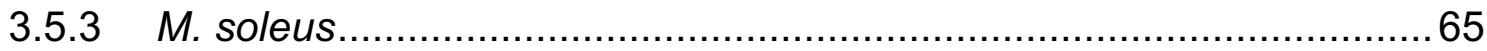

3.5.3.1 Auswertung der Muskelzellquerschnittsflächen................................65

3.5.3.2 Auswertung der Muskelzell-Äquivalentdurchmesser ..........................67

3.6 Serum-Kreatinkinase-Werte zum Versuchsende ................................69

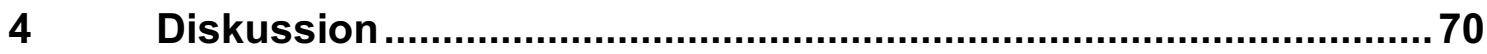

4.1 Körpergewichte, Muskelgewichte und Futteraufnahme ....................... 70

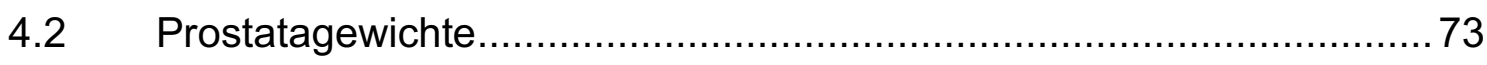

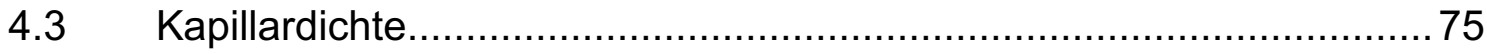

4.4 Muskelzellquerschnittsflächen und Muskelzell-

Äquivalentdurchmesser 
4.5 Muskelzelltypverhältnis des $M$. longissimus ................................ 80

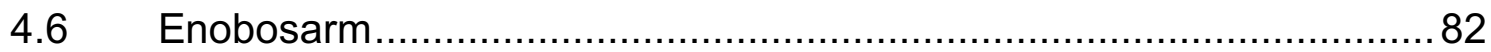

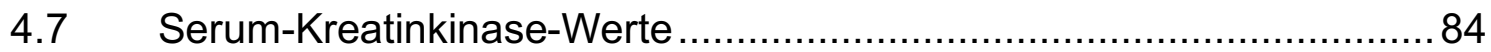

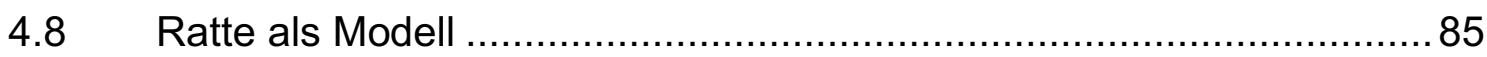

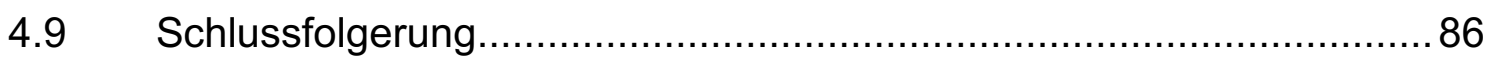

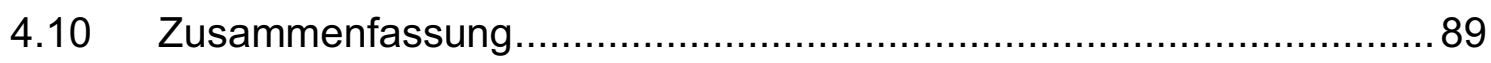

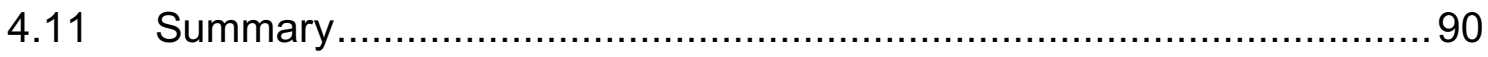

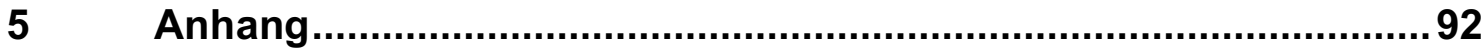

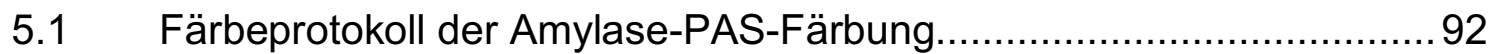

5.2 Färbeprotokoll der ATPase-Färbung mit Diaphorase .........................93

5.3 Ansätze der Färbeprotokolle ....................................................... 95

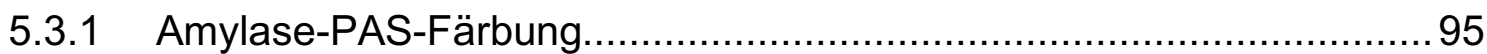

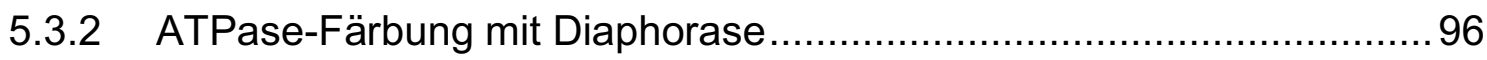

$5.4 \quad$ Tabellarische Darstellungen relevanter Daten .............................. 99

5.4.1 Futteraufnahme und Wirkstoffaufnahme im Versuchsverlauf...............99

5.4.2 Körper-, Muskel- und Prostatagewichte .................................... 102

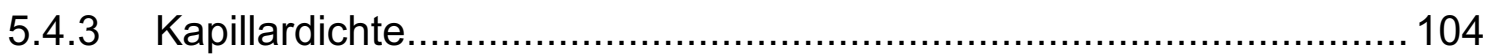

5.4.4 Muskelzellquerschnittsflächen und MuskelzellÄquivalentdurchmesser....................................................... 104

5.4.5 Verhältnis der Muskelzelltypen des M. longissimus ........................ 107

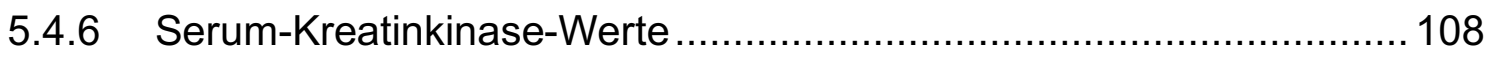

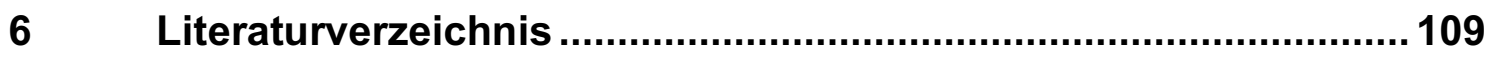




\section{Abbildungsverzeichnis}

Abbildung 1: Schematische Darstellung des Sarkomers mit Anordnung der Myofilamente in relaxiertem Zustand.......................................... 5

Abbildung 2: Strukturformel der Substanz Enobosarm .............................. 19

Abbildung 3: Zeitlicher Versuchsablauf.................................................. 24

Abbildung 4: Ligatur der Leitungsbahnen des Testiculus dexter.....................28

Abbildung 5: Präparation des M. soleus ................................................. 30

Abbildung 6: Auswertung der Amylase-PAS-Färbung (M. gastrocnemius; 100fache Vergrößerung) ......................................................... 33

Abbildung 7: Auswertung der ATPase-Färbung mit Diaphorase

(M. gastrocnemius; 100fache Vergrößerung) .................................. 34

Abbildung 8: Durchschnittliche tägliche Futteraufnahme ..............................39

Abbildung 9: Durchschnittliche tägliche Aufnahme von Enobosarm ................40

Abbildung 10: Durchschnittliche tägliche Aufnahme von Testosteronpropionat 40

Abbildung 11: Durchschnittliche Körpergewichte im Versuchsverlauf ............. 42

Abbildung 12: Körpergewichte zum Zeitpunkt der Orchiektomie .................... 42

Abbildung 13: Körpergewichte zum Zeitpunkt von Osteotomie und

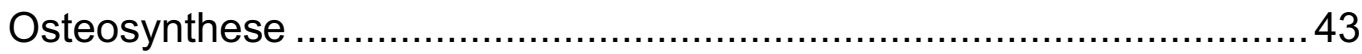

Abbildung 14: Körpergewichte zum Zeitpunkt der Tötung ...........................43

Abbildung 15: Gewichte der Mm. levatores anorum ................................. 44

Abbildung 16: Gewichte der Mm. gastrocnemii................................... 45

Abbildung 17: Muskelgewichte der Mm. gastrocnemii / Körpergewichte .......... 45

Abbildung 18: Gewichte der Mm. solei............................................... 46

Abbildung 19: Muskelgewichte der Mm. solei / Körpergewichte ..................... 46

Abbildung 20: Korrelation der Körpergewichte und der Muskelgewichte der

Mm. gastrocnemii ..

Abbildung 21: Korrelation der Körpergewichte und der Muskelgewichte der

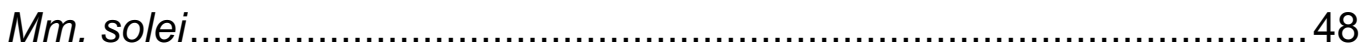

Abbildung 22: Prostatagewichte der Versuchstiere .................................. 49

Abbildung 23: Anzahl Kapillare / Anzahl Muskelzellen der Mm. longissimi....... 50

Abbildung 24: Anzahl Kapillare / Anzahl Muskelzellen der Mm. gastrocnemii .. 51

Abbildung 25: Anzahl Kapillare / Anzahl Muskelzellen der Mm. solei ............... 51

Abbildung 26: Muskelzellquerschnittsflächen, Typ-1 der Mm. longissimi.......... 52 
Abbildung 27: Muskelzellquerschnittsflächen, Typ-1 der Mm. longissimi /

Körpergewichte 53

Abbildung 28: Muskelzellquerschnittsflächen, Typ-2 der Mm. longissimi. 53

Abbildung 29: Muskelzellquerschnittsflächen, Typ-2 der Mm. longissimi. .54

Abbildung 30: Muskelzell-Äquivalentdurchmesser, Typ-1 der Mm. longissimi.. 55 Abbildung 31: Muskelzell-Äquivalentdurchmesser, Typ-1 der Mm. longissimi /

Körpergewichte 55

Abbildung 32: Muskelzell-Äquivalentdurchmesser, Typ-2 der Mm. longissimi.. 56 Abbildung 33: Muskelzell-Äquivalentdurchmesser, Typ-2 der Mm. longissimi /

Körpergewichte .56

Abbildung 34: Verhältnisse der Muskelzellanzahl Typ-1 zur

Gesamtmuskelzellanzahl der Mm. longissimi.

Abbildung 35: Verhältnisse der Muskelzellanzahl Typ-2 zur

Gesamtmuskelzellanzahl der Mm. longissimi. 57

Abbildung 36: Muskelzellquerschnittsflächen, Typ-1 der Mm. gastrocnemii .....58 Abbildung 37: Muskelzellquerschnittsflächen, Typ-1 der Mm. gastrocnemii /

Körpergewichte 59

Abbildung 38: Muskelzellquerschnittsflächen, Typ-1 der Mm. gastrocnemii ..... 59 Abbildung 39: Muskelzellquerschnittsflächen, Typ-2 der Mm. gastrocnemii ..... 60 Abbildung 40: Muskelzellquerschnittsflächen, Typ-2 der Mm. gastrocnemii /

Körpergewichte 60

Abbildung 41: Muskelzellquerschnittsflächen, Typ-2 der Mm. gastrocnemii /

Muskelgewichte

Abbildung 42: Muskelzell-Äquivalentdurchmesser, Typ-1 der

Mm. gastrocnemii .

Abbildung 43: Muskelzell-Äquivalentdurchmesser, Typ-1 der

Mm. gastrocnemii / Körpergewichte

Abbildung 44: Muskelzell-Äquivalentdurchmesser, Typ-1 der

Mm. gastrocnemii / Muskelgewichte. 63

Abbildung 45: Muskelzell-Äquivalentdurchmesser, Typ-2 der

Mm. gastrocnemii . 63

Abbildung 46: Muskelzell-Äquivalentdurchmesser, Typ-2 der

Mm. gastrocnemii / Körpergewichte 
Abbildung 47: Muskelzell-Äquivalentdurchmesser, Typ-2 der

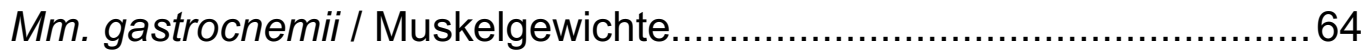

Abbildung 48: Muskelzellquerschnittsflächen, Typ-1 der Mm. solei.................. 65

Abbildung 49: Muskelzellquerschnittsflächen, Typ-1 der Mm. solei /

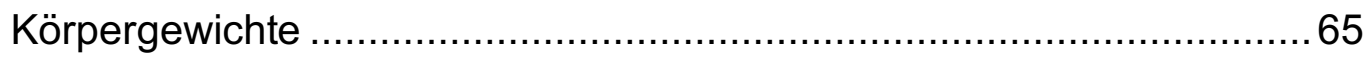

Abbildung 50: Muskelzellquerschnittsflächen, Typ-1 der Mm. solei /

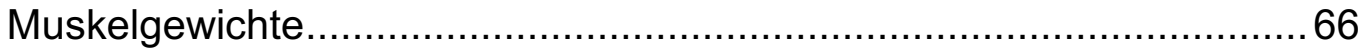

Abbildung 51: Muskelzell-Äquivalentdurchmesser, Typ-1 der Mm. solei ..........67

Abbildung 52: Muskelzell-Äquivalentdurchmesser, Typ-1 der Mm. solei I

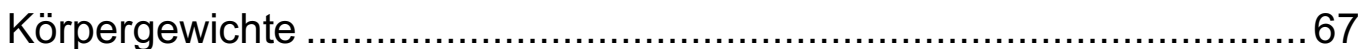

Abbildung 53: Muskelzell-Äquivalentdurchmesser, Typ-1 der Mm. solei I

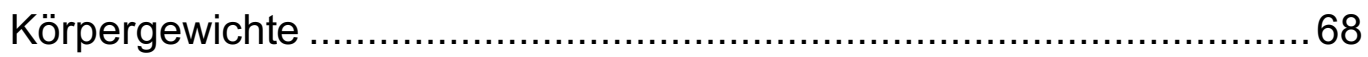

Abbildung 54: Kreatinkinase-Werte der Versuchstiere im Serum ....................69 


\section{Tabellenverzeichnis}

Tabelle 1: Klassifizierung der Skelettmuskelzellen ................................... 9

Tabelle 2: Namen des verwendeten SARM .......................................... 20

Tabelle 3: Pharmakokinetik radioaktiv markierten Gtx-024 .......................... 20

Tabelle 4: Übersicht über Gruppen und Behandlungen ................................. 25

Tabelle 5: Schmerzmedizinische Versorgung nach Osteotomie und

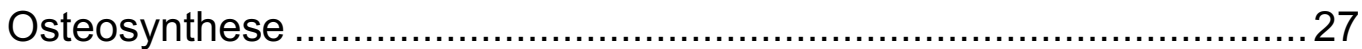

Tabelle 6: Abkürzungen und Behandlungen der Versuchsgruppen ................. 37

Tabelle 7: Versuchsgruppengrößen zum Versuchsende .............................. 38

Tabelle 8: Durchschnittliche tägliche Futteraufnahmen im Versuchsverlauf ..... 99

Tabelle 9: Durchschnittliche tägliche Wirkstoffaufnahme im Versuchsverlauf 101

Tabelle 10: Durchschnittliche Körpergewichte im Versuchsverlauf................. 102

Tabelle 11: Durchschnittliche Muskelgewichte $\mathrm{Mm}$. levatores anorum,

Mm. gastrocnemii und $\mathrm{Mm}$. solei................................................... 103

Tabelle 12: Durchschnittliche Prostatagewichte .................................... 103

Tabelle 13: Durchschnittliche Anzahl Kapillare / Anzahl Muskelzellen der

Mm. longissimi , Mm. gastrocnemii und Mm. solei .......................... 104

Tabelle 14: Durchschnittliche Muskelzellquerschnittsflächen der

Mm. longissimi sowie durchschnittliche Muskelzellquerschnittsflächen /

Körpergewichte .................................................................. 104

Tabelle 15: Durchschnittliche Muskelzell-Äquivalentdurchmesser Typ-1 und

Typ-2 der Mm. longissimi sowie durchschnittliche Muskelzell-

Äquivalentdurchmesser / Körpergewichte.

Tabelle 16: Durchschnittliche Muskelzellquerschnittsflächen, Typ-1 und Typ-

2 der $M m$. gastrocnemii sowie durchschnittliche

Muskelzellquerschnittsflächen / Körpergewichte bzw. Muskelgewichte105

Tabelle 17: Durchschnittliche Muskelzell-Äquivalentdurchmesser, Typ-1 und

Typ-2 der Mm. gastrocnemi sowie durchschnittliche Muskelzell-

Äquivalentdurchmesser / Körpergewichte bzw. Muskelgewichte 106

Tabelle 18: Durchschnittliche Muskelzellquerschnittsflächen, Typ-1 der

Mm. solei sowie durchschnittliche Muskelzellquerschnittsflächen /

Körpergewichte bzw. Muskelgewichte. 106 
Tabelle 19: Durchschnittliche Muskelzell-Äquivalentdurchmesser, Typ-1 der Mm. solei sowie durchschnittliche Muskelzell-Äquivalentdurchmesser / Körpergewichte bzw. Muskelgewichte.. 107

Tabelle 20: Verhältnisse der Muskelzellanzahl von Typ-1 und Typ-2 zur

Gesamtmuskelzellanzahl der Mm. longissimi. 107

Tabelle 21: Durchschnittliche Serum-Kreatinkinase-Werte. 108 


\section{Abkürzungsverzeichnis}

Aqua dest. Aqua destillata

ATP Adenosintriphosphat

ATPase Adenosintriphosphatase

$\mathrm{Ca}^{2+} \quad$ Calcium in ionisierter Form

d

Tag

DXA dual-energy X-ray absorptiometry

IGF-1 insulin-like growth factor-1

KG Körpergewicht

MyHC myosin heavy chain

$\mathrm{NaCl} \quad$ Natriumchlorid

NADP Nicotinamidadenindinukleotidphosphat

p.o. peros

PAS periodic-acid-Schiff

PSA prostataspezifisches Antigen

s.c. sub cutem

SARMs Selektive Androgenrezeptor-Modulatoren

SD Standardabweichung

UMG Universitätsmedizin Göttingen

ZTE Zentrale Tierexperimentelle Einrichtung 


\section{Einleitung}

\subsection{Kontext und Zielsetzung}

Osteoporose ist eine weit verbreitete systemische Skeletterkrankung, die durch eine erhöhte Knochenfragilität mit einhergehender Frakturneigung definiert ist (Consensus Development Conference 1993). Im Wesentlichen als postmenopausale Erkrankung erforscht, wurde die männerbetreffende Osteoporose lange vernachlässigt, wobei $17 \%$ der über 70-jährigen Männer an Osteoporose erkrankt sind (Scheidt-Nave et al. 1997).

Bemerkenswert ist die Assoziation von Osteoporose mit Sarkopenie (Monaco et al. 2011; Verschueren et al. 2013). Sarkopenie beschreibt eine generalisierte Erkrankung der Skelettmuskeln, einhergehend mit einem Rückgang der Muskelmasse und/oder -qualität, sowie der körperlichen Kraft (Cruz-Jentoft et al. 2019). Die sich daraus ergebende Beeinträchtigung des muskuloskelettalen Systems hat nicht nur eine Potenzierung der Frakturneigung (Adler 2014), sondern darüber hinaus auch eine Minderung der Lebensqualität (Jahelka et al. 2009; Adachi et al. 2010) sowie zukünftig deutlich steigende sozio-ökonomische Belastungen für die Gesellschaft zur Folge (Bleibler et al. 2013).

Unter anderen nimmt das Steroidhormon Testosteron eine zentrale Rolle für die Gesundheit des muskuloskelettalen Systems ein. Es ist aber auf Grund seiner möglichen Nebenwirkungen, wie beispielsweise der Begünstigung von Erkrankungen der Prostata oder kardiovaskulären Ereignissen, therapeutisch kritisch zu sehen (Gruenewald und Matsumoto 2003; Basaria et al. 2010).

Mit selektiven Androgenrezeptor-Modulatoren (SARMs) ist eine neue, potentiell nebenwirkungsarme Substanzgruppe Gegenstand der derzeitigen Forschungen und könnte eine Therapieoption für Osteoporose und Sarkopenie bieten (Omwancha und Brown 2006). Speziell die Erforschung der Substanz Enobosarm 
lieferte bisweilen vielversprechende Ergebnisse (Dalton et al. 2011; Dobs et al. 2013; Crawford et al. 2016).

Im Kontext dieser Erkenntnisse untersucht diese experimentelle Arbeit am Modell der orchiektomierten Ratte, welchen Einfluss der SARM Enobosarm auf die mit Osteoporose assoziierte Sarkopenie nehmen kann. Dafür wurden folgende Parameter anhand der Mm. longissimi, gastrocnemii und solei erhoben und mit denen von Kontrollgruppen verglichen: die Ratio von Typ-1- zu Typ-2Muskelzellen, die Muskelzellquerschnittsflächen und -äquivalentdurchmesser sowie die Kapillardichte. Darüber hinaus wurde das Gewicht von Prostata und $M$. levator ani ermittelt. Das Gewicht des M. levator ani dient als Indikator für die anabole Wirkung der Therapien. Das Gewicht der Prostata dient hingegen als Indikator für die androgene Wirkung der Therapie. Beide Parameter werden darüber hinaus zur Erfolgsbestätigung der Orchiektomie eingesetzt (Eisenberg und Gordan 1950; Hershberger et al. 1953). Zur Beurteilung von etwaiger Muskelzellschädigung wurde die Aktivität der Kreatinkinase im Serum bestimmt (Lang 2013).

\subsection{Muskulatur}

Die vorrangige Eigenschaft von Muskelzellen ist ihre Kontraktionsfähigkeit. Grundlegend dafür ist die Umwandlung von chemischer Energie in mechanische Arbeit. Die Kontraktionsfähigkeit ist wesentlich für den Erhalt des Lebens und hat facettenreiche Funktionen. Beispiele hierfür sind die Herzkontraktion, die Atmung, die Regulierung des Kreislaufes sowie die Stabilisierung und Bewegung des Körpers (Welsch und Deller 2010).

Von den verschiedenen existierenden Muskelgewebsarten ist für die hier vorliegende Arbeit die willkürlich innervierbare Skelettmuskulatur von besonderem Interesse, da sie einen wesentlichen Teil des menschlichen muskuloskelettalen Systems ausmacht und am Modell der orchiektomierten Ratte an den Mm. longissimi, gastrocnemii und solei stellvertretend untersucht wird. Darüber hinaus 
spielen andere Muskelgewebsarten bezüglich der im Folgenden besprochenen Pathologien eine untergeordnete Rolle und werden hier nicht weiter behandelt.

\subsubsection{Anatomische und histologische Grundlagen}

\subsubsection{Embryologie der Skelettmuskulatur}

Embryologischer Ursprung der Skelettmuskulatur sind Mesodermzellen, welche den entsprechenden Dermomyotomen der Somiten, dem Schlundbogen oder dem prächordalen Mesoderm entstammen. Als Ausnahme zu diesen Zellursprüngen ist die Irismuskulatur zu erwähnen, welche ektodermalen Ursprungs ist. Die Myogenese beginnt mit noch einzelligen, sich elongierenden Myoblasten, welche sich weiter zu mehrkernigen Myotuben vereinen. Die Myotuben nehmen im Verlauf weitere Myoblasten auf und die Zellkerne werden nach peripher verlagert. So entsteht der notwendige Platz für den kontraktilen Apparat. Erst innerhalb dieser Synzytien werden dann Myofilamente gebildet, welche maßgeblich für den Aufbau der Sarkomere (siehe 1.2.2) und letztendlich für die Kontraktionsfähigkeit der Muskelfaser sind.

Das Endomysium umgibt die Skeletmuskelfasern und besteht aus retikulären Fasern, welche der muskeleigenen Basallamina entspringen. Perimysium und Epimysium sind hingegen fibroblastären Ursprungs. Fast alle Skelettmuskelfasern entwickeln sich prae partum, die restlichen überwiegend vor Abschluss des ersten Lebensjahres. Zur Unterstützung der Regeneration und des Wachstums liegen den reifen Fasern innerhalb der Basallamina Satellitenzellen an. Dieser Zelltypus entspricht ruhenden Myoblasten mit Stammzellcharakter (Moore und Persaud 2007).

\subsubsection{Die Skelettmuskulatur}

Ein Skelettmuskel setzt sich aus bis zu $5 \mathrm{~cm}$ langen und zwischen $10 \mu \mathrm{m}$ und $100 \mu \mathrm{m}$ dicken Muskelfasern zusammen. Etwa 100 dieser Muskelfasern bilden zusammen eine Funktionseinheit - das Primärbündel. Aus diesen besteht wiederum das Sekundärbündel. Die Primärbündel werden durch das kollagenfaserige 
Perimysium internum und die Sekundärbündel durch das Perimysium externum voneinander abgegrenzt. Ein Muskel entspricht der Anzahl Sekundärbündeln, welche von einem Epimysium umgeben werden. Das Epimysium geht schließlich in die Muskelfaszie über.

Leitungsbahnen treten via Area nervovasculosae in den Muskel über und ziehen über das Perimysium externum in die Tiefe. Im Endomysium schließt sich ein Kapillarnetz an. Die Kapillaren sind schlingenförmig konfiguriert und so in der Lage, unterschiedliche Längenzustände der Muskelfasern zu tolerieren.

Die neuronalen Afferenzen der Skelettmuskulatur entstammen dem somatischen Nervensystem, welche über Motoneuronen im Rückenmark und ihre entsprechenden motorischen Endplatten für die Initiation der Kontraktion sorgen. Die Kontraktionskraft resultiert sowohl in Bewegung als auch in Stabilisierung der Zielkörper. In den meisten Fällen wird die Kontraktionskraft durch tendinöse Insertion an den jeweiligen Zielkörpern übersetzt. Das Ausmaß der Kontraktionskraft eines Muskels wird über die variable Anzahl innervierter motorischer Einheiten gesteuert. Eine motorische Einheit kann sich aus weniger als 100 bis zu über 1000 Muskelfasern und jeweils einem dazugehörigen Motoneuron zusammensetzen (Welsch und Deller 2010; Lüllmann-Rauch und Asan 2015).

\subsubsection{Die Muskelfaser}

Der Muskel wird gemeinhin auch als Fleisch bezeichnet. Somit verwundert es nicht, dass die histologische Terminologie der Muskelfaser zu Teilen von der altgriechischen Vokabel für Fleisch, sarx, abgeleitet ist (Gemoll et al. 2000). Beispiele für auf sarx zurückgehende Termini sind das besonders bewegungsstabile Sarkolemm (die Plasmamembran), das sarkoplasmatische Retikulum, wichtig für die intrazelluläre Calciumversorgung, sowie das Sarkoplasma. Neben den bis zu hunderten Kernen einer Muskelfaser sind auch die Mitochondrien in besonders großer Zahl vorhanden, um den erhöhten Energiebedarf dieses Zelltyps zu decken. 
Der Terminus Myofibrille beschreibt eines von vielen kontraktilen Elementen einer Muskelzelle. Die Myofibrillen erstrecken sich über die ganze Länge der Faser und bilden in ihrer Gesamtheit den kontraktilen Apparat. Lichtmikroskopisch fällt eine regelmäßige und sich ebenfalls über die gesamte Muskelfaser erstreckende Querstreifung auf. Mit Hilfe eines Polarisationsmikroskops lassen sich im längsgeschnittenen Muskelpräparat verschiedene Banden identifizieren (Abbildung 1). Die dunkle A-Bande bleibt während der Kontraktion konstant, wohingegen sich die hellere I-Bande verkürzt und in die A-Bande hineingleitet. Die A-Bande ist mittig durch eine hellere H-Zone geteilt, in deren Mitte wiederum ein schmaler dunklerer M-Streifen liegt. Die I-Bande wird durch die Z-Linie halbiert. Die Strecke zwischen zwei Z-Linien definiert die funktionelle Einheit der Myofibrillen - das Sarkomer. Ein Sarkomer ist in relaxiertem Zustand etwa 2,2 $\mu \mathrm{m}$ lang und bildet, teils zu Tausenden, eine Myofibrille (Welsch und Deller 2010; Lüllmann-Rauch und Asan 2015).

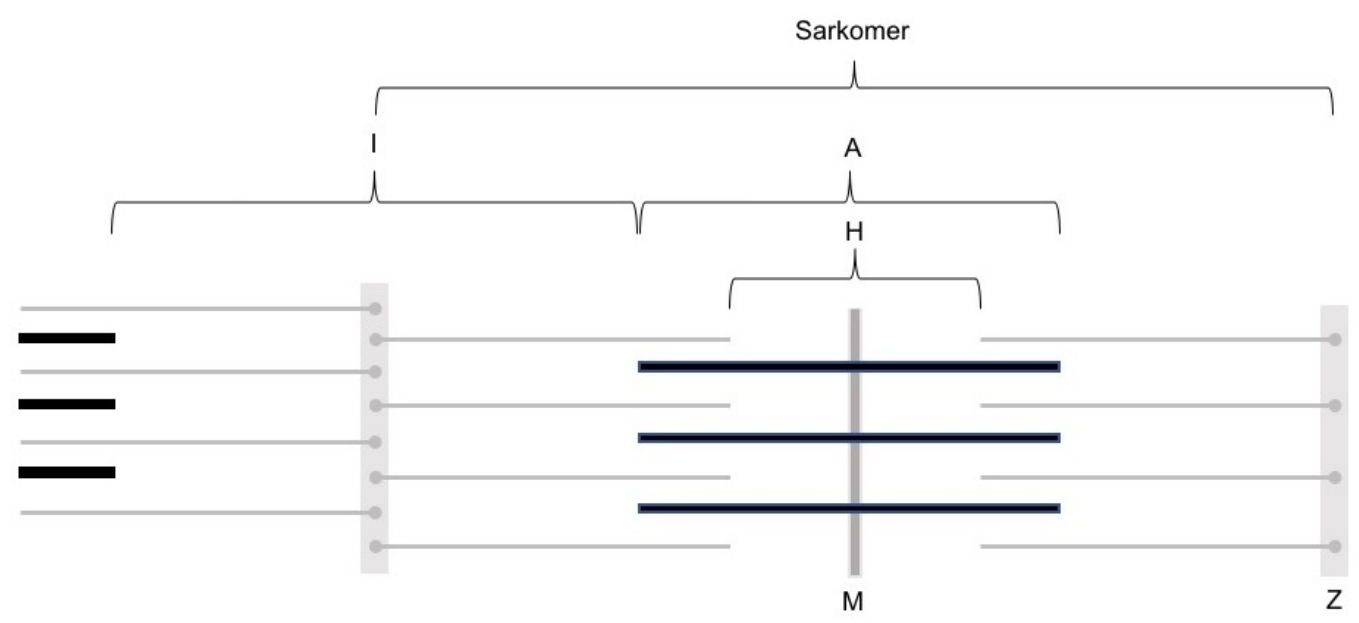

Abbildung 1: Schematische Darstellung des Sarkomers mit Anordnung der Myofilamente in relaxiertem Zustand; eigene Abbildung (nach Lüllmann-Rauch und Asan 2015); I: isothrophe Bande, A: anisothrophe Bande, H: Hensen-Zone, M: Mittelstreifen, Z: Zwischen-Linie; die Verwendung erfolgte mit freundlicher Genehmigung des Thieme-Verlags

\subsubsection{Physiologische und biochemische Grundlagen}

Sarkomere sind überwiegend aus Myofilamenten aufgebaut. Die Proteine Myosin, Aktin und Troponin sind wesentliche Bestandteile der Myofilamente und 
spielen eine entscheidende Rolle im Kontraktionsablauf. Zu Beginn der Kontraktion breitet sich ein Aktionspotential, von der motorischen Endplatte kommend, über das Sarkolemm aus. Dies führt zu einer intrazellulären Calcium-Ausschüttung $\left(\mathrm{Ca}^{2+}\right)$ aus dem Sarkoplasmatischen Retikulum. Die Bindung von $\mathrm{Ca}^{2+}$ an Troponin C wirkt via Aktin auf die Adenosintriphosphatase (ATPase) des Myosins. Unter Verbrauch des Energieträgers Adenosintriphosphat (ATP) gleiten die sich überlappenden Aktin- und Myosinfilamente um etwa 4-10 nm pro Zyklus in entgegengesetzter Richtung und das Sarkomer verkürzt sich. Die Umwandlung von chemischer Energie in mechanische Verkürzung führt also zur Kontraktion. Solange die $\mathrm{Ca}^{2+}$-Konzentration entsprechend hoch ist, wiederholen sich diese Zyklen bis hin zu einer Sarkomerverkürzung von $10-30 \%$. Die $\mathrm{Ca}^{2+}-\mathrm{Mg}^{2+}-\mathrm{ATP}-$ asen in der Membran des sarkoplasmatischen Retikulums und die sarcoplasmic/endoplasmic reticulum calcium ATPase pumpen schließlich die Ca-Ionen in ihr Reservoir zurück und es kommt zur Relaxation (Welsch und Deller 2010; Lang 2013; Lüllmann-Rauch und Asan 2015).

\subsubsection{Klassifizierung der Skelettmuskelzellen}

Die Skelettmuskulatur ist grundsätzlich in Fasern der Arbeitsmuskulatur, auch extrafusale Fasern, und Fasern der Muskelspindeln, auch intrafusale Fasern, zu unterteilen. Muskelspindeln fungieren als Dehnungsrezeptoren, welche Längenänderungen des Muskels detektieren. Gleichzeitig kann deren Länge und Spannung efferent gesteuert und so die Rezeptorempfindlichkeit beeinflusst werden. Den Propriorezeptoren zugehörig, schützen die Muskelspindeln den Muskel vor einer Überdehnung durch auslösen eines Muskelreflexes mit konsekutiver Verkürzung. Ein klassisches Beispiel hierfür ist der Patellarsehnenreflex. Die intrafusalen Fasern kommen insgesamt in verhältnismäßig niedrigerer Anzahl vor. Sie verlaufen parallel zu den Fasern der Arbeitsmuskulatur und haben einen Durchmesser von 5-20 $\mu \mathrm{m}$.

Die Arbeitsmuskulatur kann innerhalb von Millisekunden kontrahieren und wieder relaxieren. Man spricht deshalb auch von twitch fibres (engl.), was so viel wie 
Zuckungsfasern bedeutet. Zuckungsfasern sind fähig, über ihre Membran ein Aktionspotential mit einer Geschwindigkeit von etwa $5 \mathrm{~m} / \mathrm{s}$ fortzuleiten. Diese Geschwindigkeit würde längere Fasern dahingehend limitieren, dass sie sich nicht synchron kontrahieren könnten. Die Nervenleitgeschwindigkeit hingegen ist mit etwa $50 \mathrm{~m} / \mathrm{s}$ deutlich höher. Angesichts dieser Geschwindigkeitsdifferenz lässt sich nachvollziehen, warum längere Fasern von mehreren motorische Endplatten versorgt werden.

Von den Zuckungsfasern werden die Tonusfasern unterschieden. Diese sind jedoch nicht im Stande ein Aktionspotential über ihre Membran fortzuleiten. Deshalb sind sie synaptisch reich versorgt. Daraus resultiert allerdings eine eingeschränkte Kontraktionsgeschwindigkeit. Man findet Tonusfasern unter anderem in Muskelspindeln oder den äußeren Augenmuskeln vor.

Die Zuckungsfasern lassen sich auf Grund ihrer Zuckungseigenschaften in weitere Typen unterteilen. Langsam zuckende Fasern werden als Typ-1-Fasern bezeichnet. Dieser Begriff beschreibt Fasern, die normale Halte- und Bewegungsfunktionen erfüllen. Damit diese Dauerleistung gewährleistet werden kann, sind Typ-1-Fasern reich an Mitochondrien. Der Energiebedarf wird also weitestgehend durch oxidative, also aerobe Prozesse, gedeckt (Tabelle 1). Hierfür dienen Fetttropfen als Energiespeicher. Um den Sauerstoffbedarf zu decken, ist die intrazelluläre Proteinkonzentration des sauerstoffbindenden Myoglobins adäquat hoch. Typ-1-Fasern imponieren deswegen farblich rot. In Muskeln mit ausgeprägter Haltefunktion überwiegt die Anzahl der Typ-1-Fasern.

Schnell zuckende Fasern werden als Typ-2-Fasern bezeichnet. Ihre wesentliche Funktion liegt in schnellen, kurzen und kraftvollen Kontraktionen. Typ-2-Fasern haben einen niedrigen Myoglobingehalt, sind deswegen heller und werden als weiße Muskelfasern bezeichnet. Die Kontraktionsgeschwindigkeit ist zwischen zwei bis viermal größer als die der roten Muskulatur. Es verwundert also nicht, dass die Leistung schneller erschöpft ist und bis zu dreimal mehr Energie bedarf, als die der Typ-1-Fasern. Die benötigte Energie wird größtenteils aus anaerober 
Glykolyse gewonnen. Die dafür nötige Glukose wird von den Fasern in Form von Glykogen gespeichert.

Darüber hinaus können Muskelfasern histochemisch unterschieden werden. Dabei spielt der Nachweis von Enzymen mittels spezieller Färbemethoden (siehe 2.4) eine wichtige Rolle. Allen voran ist die Myosin-ATPase-Reaktion zu nennen. Diese kann zur Unterscheidung herangezogen werden, weil die Myosin-ATPasen der Fasertypen heterogen sind und unter alternierenden $\mathrm{pH}$-Bedingungen verschieden reagieren. Zum Beispiel reagieren die Typ-2-Fasern bei einem alkalischen $\mathrm{pH}$-Wert von 10,4 positiv und stellen sich dunkel dar. Der gleiche Fasertyp zeigt aber bei einem $\mathrm{pH}$-Wert von 4,3 eine Säurelabilität, reagiert infolgedessen negativ und stellt sich hell dar. Das Reaktionsverhalten der Typ-1-Fasern zeigt sich unter Einfluss der oben genannten pH-Werte genau gegensätzlich. Wenn man nun den pH-Wert auf 4,6 einstellt, reagieren nicht nur die Typ-1-Fasern positiv, sondern auch ein Teil der Typ-2-Fasern. Diese Fasern werden als Typ2B-Fasern von den hier nichtreaktiven Typ-2A-Fasern unterschieden. Ergänzend gibt es einen kleinen Teil von Muskelfasern, die sich histochemisch intermediär zeigen, da sie Myosine der Typ-1- und Typ-2-Fasern innehaben. Man spricht von Typ-C-Fasern oder Typ-AB-Fasern.

Auf molekularer Ebene lassen sich die Muskelfasertypen schließlich noch weiter differenzieren. Die Untersuchung eines Bestandteils des Myosins erbringt weitere Information bezüglich des Muskelfasertyps. Dazu wird die schwere Kette, engl. myosin heavy chain (MyHC), bestimmt (Drenckhahn 2008). Die Klassifizierung der Muskelfasertypen anhand der MyHCs ist jedoch im Rahmen dieser Arbeit nicht relevant und soll hier nicht weiter behandelt werden. 
Tabelle 1: Klassifizierung der Skelettmuskelzellen (Brooke und Kaiser 1970; Peter et al. 1972; Drenckhahn 2008); SO: slow oxidative; FOG: fast oxidative-glycolytic; FG: fast glycolytic

\begin{tabular}{llll}
\hline & \multicolumn{3}{c}{ Muskelzelltyp } \\
\cline { 2 - 4 } Parameter & Typ-1 & Typ-2A & Typ-2B \\
\hline \multirow{2}{*}{ Kontraktionsgeschwindigkeit } & langsam & schnell & schnell \\
Aktivität der Myosin-ATPase & mittel & hoch & sehr hoch \\
Ausdauer & lang & mittel & kurz \\
Mitochondrien-Anzahl & hoch & hoch & niedrig \\
Glykogenspeicher & klein & mittel & groß \\
Fettspeicher & groß & mittel & klein \\
Z-Streifen & breit & mittel & schmal \\
MyHC & MyHC-I( $\beta)$ & MyHC-IIa & MyHC-IIx \\
Muskelfarbe & rot & rot & weiß \\
Energiegewinnung & aerob & aerob/anaerob & anaerob \\
weitere Klassifizierungen & SO & FOG & FG \\
& oxidativ & intermediär & glykolytisch \\
\hline
\end{tabular}

\subsection{Sarkopenie}

Der Terminus Sarkopenie lässt sich etymologisch folgendermaßen entschlüsseln: Wie oben beschrieben, bedeutet sarx im Altgriechischen Fleisch. In der griechischen Mythologie wird die Göttin der Armut Penia genannt. Gleichzeitig wird Penia schlicht als Armut übersetzt. Die Armut an Fleisch ist natürlich heute in wissenschaftlichem und klinischem Kontext keine ausreichende Definition.

Der Begriff wurde erstmalig vor mittlerweile drei Dekaden von Irwin H. Rosenberg vorgeschlagen und verwendet (Rosenberg 1989). Die anfänglich uneinheitlichen Definitionen der Sarkopenie zeigen mittlerweile klare Ähnlichkeiten zueinander auf und machen eine klinische Anwendbarkeit des weltweit erworbenen Wissens möglich, was sich unter anderem in einer Integration in das Klassifikationssystems ICD-10-CM wiederspiegelt (Vellas et al. 2018). 
Muscaritoli et al. definieren Sarkopenie als eine Verfassung, die durch Verlust an Muskelmasse sowie an Muskelkraft charakterisiert ist. Obwohl Sarkopenie vorherrschend eine Erkrankung der älteren Bevölkerung ist, schließt diese Definition auch die Erkrankung junger Menschen mit ein. Zur Diagnosesicherung wird vorgeschlagen, die gleichzeitige Präsens der beiden folgenden Kriterien zu bestätigen. Erstens, eine Muskelmasse die mindestens zwei Standardabweichungen (SD) unter dem Durchschnitt einer vergleichbaren Gruppe junger Erwachsener liegt. Und zweitens, eine auf vier Meter gemessene Ganggeschwindigkeit von unter $0,8 \mathrm{~m} / \mathrm{s}$ (Muscaritoli et al. 2010).

Morley et al. schlagen vor, den Ausdruck „Sarkopenie mit limitierter Mobilität“ zu verwenden. Mit Hilfe der folgenden zwei Kriterien sollen Fälle definiert werden, die eine Therapie erfordern. Ein potentieller Muskelmassenverlust ist ebenfalls nach oben genanntem Vorgehen zu beurteilen. Außerdem erfüllt eine Gehgeschwindigkeit von gleich oder weniger als $1 \mathrm{~m} / \mathrm{s}$ oder eine Gehstrecke von weniger als $400 \mathrm{~m}$ in sechs Minuten das zweite positives Kriterium (Morley et al. 2011).

Fielding et al. definieren Sarkopenie als ein komplexes Syndrom, wobei es zu einem, mit dem Alter assoziierten, Massen- und Funktionsverlust der Skelettmuskulatur kommt. Neben dem Muskelschwund kann es zu einem erhöhten Körperfettanteil kommen. Die Diagnosesicherung basiert hier auf einer Gehgeschwindigkeit von unter $1 \mathrm{~m} / \mathrm{s}$ und einer fettfreien Körpermasse unter der 20sten Perzentile, bezogen auf Werte gesunder junger Erwachsener (Fielding et al. 2011).

Für Cruz-Jentoft et al. war Sarkopenie zunächst ein durch fortschreitenden und generalisierten Skeletmuskelmassen- und Kraftverlust charakterisiertes Syndrom mit einem Risiko ungünstiger Folgen, wie physische Behinderung, verminderte Lebensqualität und sogar Tod. Neuerdings wird jedoch der Verlust an Muskelkraft als das primäre Definitionskriterium herangezogen, da dieser als verlässlichster Parameter zur Evaluierung der Muskelfunktion erachtet wird und besser als die Muskelmasse mit ungünstigen Folgen der Erkrankung korreliert. 
Nach detektierter Muskelkraftverminderung führt die Feststellung einer verminderten Muskelmasse oder Muskelqualität zur Diagnosesicherung. Wenn zusätzlich die körperliche Leistungsfähigkeit erniedrigt ist, sollte die Sarkopenie als schwer eingestuft werden. Darüber hinaus kann die Sarkopenie in primär, also solitär altersbedingt, oder sekundär, also altersbedingt und/oder ein erkennbarer spezifischer Auslöser der Sarkopenie, kategorisiert werden. Sarkopenie, welche weniger als sechs Monate besteht, wird als akut und, welche mehr als sechs Monate besteht, als chronisch subkategorisiert (Cruz-Jentoft et al. 2010; CruzJentoft et al. 2019).

Über die Etablierung einer Definition hinaus bedürfen Themengebiete wie Epidemiologie, Diagnostik und Therapie der Sarkopenie weiterer Diskussion und Forschung.

Die European Working Group on Sarcopenia in Older People um Cruz-Jentoft untersuchte die Prävalenz von Sarkopenie rückblickend. Eine Untersuchung unter Einbeziehung des Alters war auf Grund der Studienlage nicht möglich. Jedoch lag das Alter, soweit es in den Studien angegeben war, zwischen 59,2 und 85,8 Jahren. Die Prävalenz für ältere Erwachsene liegt zwischen 1-29\%. Hingegen weisen ältere Menschen, die in Pflegeeinrichtungen leben, eine Krankheitshäufigkeit von 14-33 \% auf. Rund 10 \% der älteren Menschen, die akut im Krankenhaus versorgt sind, leiden an Sarkopenie. Die meisten Untersuchungen zeigten im Übrigem keinen signifikanten Prävalenzunterschied zwischen weiblichen und männlichen Untersuchten (Cruz-Jentoft et al. 2014).

Auch wenn die Ätiologie der Sarkopenie bis dato weitestgehend unklar ist (Lightfoot et al. 2014), sind dennoch einige Aspekte der Ätiologie untersucht. Beispielsweise kommt es im Alter zu einer Denervation von einzelnen Muskelfasern und damit einhergehender Reduktion von Typ-2-Fasern. Des Weiteren kommt es zu einer verminderten Ausschüttung von Growth Hormone, welche einerseits über seinen konsekutiv verminderten Effektor insulin-like growth factor-1 (IGF-1), zu einer generellen Muskelatrophie führt und andererseits eine verminderte $\mathrm{Ca}^{2+}$-Ausschüttung aus dem sarkoplasmatischen Retikulum und 
somit eine verminderte Kontraktilität nach sich zieht. IGF-1 ist ebenfalls ein wichtiger Mediator des Muskel- und Knochenwachstums. So zum Beispiel als ein Gegenspieler des Muskelwachstum hemmenden Proteins Myostatin. IGF-1 ist weiter in der Lage, den für die Proteinsynthese und die Verzögerung des Proteinabbaus wichtigen PI(3)/Akt-Pfad zu aktivieren. Diese Kaskade reguliert die Glukoseaufnahme des Skelettmuskels. Eine Signalverminderung hat folglich mehr Einfluss auf die Atrophie glykolytischer Typ-2-Fasern als auf die von oxidativen Typ-2-Fasern (Tarantino et al. 2013). Ein Konzentrationsabfall von Östrogen oder Testosteron scheint ebenfalls einen wichtigen Part im Entstehungsprozess der Krankheit zu spielen (Baumgartner et al. 1999; Morley et al. 2011; Terracciano et al. 2013).

Um Sarkopenie suffizient, im Sinne von Diagnosekriterien, beurteilen zu können, gibt es eine Reihe von Methoden. Die Bestimmung der Muskelmasse kann durch bildgebende Verfahren wie Computertomographie, Magnet Resonanz Tomographie, Sonographie oder Dual-energy X-ray absorptiometry (DXA) geschehen. Die Bioelektrische Impendanzanalyse, als nicht bildgebendes Verfahren, stellt eine weitere diagnostische Alternative dar, wobei die Aussagekraft der Messergebnisse aufgrund verschiedener Variablen kritisch betrachtet werden muss. Beispielsweise erfolgen die Konversionsrechnungen der primären Messergebnisse auf der Grundlage spezifischer Populationswerte, wobei diese weltweit nicht ausreichend erhoben und in entsprechende Konversionsformeln übertragen sind. Auch variieren die Messergebnisse in Abhängigkeit von Gerätehersteller sowie vom Hydratationsstatus des Patienten. Darüber hinaus kann eine Ermittlung des gesamten oder partiellen Körperkaliums in Bezug auf das fettfreie Körpergewebe aufschlussreich sein (Cruz-Jentoft et al. 2010; Sergi et al. 2015; Reiss et al. 2016; Cruz-Jentoft et al. 2019). Es lässt sich vermuten, dass die D3-Kreatinin-Verdünnungsmethode, die auf der Messbarkeit markierten Kreatinins basiert, als ein neues Diagnoseverfahren etabliert werden könnte (Clark et al. 2014). Ebenfalls hat die Konzentrationsmessung des C-Terminal Agrin Fragment, ein Baustein aus dem Bereich der elektromechanischen 
Kopplung, möglicherweise das Potential, die Diagnostikmöglichkeiten der Sarkopenie zu erweitern (Drey et al. 2013). Die Detektion von so genannten Neoepitopen verspricht darüber hinaus die Möglichkeit, das Fortschreiten einer Sarkopenie zu diagnostizieren (Nedergaard et al. 2013).

Zur Beurteilung der Muskelkraft bietet die Erfassung des Händedrucks ein probates Mittel und korreliert darüber hinaus mit der Kraft der unteren Extremitäten (Lauretani et al. 2003). Chair stand test measures, also das zeitliche Objektivieren des repetitiven Aufstehens von einem Stuhl ohne die Hilfe der Arme, bietet ein weiteres adäquates Diagnostikum. Auch die Kraftmessung der Knieextension bzw. -flexion kann diagnostisch hilfreich sein, wobei diese sich auf Grund von benötigten Messinstrumenten klinisch als nicht praktikabel erweist. Cruz-Jentoft et al. schlagen weiter vor, die Short Physical Performance Battery zu nutzen, um Balance, Kraft, Ausdauer und Gehgeschwindigkeit zu untersuchen. Dabei wird die Fähigkeit des Stehens in verschiedenen Positionen, die Gehgeschwindigkeit in m/s und das Aufstehen von und das Setzen auf einen Stuhl in fünfmaliger Repetition beurteilt. Die solitäre Untersuchung der Gehgeschwindigkeit hat an sich einen nicht zu vernachlässigenden prognostischen Wert bezüglich Gesundheitsaspekten wie z.B. einer starken Mobiliätseinschränkung. Zwei weitere Tests spielen in der Diagnostik von Sarkopenie eine Rolle. Der Timed get-up-and-go-Test zeigt das Patientenverhalten bezüglich der Bewegungsabfolge: von einem Stuhl aufstehen, gehen und sich wieder setzen. Abschließend ist der Stair climb power-Test zu nennen, der aber nicht für die klinische Verwendung, sondern nur für Forschungszwecke empfohlen wird.

Zusammenfassend empfehlen Cruz-Jentoft et al. folgende Diagnostik-Abfolge: Zunächst die Verwendung des SARC-F-Fragebogens zur Evaluation einer möglichen Sarkopenie. Fällt dieser positiv aus oder bei klinischem Verdacht sollte die Stärke des Händedrucks und chair stand test measures zur Ermittlung der Muskelkraft erfolgen. Zur Diagnosesicherung im Sinne der Feststellung einer erniedrigten Muskelmasse sollten DXA und bioelektrische Impendanz-Messverfahren sowie ggf. Magnetresonanz- und Computertomographie durchgeführt werden. 
Um schließlich die Schwere der Sarkopenie zu objektivieren stehen die verschiedenen o.g. Tests zur Beurteilung der körperlichen Leistungsfähigkeit zur Verfügung (Cruz-Jentoft et al. 2010; Cruz-Jentoft et al. 2019).

Die Beurteilung der Muskelqualität wird hingegen für den klinischen Alltag nicht empfohlen. Definiert ist diese unter anderem als Muskelkraft pro Muskelquerschnitt oder Muskelmasse (Roubenoff und Hughes 2000) sowie grundlegend durch die mikroskopische oder makroskopische Beurteilung der Muskelkomposition (McGregor et al. 2014). Hierfür stehen unterschiedliche diagnostische Mittel, wie beispielsweise Magnetresonanz- oder Computertomographie und die Sonographie, zur Verfügung, wobei bis dato eine Anwendung im klinischen Alltag in Ermangelung allgemeingültiger Empfehlungen nicht möglich ist (Cruz-Jentoft et al. 2019).

Differentialdiagnostisch ist wichtig zu erwähnen, dass die Sarkopenie nicht die einzige mit Muskelmassenverlust assoziierte pathologische Entität darstellt. Dafür beispielhaft sind Mangelernährung und Kachexie. Im Zuge der Mangelernährung kommt es nicht nur zu der Verringerung von Muskelmasse, sondern auch zur Abnahme der Körperfettmasse. Kachexie wird als multifaktorielles Syndrom verstanden, worunter es unter anderem zu ungewolltem Körpergewichtsverlust, genauer dem Verlust von Muskelmasse als auch meist, aber nicht notwendigerweise, von Körperfettmasse kommt, welcher durch Ernährungsmaßnahmen nicht aufgehoben werden kann und generell mit einer Inflammation einhergeht (Evans et al. 2008, Leitlinie Terminologie in der klinischen Ernährung 2013). Im Unterschied dazu ist für die Sarkopenie weder der Verlust von Körperfettmasse noch das Auftreten eines entzündlichen Prozesses maßgebend, sondern ausschließlich der Verlust von Muskelkraft und Muskelmasse oder -qualität (Cruz-Jentoft et al. 2019). Es kann also gefolgert werden, dass kachektische Patienten meist sarkopenisch sind, die meisten sarkopenischen Patienten aber nicht kachektisch sind (Cruz-Jentoft 2013). Eine sorgfältige Differentialdiagnostik ist unabdingbar, um adäquate therapeutische Maßnahmen einleiten zu können. 
Es gibt bis dato keine standardisierten Therapieschemata für Sarkopenie, aber dennoch gewichtige Indizien für sinnvolle Interventionen. Die regelmäßige körperliche Ertüchtigung in Form von Widerstandstraining (z. B. Krafttraining) allein (Scanlon et al. 2014) oder Kombinationstraining (zusätzliches Balance-, Flexibilitäts- und Aerobic Training) über einen Zeitraum von mehr als drei Monaten (Goodpaster und Chomentowski 2008) hat einen positiven Effekt auf körperliche Leistungsfähigkeit. Auch Muskelmasse und Muskelkraft werden positiv beeinflusst, wobei der Einfluss auf die Muskelmasse weniger zuverlässig ist. Die Studienlage zu ernährungswissenschaftlichen Interventionen ist nicht hinreichend. Die Supplementation von essentiellen Aminosäuren (mit mindestens 2,5 g Leucin) und 3-Hydroxy-3-Methylbuttersäure könnte einen positiven Effekt auf oben genannte Muskelparameter haben (Cruz-Jentoft et al. 2014). Klinisch anwendbare Medikamente sind derzeit nicht verfügbar, jedoch Gegenstand intensiver Forschung (Drescher et al. 2015).

Abschließend und für die hier vorliegende Arbeit von kontextualer Wichtigkeit ist die Feststellung, dass ältere Männer (Durchschnittsalter 59,6 Jahre) mit Sarkopenie eine signifikant erniedrigte Knochendichte haben und einer erhöhten Wahrscheinlichkeit ausgesetzt sind, an Osteoporose zu erkranken (Verschueren et al. 2013).

\subsubsection{Zusammenhänge von Sarkopenie und Osteoporose}

Es ist offensichtlich, dass eine verminderte Funktionalität der Skelettmuskulatur und das Sturzrisiko eines Menschen zusammenhängen. Nun kommt es bei einer Sarkopenie nicht nur zu einer Abnahme der Muskelmasse, sondern auch zu einer Verminderung von Kraft und Leistungsfähigkeit (Cruz-Jentoft et al. 2019). Infolge der verminderten Knochendichte im Zuge einer Osteoporose und der damit einhergehenden verminderten Knochenstabilität (Consensus Development Conference 1993, S. 646, Leitlinie Osteoporose 2014), ergibt sich für den Patienten ein erhöhtes Frakturrisiko. Da die Sarkopenie mit der Osteoporose assoziiert zu sein scheint (Monaco et al. 2011; Verschueren et al. 2013) und nichtvertebrale 
Frakturen sowie bei älteren Männern auch vertebrale Frakturen (Freitas et al. 2008) am häufigsten sturzbedingt sind (Costa et al. 2013), stellt diese Kombination der beiden Erkrankungen eine reale gesundheitliche Gefährdung im Sinne einer erhöhten Frakturneigung (Adler 2014) für den erkrankten Menschen dar. Eine Osteoporose-assoziierte Fraktur hat nicht nur eine signifikante Reduktion der Lebensqualität zur Folge (Jahelka et al. 2009; Adachi et al. 2010). Auch sozioökonomische Konsequenzen der manifesten Osteoporose sind nicht zu vernachlässigen: Die finanzielle Belastung des Gesundheitssystems steigt im Verhältnis zu Kontrollgruppen im Folgejahr einer Osteoporose-assoziierten Fraktur um das 2,2-3,5-Fache an (Budhia et al. 2012). Als Folge des demographischen Wandels in Richtung einer durchschnittlich älteren und insgesamt älter werdenden Bevölkerung ist von einer zukünftig steigenden finanziellen Belastung des Gesundheitssystems auf Grund eines prognostizierten Anstiegs der Osteoporose-assoziierten Frakturen auf mehr als das Doppelte bis zum Jahr 2050 auszugehen (Bleibler et al. 2013).

Die Entwicklung von diagnostischen Werkzeugen wie dem Fracture Risk Assessment Tool, welches auch Menschen ohne verminderte Knochendichte miteinbezieht, zeigt, dass eine verminderte Knochendichte die erhöhte Frakturneigung im Alter nicht allein erklären kann (Kanis et al. 2010). Osteoporose-assoziierte Frakturen sind das Resultat einer multifaktoriellen Entwicklung. Die Untersuchung sarkopenischer und nicht-sarkopenischer postmenopausaler Frauen zeigte eine deutliche Assoziation von Sarkopenie, nicht nur mit Osteoporose, sondern auch mit erhöhtem Sturz- und Frakturrisiko (Sjöblom et al. 2013). Binkley et al. sehen derart deutliche Parallelen zwischen Osteoporose und Sarkopenie, dass man von ein und derselben Erkrankung ausgehen könnte, die sich an unterschiedlichen Manifestationsorten zeigt. Darüber hinaus könnten die beiden Krankheitsbilder begrifflich unter „Dismobilitäts-Syndrom“ vereint werden (Binkley et al. 2013).

Eine grundlegende Theorie zum muskuloskelettalen System offeriert Frost unter dem Terminus „mechanostat“. Es wird davon ausgegangen, dass sich die 
Knochendichte u.a. in Abhängigkeit von der biomechanischen Beanspruchung der Muskeln verändert (Frost 1987; Frost 2003). Folglich könnte Sarkopenie bzw. eine verminderte biomechanische Beanspruchung der Knochen die Entstehung einer Osteoporose begünstigen. Girgis bemerkt die Notwendigkeit von Therapieansätzen, die auf das muskuloskelettale System als Ganzes zielen. Den singulären Betrachtungsweisen von Sarkopenie und Osteoporose wird der Begriff des muskuloskelettalen Alterns, also die konsensuelle Atrophie von Muskel und Knochen, gegenübergestellt (Girgis 2015).

Die hier vorliegende Arbeit unternimmt dementsprechend den Versuch, die Möglichkeit eines allgemeineren Therapieansatzes auszuloten, indem die Auswirkungen des SARMs Enobosarm auf die Skelettmuskulatur der Ratte erforscht werden.

\subsection{Selektive Androgenrezeptor-Modulatoren}

Selektive Androgenrezeptor-Modulatoren sind Substanzen mit Affinität zu dem Androgenrezeptor. Infolge von Ligandenbindung kann es zu Genexpression, also der Biosynthese von Proteinen (Shang et al. 2002) oder zu nicht-genomischen, deutlich schnelleren Reaktion, kommen (Estrada et al. 2003). SARMs bieten theoretisch ein androgenes und anaboles Wirkprofil (Negro-Vilar 1999; Bhasin und Jasuja 2009). Die Selektivität dieser Substanzen begründet sich aber in ihren Wirkungen, die sich auf bestimmte Zielgewebe limitieren. So sind deutliche Unterschiede von androgener und anaboler Wirkung untersucht und beschrieben (Narayanan et al. 2008). Die deutlich reduzierten unerwünschten androgenen Arzneimittelwirkungen eröffnen im Gegensatz zu Steroidhormonen, wie z.B. Testosteron, neue Therapieoptionen (Cilotti und Falchetti 2009). Als mögliche klinische Einsatzbereiche sind verschiedene, mit dem Verlust von Muskelmasse assoziierte Krankheiten zu nennen. Dazu zählen in erster Linie Krebserkrankungen, terminales Nierenversagen, Osteoporose, Senilität und Hypogonadismus (Segal et al. 2006). 
SARMs können grundsätzlich in steroidal bzw. nicht-steroidal unterschieden werden (Srinath und Dobs 2014). Nicht-steroidale SARMs werden weder von der 5-alpha-Reduktase zu Dihydrotestosteron noch von Aromatasen zu Estradiol umgewandelt. Dies könnte beispielweise therapiebedingte Prostatahyperplasie oder Gynäkomastie vermeiden (Zilbermint und Dobs 2009). Negro-Vilar fasste schon 1999 die wünschenswerten Eigenschaften der SARMs zusammen: Wirkneutralität gegenüber Prostata-, Brust- und Hautanhangsgewebe, Stimulation von Knochen- und Muskelwachstum sowie von Muskelkraft und schließlich orale Verfügbarkeit (Negro-Vilar 1999).

SARMs sind bis dato nicht für den klinischen Einsatz zugelassen. Die Substanz Enobosarm hat jedoch in klinischen Studien bis in die Phase III signifikante Ergebnisse erzielt (Srinath und Dobs 2014).

\subsubsection{Enobosarm}

Der in diesem Versuchsaufbau applizierte SARM wurde von der Firma GTx Incorporated entwickelt und ist den nicht-steroidalen Aryl-Proprionamiden zuzuordnen (Zilbermint und Dobs 2009). Die Namensvielfalt ist in Tabelle 2 ersichtlich. Zuerst unter dem Namen S-22 geführt, wurde die Pharmakokinetik (Tabelle 3) der Substanz (Abbildung 2) in zwei Tierversuchen untersucht (Kim et al. 2005; Kim et al. 2013). 


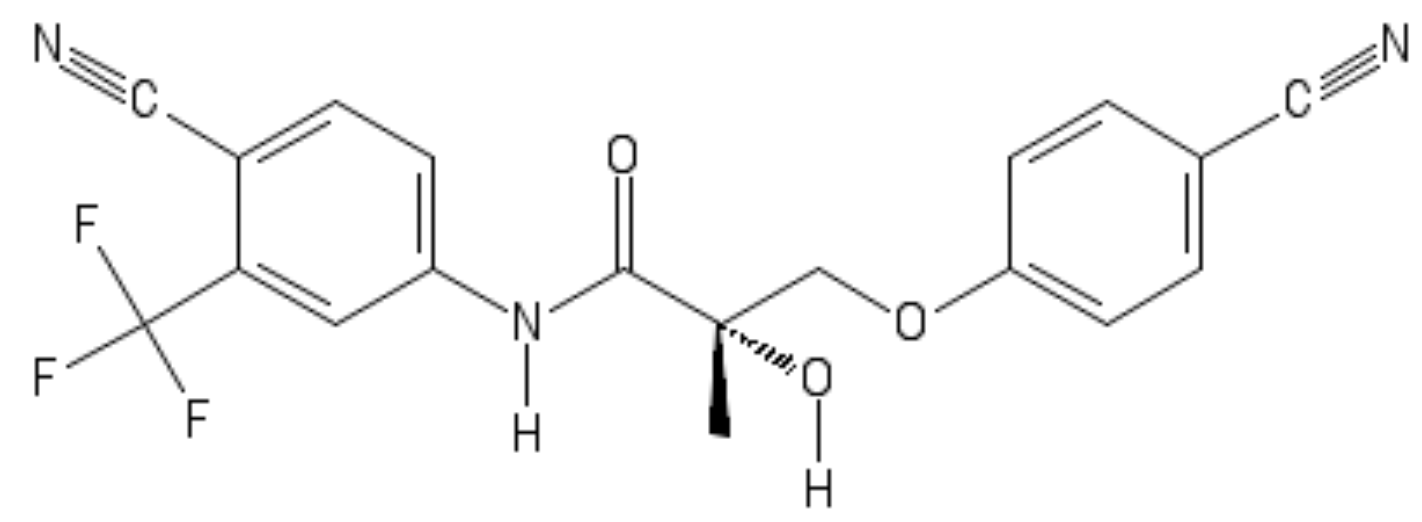

Abbildung 2: Strukturformel der Substanz Enobosarm; eigene Abbildung nach Kim et al. 2013; die Verwendung erfolgte mit freundlicher Genehmigung des Autors

In einer klinischen Phase-II-Studie zeigten die Mitarbeiter von GTx Incorporated, dass die Substanz, nun GTx-024 oder Enobosarm genannt, signifikant die fettfreie Körpermasse sowie die körperliche Leistungsfähigkeit positiv beeinflusst (Dalton et al. 2011). Eine weitere klinische Phase-II-Studie zeigte ebenfalls einen Anstieg der fettfreien Körpermasse. Dies jedoch im Unterschied zur vorangegangenen Studie bei onkologisch erkrankten Erwachsenen. Zwischen den Versuchsgruppen und der Kontrollgruppe zeigten sich hier keine Sicherheitsunterschiede bezüglich der Einnahme der Substanz (Dobs et al. 2013). Die klinischen Phase-III-Studien POWER1-2 sind abgeschlossen, wobei die Ergebnisse nur teilweise und vorläufig publiziert wurden. In beiden Studien wurde die Wirksamkeit von Enobosarm bei onkologisch erkrankten Erwachsenen hinsichtlich Muskelmasse und körperlicher Leistungsfähigkeit untersucht. POWER1 ließ eine signifikante Verbesserung der fettfreien Körpermasse und der körperlichen Leistungsfähigkeit verzeichnen. POWER2 zeigte ebenfalls eine Verbesserung der fettfreien Körpermasse, jedoch keine Verbesserung der körperlichen Leistungsfähigkeit, welche in beiden Versuchen mittels stair climb power evaluiert wurde (Srinath und Dobs 2014; Crawford et al. 2016). Angesichts der nur teilweise gegebenen signifikanten Verbesserung der körperlichen Leistungsfähigkeit lässt sich die erwartete Wirksamkeit hinsichtlich einer suffizienten Therapie der 
Sarkopenie, sowie eine konsekutive Verbesserung der Lebensqualität und Mortalität der Patienten, zunächst nicht ausreichend darstellen. Aus finanziellen Gründen und einer nicht zu erwartenden Zulassung auf dem amerikanischen Markt, habe die Firma Gtx Incorporated mittlerweile Forschung auf diesem Gebiet bis auf weiteres eingestellt (Garber 2016).

Tabelle 2: Namen des verwendeten SARM

\begin{tabular}{ll}
\hline Name & Quelle \\
\hline Ostarine $^{\circledR}$ & (Zilbermint und Dobs 2009; Kim et al. \\
& 2013) \\
Enobosarm & (Dalton et al. 2011) \\
GTx-024 & (Dalton et al. 2011) \\
S-22 & (Kim et al. 2005) \\
MK-2866 & (Zilbermint und Dobs 2009) \\
[3-(4-Cyano-phenoxy)-N-(4-cyano-3- & (Kim et al. 2005) \\
trifluoromethyl-phenyl)-2-hydroxy-2- & \\
methyl-propionamide] & \\
\hline
\end{tabular}

Tabelle 3: Pharmakokinetik radioaktiv markierten Gtx-024 (10 mg/kg KG, per os) in Ratten (Kim et al. 2013); Cmax: durchschnittliche maximale Radioaktivitätskonzentration im Plasma; Tmax: Zeitpunkt von Cmax; F: orale Bioverfügbarkeit; T1/2: Halbwertszeit

\begin{tabular}{lll}
\hline Parameter & Männlich & Weiblich \\
\hline Cmax $(\mu \mathrm{g}-\mathrm{Eq} / \mathrm{ml})$ & $3,82 \pm 0,59$ & $5,40 \pm 1,28$ \\
$\operatorname{Tmax}(\mathrm{h})$ & $4,0 \pm 0$ & $4,0 \pm 0$ \\
$\mathrm{~F}(\%)$ & 100 & 105 \\
$\mathrm{~T} 1 / 2(\mathrm{~h})$ & $14,0 \pm 3,4$ & $16,3 \pm 4,0$ \\
\hline
\end{tabular}




\subsection{Testosteronpropionat}

Testosteronpropionat ist ein Ester des Steroidhormons Testosteron. Schon vor Dekaden wurde die anabole, sowie androgene Wirkung dieser Substanz in Tierversuchen erforscht (Korenchevsky et al. 1937; Eisenberg und Gordan 1950). Auch zeigte Testosteronpropionat in Bezug auf seine Wirkung eine höhere Aktivität als Testosteron (Miescher et al. 1936).

Bei über 65 Jahre alten gesunden Männern zeigte Testosteron eine Erhöhung der fettfreien Körpermasse, einhergehend mit einer Erniedrigung der Gesamtkörperfettmasse. Eine Verbesserung der an Knieextension und -flexion gemessenen Kraft zeigte sich nicht (Snyder et al. 1999). Jedoch erbrachten andere Untersuchungen ambivalente Ergebnisse bezüglich körperlicher Leistungsfähigkeit und Kraft, wobei Versuchsgruppen signifikante Verbesserung erfuhren und andere nicht. Die Untersuchungen zeigten weiter, dass die Sicherheit eines erfolgreichen therapeutischen Einsatzes in Abhängigkeit von verschiedenem Patientenklientel auf Grund möglicher unerwünschter Arzneimittelwirkungen unzureichend erforscht ist (Gruenewald und Matsumoto 2003). Während einer Testosterontherapie wäre es notwendig das Blutbild und das prostataspezifische Antigen (PSA) sowie die Prostata selbst zu untersuchen, um zum einen eine Polyzythämie und zum anderen ein Prostatakarzinom vermeiden oder früh erkennen zu können (Cilotti und Falchetti 2009). Eine Testosterontherapie kann ebenfalls zu einem erhöhten Risiko kardiovaskulärer Ereignisse führen (Basaria et al. 2010), wobei dies kontrovers diskutiert wird und teilweise gegenläufige Meinungen im Sinne kardioprotektiver Eigenschaften von Testosteron geäußert werden (Anawalt und Yeap 2018; Gagliano-Jucá und Basaria 2019). Auch Schlafapnoe gilt als mögliche unerwünschte Arzneimittelwirkung (Cistulli et al. 1994). Zu den bereits genannten möglichen unerwünschten Arzneimittelwirkungen ist eine potentielle Hepatotoxizität hinzuzufügen sowie eine Bemängelung der oralen Verfügbarkeit von Testosteron (Westaby et al. 1977; Srinath und Dobs 2014). In einem vorangegangenen Versuchen konnte 
jedoch gezeigt werden, dass eine orale Applikation von Testosteronpropionat eine befriedigende Wirkstoffkonzentration im Serum von Ratten erzielt (Stuermer et al. 2009).

Testosteron wird schließlich als körpereigenes Hormon von Enzymen zu wirksamen Hormonen verändert. Die $5 \alpha$-Reduktase konvertiert es zu dem potenteren $5 \alpha$-Dihydrotestosteron und die Aromatase zu Estradiol (Kicman 2008). Es sollte jedoch grundsätzlich festgehalten werden, dass die Datenlage bezüglich der Anwendbarkeit von Testosteron als nicht ausreichend angesehen wird (Bassil et al. 2009; Osterberg et al. 2014) und Gegenstand weiterer Forschung und Diskussion sein sollte. 


\section{Material und Methoden}

\subsection{Versuchstiere und deren Haltung}

Für den Versuch wurden Ratten des Stammes Sprague Dawley im Alter von sechs bis acht Monaten bei der Firma Janvier aus Saint-Berthevin in Frankreich bestellt. Diese wurden in Räumlichkeiten der Zentralen Tierexperimentellen Einrichtung (ZTE) der Universitätsmedizin Göttingen untergebracht. Tierärzten und Pflegepersonal der ZTE oblag die Verantwortung für die Tiere. In den Räumlichkeiten herrschte eine Temperatur von $20{ }^{\circ} \mathrm{C}$, eine Luftfeuchtigkeit von ca. 55 \% und ein zwölfstündiger deckenlichtgesteuerter Tag-Nacht-Rhythmus. Zu Beginn des Versuches behausten jeweils drei Tiere einen Käfig, namentlich Makrolon IV® (Zoonlap, Castop-Rrauxel, Deutschland). Diese wurden alle sieben Tage durch einen gereinigten und desinfizierten Käfig ersetzt. In diesem Zuge wurde das Körpergewicht der Ratten ermittelt und dokumentiert (Waage: KERN 44049N, KERN \& SOHN GmbH, Balingen-Frommern, Deutschland). Das Restfutter wurde ebenfalls wöchentlich gewogen und wieder auf 1500g Futter aufgestockt. Ziel dessen war die genaue Ermittlung der Verzehrmenge und der daraus resultierenden Wirkstoffaufnahme. Die sojafreien und phytoestrogenarmen FutterPellets (V554-000 R/MH $10 \mathrm{~mm}$ ) wurden von der Firma ssniff Spezialitäten $\mathrm{GmbH}$ (Soest, Deutschland) den gewünschten Wirkstoffkonzentrationen entsprechend produziert. Um Verwechslungen vorzubeugen, wurden die FutterPellets farblich gekennzeichnet. Wirkstofffreie Pellets waren blau eingefärbt, Enobosarm-haltige rot und Testosteronpropionat-haltige grün. Das demineralisierte Trinkwasser der Spenderflaschen ist zwei Mal pro Woche aufgefüllt worden und stand den Tieren ad libitum zur Verfügung. Um die Tiere identifizieren zu können, wurde ihnen im Rahmen der Orchiektomie ein Transponder (UNO Micro ID 12 mm ISO Transponder, UNO BV, Zevenaar, Niederlande) in den subkutanen Nackenbereich implantiert. Über den Transponder konnte man jedes Tier mittels eines Detektors (Mini Max II, Datamars SA, Bedano, Schweiz) einer 
fünfstelligen Nummer zuordnen. Der durchgeführte Tierversuch wurde von der Bezirksregierung Braunschweig genehmigt.

\subsection{Versuchsablauf}

Zu Beginn des Versuches bestand jede der sechs Versuchsgruppen aus 15 männlichen Ratten. In der vierten Woche nach Lieferung, wurden 75 Tiere beidseitig orchiektomiert um eine osteoporotische sowie sarkopenische Konstitution der Ratten zu verursachen (Wink und Felts 1980; Turner et al. 1989; Komrakova et al. 2011). Anschließend wurde eine erste medikamentöse Therapie (hier Prophylaxe) mit jeweils dem SARM Enobosarm bzw. Testosteronpropionat in zwei von sechs Gruppen eingeleitet (Tabelle 4). Jeweils 12 Wochen später folgte eine beidseitige Osteotomie des Femurs mit anschließenden Plattenosteosynthesen. Ab dem ersten postoperativen Tag wurden die weiteren gruppenentsprechenden Therapien (Tabelle 4) eingeleitet. In diesem Versuch ließ sich Testosteronpropionat wegen seiner zuverlässigen anabolen und androgenen Eigenschaften als Kontrolltherapie einsetzen. Schließlich, nach jeweils weiteren 6 Wochen, wurden die Tiere der Wissenschaft geopfert (Abbildung 3).

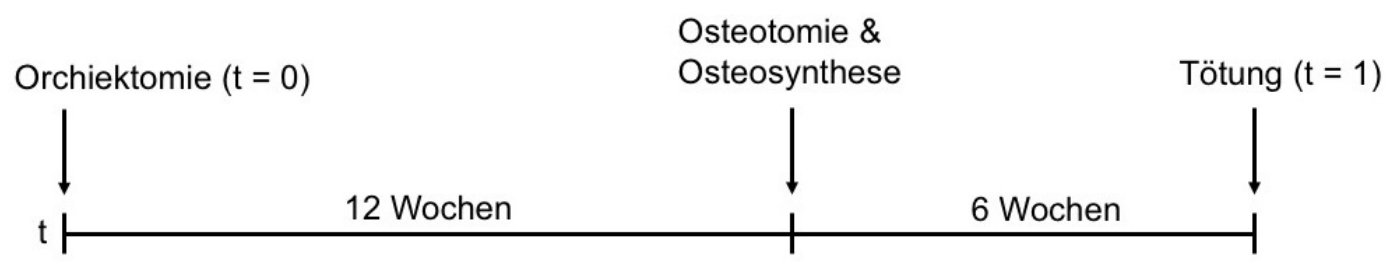

Abbildung 3: Zeitlicher Versuchsablauf $(t) ;(t=0)$ : Versuchsbeginn, $(t=1)$ : Versuchsende

Prophylaxe und Therapie wurden, wie schon beschrieben, in Form von FutterPellets appliziert. Die Substanz Enobosarm und der zugehörige Reinheitsnachweis (Purity >98 \%, Cas No.:841205-47-8) der Firma Biochempartner@ wurden über den Distributor Hölzel Diagnostika (Köln, Deutschland) bezogen. Die tägliche Zieldosis pro Tier betrug 0,4 mg/ kg Körpergewicht (KG). Adaptiert an 
ein durchschnittliches Körpergewicht von $750 \mathrm{~g}$ wurden 0,3 mg Enobosarm auf eine prognostizierte Futteraufnahme von 35 g/ Tag (d) verteilt. Testosteronpropionat wurde von Sigma-Aldrich (St. Louis, Vereinigte Staaten von Amerika) geliefert. Hier betrug die Zieldosis 46,67 mg/kg KG/d (Stürmer et al. 2005; Seidlová-Wuttke et al. 2006; Stürmer et al. 2009; Dalton et al. 2011).

Zur Förderung der Knochenauswertung eines anderen Teilversuches wurden den Tieren nach Osteotomie und Osteosynthese Farbstoffe wie folgt sub cutem (s.c.) appliziert: An Tag 23 post operationem $10 \mathrm{mg} / \mathrm{kg}$ KG Calceingrün (Waldeck GmbH, Münster, Deutschland), am 33. Tag 30 mg/kg KG Alizarinkomplexon (Merck KGaA, Darmstadt, Deutschland) und am 43. Tag 25 mg/kg KG Tertacyclinhydrochlorid (Carl Roth GmbH + Co. KG, Karlsruhe, Deutschland).

Tabelle 4: Übersicht über Gruppen und Behandlungen; ORX: Orchiektomie

\begin{tabular}{|c|c|c|}
\hline Gruppe & Operationen & Therapie \\
\hline 1: nonORX & $\begin{array}{l}\text { Osteotomie und Osteosyn- } \\
\text { these }\end{array}$ & keine \\
\hline 2: ORX & $\begin{array}{l}\text { ORX, Osteotomie und Osteo- } \\
\text { synthese }\end{array}$ & keine \\
\hline 3: SARMT & $\begin{array}{l}\text { ORX, Osteotomie und Osteo- } \\
\text { synthese }\end{array}$ & $\begin{array}{l}\text { postoperativ Enobosarm 0,4 } \\
\mathrm{mg} / \mathrm{kg} \mathrm{KG} / \mathrm{d} \text { per os (p.o.) }\end{array}$ \\
\hline 4: SARMP & $\begin{array}{l}\text { ORX, Osteotomie und Osteo- } \\
\text { synthese }\end{array}$ & $\begin{array}{l}\text { prophylaktisch und postoperativ } \\
\text { Enobosarm } 0,4 \mathrm{mg} / \mathrm{kg} \mathrm{KG} / \mathrm{d} \text { p.o. }\end{array}$ \\
\hline 5: TestT & $\begin{array}{l}\text { ORX, Osteotomie und Osteo- } \\
\text { synthese }\end{array}$ & $\begin{array}{l}\text { postoperativ Testosteronpropio- } \\
\text { nat } 46,67 \mathrm{mg} / \mathrm{kg} \mathrm{KG} / \mathrm{d} \text { p.o. }\end{array}$ \\
\hline 6: TestP & $\begin{array}{l}\text { ORX, Osteotomie und Osteo- } \\
\text { synthese }\end{array}$ & $\begin{array}{l}\text { prophylaktisch und postoperativ } \\
\text { Testosteronpropionat } 46,67 \\
\mathrm{mg} / \mathrm{kg} \mathrm{KG} / \mathrm{d} \text { p.o. }\end{array}$ \\
\hline
\end{tabular}

\subsubsection{OP-Vorbereitung}

Für die Orchiektomie sowie die Osteotomie mit Osteosynthese wurde zur Narkoseeinleitung Isofluran (Forene ${ }^{\circledR}$ 250ml, AbbVie Deutschland GmbH + Co. 
KG, Wiesbaden, Deutschland) eingesetzt. Daraufhin wurden die Tiere in narkotisiertem Zustand elektronisch identifiziert und anschließend gewogen. Im Zuge der Osteotomie und der Osteosynthese wurden dann gewichtsadaptiert zusätzlich $3 \mathrm{mg} / \mathrm{kg}$ KG Midazolam (15 mg/3 ml, ratiopharm GmbH, Ulm, Deutschland), 80 mg/kg KG Ketamin (10 g/100 ml, MEDISTAR Arzneimittelvertrieb GmbH, Ascheberg, Deutschland) und $2 \mathrm{mg} / \mathrm{kg}$ KG Xylazin (20 mg/ml Xylariem, Riemser Arzneimittel AG, Greifswald, Deutschland) intraperitoneal injiziert. Das OPGebiet wurde rasiert und mit kodan ${ }^{\circledR}$ Tinktur forte (Schülke \& Mayr GmbH, Norderstedt, Deutschland) desinfiziert. Zum Schutz der Augen wurde Coneregel (1g/50ml Dexpanthenol, Bausch \& Lomb, Berlin, Deutschland) aufgetragen. Während der Operationen wurde die Gasnarkose von den Tierärzten der ZTE weitergeführt und überwacht.

\subsubsection{OP-Nachbereitung}

Im Anschluss an die Orchiektomie sowie die Osteotomie mit Osteosynthese wurden die Tiere auf $34^{\circ} \mathrm{C}$ warmen Wärmeplatten gebettet und zugedeckt. Ein etwaiger Flüssigkeitsverlust wurde durch die Applikation von $2 \mathrm{ml}$ Natriumchlorid ( $\mathrm{NaCl})$ 0,9 \% (B. Braun Melsungen AG, Melsungen, Deutschland) s.c. ausgeglichen. Nach überwachter Aufwachphase wurden die Tiere bei wiedererlangter Agilität zurück in ihren Käfig gesetzt. Den Tieren wurde eine tierärztlich überwachte Schmerztherapie zugeführt. Im Zuge der Orchiektomie wurde den Tieren am OP-Tag und an den beiden darauffolgenden Tagen jeweils $5 \mathrm{mg} / \mathrm{kg} \mathrm{KG}$ Carprofen (Rimadyl ${ }^{\circledR}$, Zoetis Schweiz GmbH, Zürich, Schweiz) zusammen mit $2 \mathrm{ml} \mathrm{NaCl} \mathrm{0,9 \%} \mathrm{s.c.} \mathrm{verabreicht.} \mathrm{Die} \mathrm{schmerzmedizinische} \mathrm{Versorgung} \mathrm{nach}$ Osteotomie und Osteosynthese ist in Tabelle 5 ersichtlich. 
Tabelle 5: Schmerzmedizinische Versorgung nach Osteotomie und Osteosynthese; OP: Operation

\begin{tabular}{|c|c|}
\hline Zeitpunkt & Maßnahmen \\
\hline $\begin{array}{l}\text { ab } 3 \text { Tage prae } \\
\text { OP }\end{array}$ & $\begin{array}{l}\text { Beginn von Metamizol-Applikation ( } 500 \mathrm{mg} / \mathrm{ml} \text { Nova- } \\
\text { minsulfon, Zentiva, Frankfurt a.M., Deutschland), } 4 \mathrm{ml} \\
\text { pro } 11 \text { Trinkwasser, welche bis zum } 10 . \text { Tag post OP } \\
\text { weitergeführt wurde }\end{array}$ \\
\hline OP-Tag & $\begin{array}{l}\text { Buprenorphin } 0,1 \mathrm{mg} / \mathrm{kg} \text { KG s.c. }\left(0,3 \mathrm{mg} / \mathrm{ml} \text { Temgesic }{ }^{\circledR} \text {, }\right. \\
\text { RB Pharmaceuticals Limited, Berkshire, England), } 4-6 \mathrm{~h} \\
\text { post OP wiederholte Applikation, Breifutter mit Meta- } \\
\text { mizolwasser }\end{array}$ \\
\hline 1.-2. Tag post OP & $\begin{array}{l}3 \text { x pro d Buprenorphin 0,1 mg/ kg KG s.c., Breifutter } \\
\text { mit Metamizolwasser }\end{array}$ \\
\hline 3. Tag post OP & $\begin{array}{l}2 \text { x pro d Buprenorphin } 0,1 \mathrm{mg} / \mathrm{kg} \text { KG s.c., Breifutter } \\
\text { mit Metamizolwasser }\end{array}$ \\
\hline 4.-5. Tag post OP & 2 x pro d Buprenorphin 0,05 mg/ kg KG s.c. \\
\hline $\begin{array}{l}\text { 6.-10. Tag post } \\
\text { OP }\end{array}$ & Buprenorphin 0,05 mg/ kg KG s.c. bei Bedarf \\
\hline
\end{tabular}

\subsubsection{Orchiektomie}

Der Skrotalsack wurde über dem tastbaren Testikel etwa 8-10 mm longitudinal inzidiert. Über diesen Zugang war es möglich, den Testikel mitsamt den versorgenden Leitungsbahnen aus den Skrotalhüllen zu bergen. Um die versorgenden Leitungsbahnen klar darstellen zu können, wurde Fett- und Bindegewebe entfernt. Nach sicherer Darstellung wurden diese mit einer Ligatur Vicryl ${ }^{\mathrm{TM}}$ 4-0 (Ethicon, Dülmen, Deutschland) sicher unterbunden (Abbildung 4) und anschließend distal der Ligatur über einer gebogenen Klemme mit dem Skalpell abgesetzt. Um die Blutungsgefahr weiter zu minimieren, wurden kleinere Gefäße mit dem C300 Cautery Handle (Merlin Medical, Lemgo, Deutschland) 
elektronisch verödet. Analog zu der oben beschriebenen Schrittfolge wurde mit dem kontralateralen Testikel verfahren. Die intraskrotalen Wundränder wurden unter Verwendung von Vicryl ${ }^{\mathrm{TM}}$ 4-0 (Ethicon) mit Einzelknopfnähten adaptiert. Für den Wundverschluss der Skrotalhaut wurden Michel-Wundklammern (7,5 x 1,75mm, Gebrüder Martin GmbH \& Co. KG, Tuttlingen Germany) verwendet. Schließlich wurde das Operationsgebiet mit Braunol (B. Braun Melsungen AG, Melsungen, Deutschland) erneut desinfiziert.

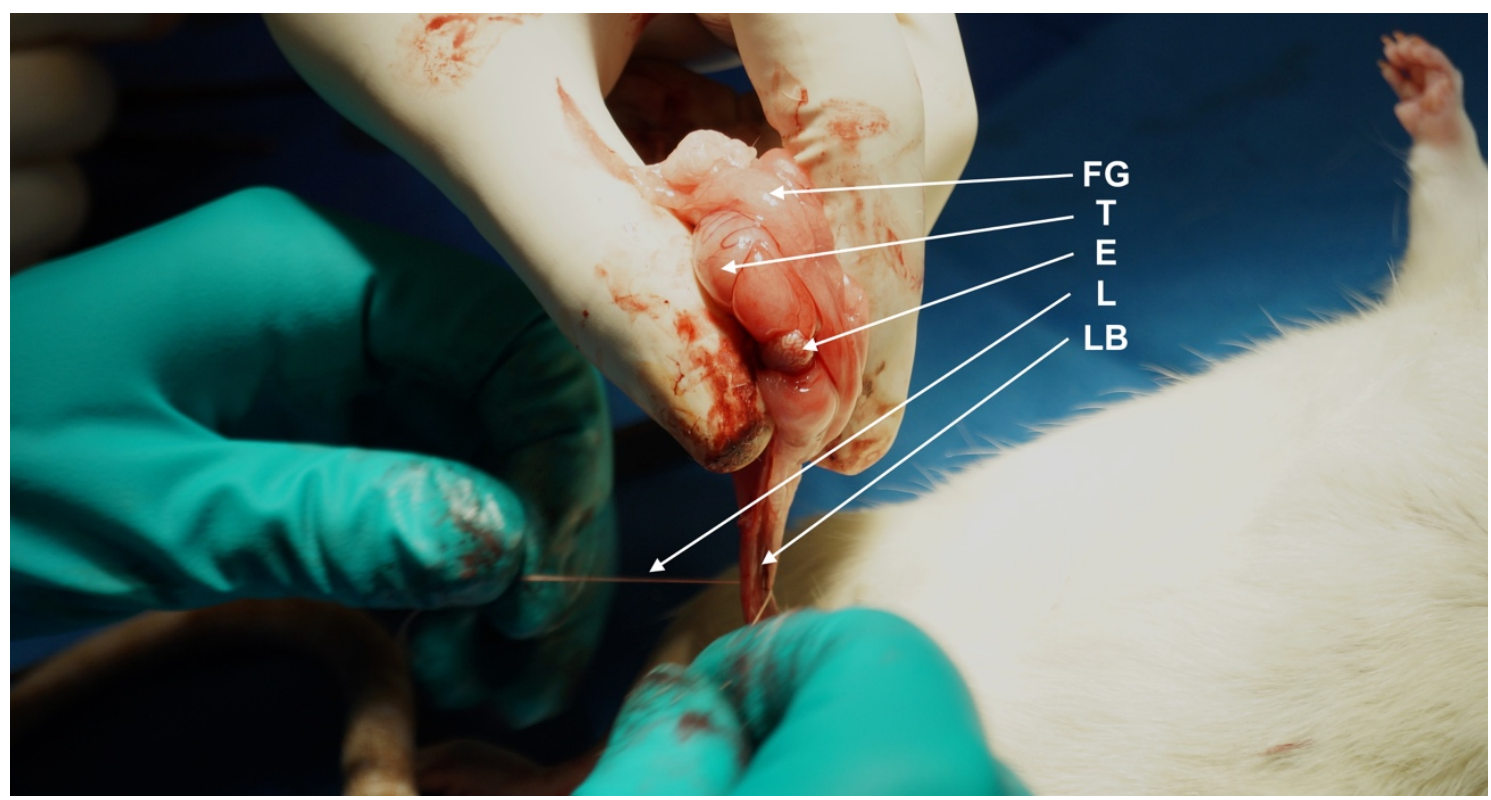

Abbildung 4: Ligatur der Leitungsbahnen des Testiculus dexter; FG: Fettgewebe, T: Testiculus, $\mathrm{E}:$ Epididymis, L: Ligatur, LB: Leitungsbahnen; eigene Abbildung

\subsubsection{Osteotomie und Osteosynthese}

Im Zuge anderer Versuche wurden die Ratten 84 Tage nach der Orchiektomie einer Osteotomie der Femora unterzogen und anschließend mit einer Plattenosteosynthese versorgt. Da die Frakturheilung unter den beschriebenen Versuchsbedingungen im Rahmen einer anderen Arbeit untersucht wird, soll hier nicht weiter auf diese Operationen eingegangen werden. 


\subsubsection{Tötung und Probengewinnung}

Genau 42 Tage nach Osteotomie und Osteosynthese wurden die Versuchstiere zur Probengewinnung getötet. Im Vorhinein wurde das Körpergewicht ermittelt und dokumentiert. Auf die $\mathrm{CO}_{2}$-Narkose folgte die Dekapitation. Direkt anschließend wurde Blut für die Serumanalyse über einen Trichter aufgefangen. Die Gewinnung der Muskelproben erfolgte unmittelbar im Anschluss, um postmortale Prozesse schnellstmöglich durch Konservierung zu unterbinden. Mit einer Schere und unter Zuhilfenahme einer anatomischen Pinzette wurde zunächst die Haut über der Tibia inzidiert und weiter der M. gastrocnemius freipräpariert. Dabei wurde oberflächliches Haut- und Muskelgewebe entfernt, teils unter Hinzunahme eines Skalpells. Es war nun möglich, beginnend am distalen Sehnenansatz der Muskeln, die Muskelgruppe ventral stumpf bis kurz vor den proximalen Ansatz des profunderen der beiden Muskeln, dem M. soleus, zu präparieren. Darauf folgte das Absetzen der distalen Sehnen der Muskeln mit dem Skalpell. Des Weiteren konnte nun der M. soleus dem Bauch des M. gastrocnemius stumpf abpräpariert und anschließend am proximalen Sehnenansatz mit dem Skalpell abgetrennt werden (Abbildung 5). Nun wurde auch der M. gastrocnemius vollständig entfernt. Das jeweilige Gewicht beider Präparate wurde ermittelt und dokumentiert. Der $M$. gastrocnemius wurde mittig und orthogonal zum Faserverlauf geteilt, um spätere Arbeiten am Mikrotom zu erleichtern.

Die Präparation des $M$. longissimus begann mit der Inzision dorsal etwa $1 \mathrm{~cm}$ oberhalb des Os sacrum bis kranial, auf Höhe der Scapula. Die darunterliegenden oberflächlichen Muskelschichten wurden entfernt. Anschließend wurde ein 4$5 \mathrm{~cm}$ langes Präparat wie folgt gewonnen: zunächst eine scharfe Inzision kranial der Crista iliaca, welche orthogonal zur Columna vertebralis geführt wurde. Daraufhin wurde der Muskel cranialwärts, von einer Pinzette auf behutsamer Spannung gehalten, scharf präpariert und im Anschluss, etwa auf Höhe der zehnten Rippe, abgesetzt.

Die Proben wurden direkt im Anschluss an ihre Präparation in flüssigem Stickstoff bei $-80^{\circ} \mathrm{C}$ konserviert. Im Vorfeld wurden die Präparate in Talkum gewälzt, 
um etwaigem Gefrierbrand vorzubeugen (Moline und Glenner 1964), und in beschriftete Alufolie gefaltet. Die Präparate der kontralateralen Seite wurden einer enzymatischen Untersuchung zugeführt. Darüber hinaus wurden Prostata sowie M. levator ani präpariert und deren Gewicht ermittelt und dokumentiert. Für andere Arbeiten wurden ferner entnommen: Tibiae, Femora, fünf Wirbelkörper, Herz, Leber, Niere, Milz sowie Teile des Gehirns.

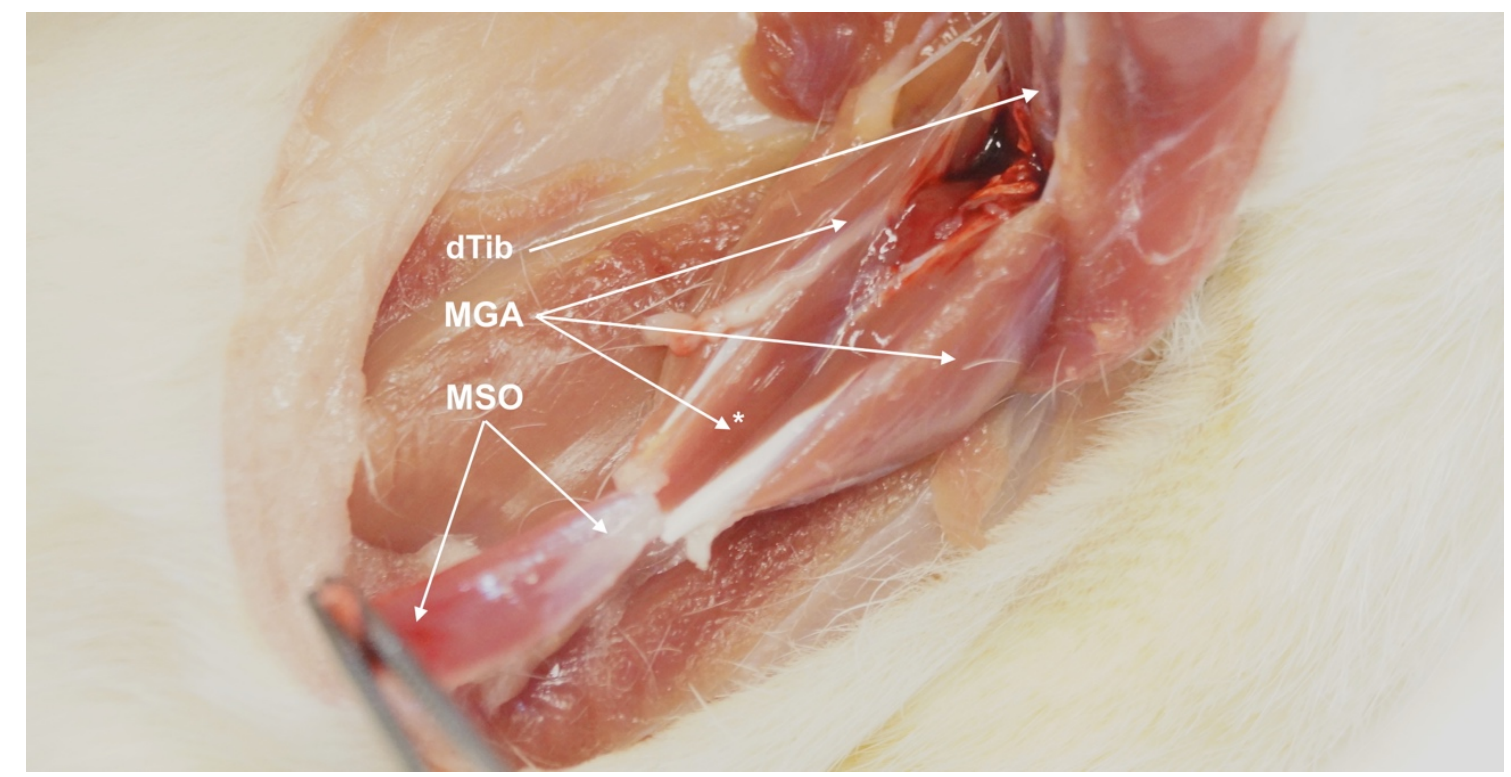

Abbildung 5: Präparation des M. soleus (MSO); MGA: M. gastrocnemius, *: distaler Muskelanteil, dTib: dorsale Tibia; eigene Abbildung

\subsection{Mikrotomie}

Für den maßgeblichen Teil der späteren Versuchsauswertung war eine Fixierung von Muskelfeinschnitten auf Objektträgern (Menzelgläser Superfrost-Plus, Thermo Scientific, Waltham, Vereinigte Staaten von Amerika) nötig. Zu diesem Zweck wurde der im Department für Nutztierwissenschaften (Georg-AugustUniversität Göttingen) befindliche Mikrotom CM 1900 Kryostat (Leica, Wetzlar, Deutschland) benutzt. Die Muskelproben wurden auf festem Kohlenstoffdioxid transportiert und anschließend bei $-20^{\circ} \mathrm{C}$ eingelagert. In der Arbeitskammer des Mikrotoms herrschten $-18{ }^{\circ} \mathrm{C}$ und die eingestellte Temperatur des auf- und abschwingenden Führungsarms betrug $-22{ }^{\circ} \mathrm{C}$. Zu Beginn wurden drei Muskelproben in einem isolierten Behältnis transportiert und in nummerisch 
aufsteigender Reihenfolge in den Arbeitsraum gelegt. Anschließend wurden pro Muskelprobe jeweils zwei Objektträger beschriftet und in der korrekten Reihenfolge bereitgelegt. Für eine optimale Auswertung war es von großer Wichtigkeit, die Muskelproben orthogonal zur Muskelfaserrichtung zu schneiden. Aus diesem Grund wurden die Muskeln nach äußerlicher Begutachtung mit einem Skalpell so vorgeschnitten, dass zum einen eine hinreichende Fixierungsfläche und zum anderen eine möglichst optimale Schnittführung entstand. Anschließend wurden die Muskelproben auf dafür vorgesehenen Fixierungsplatten mit Wasser festgefroren. Diese wurden in den Führungsarm eingeschraubt und der feststehenden Klinge bis kurz vor Berührung angenähert. Die am Gerät eingestellte Schnittdicke betrug $12 \mu \mathrm{m}$. Per Handkurbel wurde nun der Führungsarm, $12 \mu \mathrm{m}$ pro voller Umdrehung, zur Klinge hinbewegt. Dies solange, bis eine Flächengröße geschnitten war, die hinreichend mikroskopisch beurteilt werden konnte. Mit Hilfe eines mobilen Führungsglases wurde ein erster Schnitt geglättet und auf einen Objektträger gebracht, um an einem Mikroskop unter 100facher Vergrößerung kontrolliert zu werden. Bei zur Faserrichtung orthogonaler Schnittführung konnten dann die beiden passenden Objektträger mit jeweils drei bis vier Schnitten und beim M. soleus mit acht bis zwölf Schnitten bestückt werden. Ansonsten musste die Stellung der Muskelprobe zur Klinge bis zur Zufriedenheit des Bedienenden abgeändert werden. Schließlich wurden die Objektträger bei Raumtemperatur mindestens eine Stunde getrocknet und bei $-20{ }^{\circ} \mathrm{C}$ gelagert.

\subsection{Färbung der Muskelpräparate}

Für die Auswertung der Muskelproben mussten diese gefärbt werden. Pro Muskel wurden jeweils zwei verschiedene Färbungen angefertigt (Ammon 2015; Rechholz 2017). Die ATPase-Färbung mit Diaphorase nach der Horák-Methode (Horák 1983) und eine modifizierte Amylase-PAS-Färbung nach Andersen (Andersen 1975; Komrakova et al. 2009) kamen zum Einsatz. Zunächst wurden die Objektträger bei Raumtemperatur aufgetaut, senkrecht in Glasküvetten gestellt und dann weiter nach den folgenden Färbeprotokollen verfahren. Auf die 
jeweiligen Färbeprotokolle, die Zusammensetzungen der Lösungen sowie die Hersteller der verwendeten Chemikalien wird in Kapitel 5.3 eingegangen.

\subsubsection{Amylase-PAS-Färbung}

Die Periodic-Acid-Schiff (PAS) Reaktion eignet sich um Zellwände einzufärben (Baum 2008). Der zusätzliche Einsatz von Amylase unterstützt das Sichtbarwerden von glykogenhaltigen extrazellulären Strukturen. Diese Färbung ermöglicht eine Quantifizierung der im jeweiligen Muskelabschnitt enthaltenen Kapillaren (Andersen 1975).

\subsubsection{ATPase-Färbung mit Diaphorase}

Die ATPase-Färbung mit Diaphorase macht sich, wie in Kapitel 1.2.3 beschrieben, die, je nach herrschendem pH-Wert, unterschiedlichen Reaktionen der Myosin-ATPasen zunutzen. Typ-1-Fasern stellen sich stark positiv, also dunkel, und Typ-2-Fasern stellen sich negativ bis schwach positiv, sprich hell oder randständig leicht dunkel eingefärbt, dar. Mit der Diaphorase-Färbung werden zusätzlich mitochondriale Enzyme markiert. Folglich werden die oxidativen Typ1-Fasern eingefärbt. Zur Einstellung der erwünschten pH-Werte wurde Salzsäure bzw. Natriumhydroxyd verwendet.

\subsection{Auswertung}

Für die Auswertung der gefärbten Muskelfeinschnitte wurde das Mikroskop Eclipse E600 (Nikon GmbH, Düsseldorf, Deutschland) und das computergesteuerte Programm NIS-Elements AR 4.0 (Nikon $\mathrm{GmbH}$ ) verwendet. Die beiden Geräte wurden durch das Videosystem Digital Sight DS-U3 (Nikon GmbH) verbunden, welches die Übertragung des Gesichtsfeldes und hochauflösenden Fotografien dessen ermöglichte. Es wurde mit 100-facher Vergrößerung gearbeitet. 


\subsubsection{Amylase-PAS-Färbung}

Die Auswertung der Amylase-PAS-gefärbten Präparate hatte zum Ziel die Kapillardichte, also das Verhältnis der Kapillaranzahl zur Muskelzellanzahl, zu ermitteln. $\mathrm{Zu}$ diesem Zweck wurden pro Muskelpräparat zwei 0,25 $\mathrm{mm}^{2}$ messende quadratische Ausschnitte ausgewertet (Abbildung 6). Da die Objektträger mit mehreren, topographisch benachbarten Muskelquerschnitten bestückt wurden, war es wichtig auszuschließen, dass Muskelzellen zweifach ausgewertet werden. Dies wurde durch die Beschränkung auf nur einen Muskelquerschnitt pro Objektträger und Versuchstier gewährleistet.

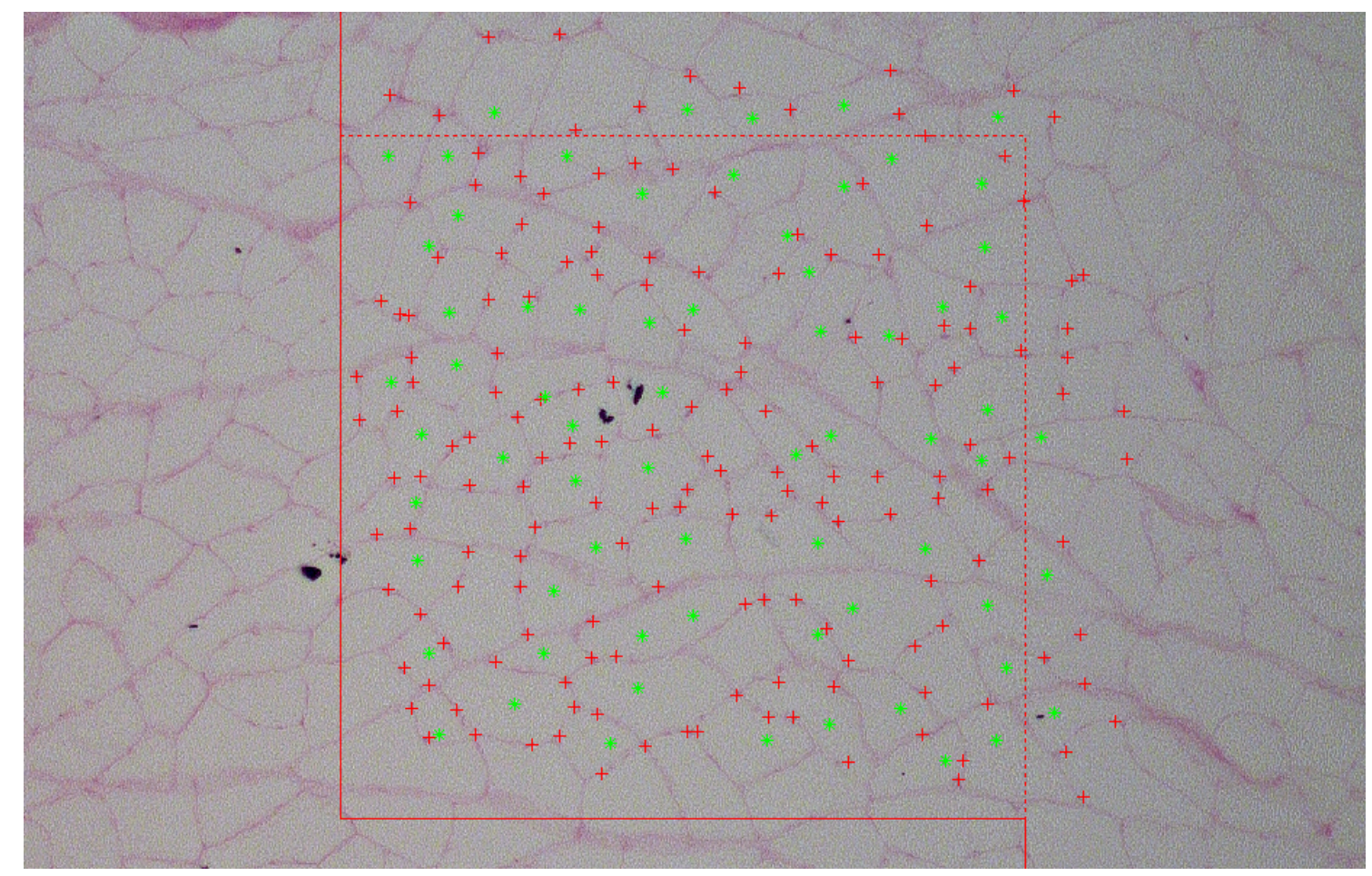

Abbildung 6: Auswertung der Amylase-PAS-Färbung (M. gastrocnemius; 100fache Vergrößerung): von der gestrichelten Linie angeschnittene Zellen wurden berücksichtigt, von der durchgezogenen Linie angeschnittene Zellen wurden nicht berücksichtigt; grün: Zelle; rot: Kapillare

Gezählt wurden die Kapillaren und Muskelzellen durch manuelle computergestützte Markierung. Die so gesammelten Zahlen konnten anschließend in eine Excel-Datei (Microsoft Cooperation, Redmond, Vereinigte Staaten von Amerika) exportiert und dort weiterverarbeitet werden. Dieses Vorgehen wurde auf alle Schnitte der Mm. longissimi, gastrocnemii und solei angewendet. 


\subsubsection{ATPase-Färbung mit Diaphorase}

In Betrachtung der ATPase-Färbungen wurde die durchschnittliche Querschnittsfläche der verschiedenen Muskelzelltypen in drei Ausschnitten eines Muskelquerschnittes ermittelt. Dafür wurden pro Ausschnitt 30 Zellquerschnitte jeweils eines Zelltyps vermessen. Es wurde zwischen oxidativen und intermediären, als Typ-1-Zellen und glykolytischen, als Typ-2-Zellen differenziert (Abbildung 7). Der M. soleus weist jedoch ein derart einseitiges Zellverhältnis auf, dass hier nur Typ-1-Zellen ausgewertet wurden (Armstrong und Phelps 1984; Wigston und English 1992). Hierzu wurden die Zellquerschnitte entlang ihrer Zellgrenzen markiert. Neben der so errechenbaren Fläche wurde auch der Muskelzell-Äquivalentdurchmesser ermittelt. Die gesammelten Daten wurden schließlich zur Weiterverarbeitung in eine Excel-Datei exportiert.

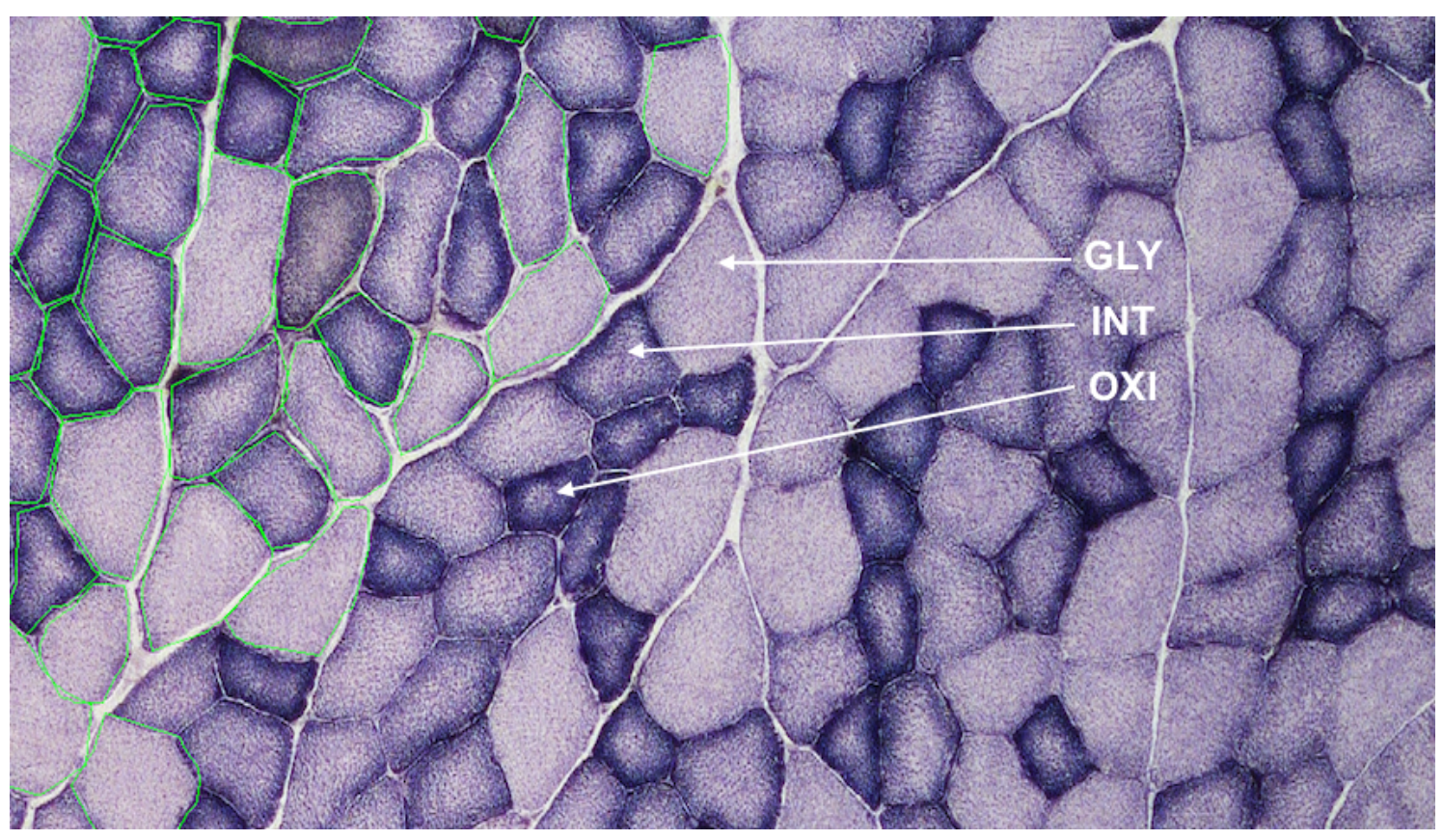

Abbildung 7: Auswertung der ATPase-Färbung mit Diaphorase (M. gastrocnemius; $100 f a c h e$

Vergrößerung): grüne Umrandung zur Bestimmung der Muskelzellquerschnittsflächen sowie der Muskelzell-Äquivalentdurchmesser; GLY: glykolytische Muskelzelle; INT: intermediäre (glykolytisch + oxidativ) Muskelzelle; OXI: oxidative Muskelzelle

Weiter wurden die Präparate des M. longissimus auf das Verhältnis seiner Zelltypen untersucht. Hierzu wurden zwei Flächen à $0,5 \mathrm{~mm}^{2}$ eines Muskelschnittes, insgesamt also $1 \mathrm{~mm}^{2}$, ausgezählt. Da das Zelltypverhältnis des 
M. gastrocnemius stark variierte und bei dem M. soleus, wie schon beschrieben, einseitig zu Gunsten von Typ-1-Zellen verschoben ist, wurde bei den zuletzt genannten auf eine taxonomische Auswertung verzichtet.

\subsection{Serum-Kreatinkinase}

Die Bestimmung der Kreatinkinase im Rattenserum wurde im Institut für Klinische Chemie der Universitätsmedizin Göttingen durchgeführt. Die Quantität von Kreatinkinase wurde in Units pro Liter (U/1) beschrieben, wobei eine Unit durch die Enzymaktivität definiert ist, welche ein $\mu$ mol Substrat in einer Minute bei $30^{\circ} \mathrm{C}$ umsetzt (Commission of Editors of Biochemical Journal 1965). Zur Analyse wurde vom Institut die Maschine Architect c16000 (Abbott, Wiesbaden, Deutschland), sowie der flüssige, gebrauchsfertige Doppelreagenz-Kit REF 7D63-21 (Abbott) verwendet. Die im Serum enthaltene Kreatinkinase katalysiert die Phosphorylierung von Adenosindiphosphat. Im Zuge dessen entsteht ATP. Über zwei weitere Zwischenschritte wird reduziertes Nicotinamidadenindinukleotidphosphat (NADP) generiert, dessen Bildungsrate sich proportional zur eingesetzten Kreatinkinase-Aktivität verhält. Die Bildungsrate von reduziertem NADP wird schließlich optisch nachgewiesen (Kling 2015).

\subsection{Statistik}

Die erhobenen Daten wurden mit dem Computerprogramm Excel gesammelt und weiterverarbeitet. Aus den Werten der Muskelzellenquerschnittsflächen bzw. der Muskelzell-Äquivalentdurchmesser eines Tieres wurden die Mittelwerte errechnet. Diese wurden zusätzlich auf das finale Körpergewicht und das jeweilige Muskelgewicht bezogen. Für die weitere statistische Auswertung der Daten, sowie deren graphische Darstellung wurde das Computerprogramm Prism 5.0 (Graph Pad Software Inc., San Diego, Vereinigte Staaten von Amerika) verwendet. Aus den Einzelwerten wurden die Gruppenmittelwerte sowie die Standardabweichungen errechnet. Um diese Ergebnisse vergleichend zu prüfen, 
wurde eine one-way analysis of variance (auch: one-way ANOVA) durchgeführt. Zur weiteren Analyse wurde der Tukey's Multiple Comparison Test verwendet. Wenn im Vorfeld durch den Barttlets's test for equal variances keine ausreichende Varianzhomogenität festgestellt werden konnte, wurde der Kruskal-Wallis Test sowie der Dunn's Multiple Comparison Test angeschlossen (Rechholz 2017). Die Bestimmung der Stärke des linearen Zusammenhangs von Körper- und Muskelgewicht erfolgte mithilfe des Pearson correlation coefficient (Pearson $r$ ) und der linearen Einfachregression (Regressionsgrade, $\mathrm{R}^{2}=$ Bestimmtheitsmaß). Für die durchgeführten Tests wurde das Signifikanzniveau auf $\alpha=0,05$ festgelegt. 


\section{Ergebnisse}

Im folgenden Abschnitt werden die Ergebnisse des Versuches dargestellt und beschrieben. Die sechs Versuchsgruppen sind in Tabelle 6 aufgeführt. Eine zusätzliche tabellarische Darstellung der Ergebnisse ist im Anhang zu finden.

Tabelle 6: Abkürzungen und Behandlungen der Versuchsgruppen; prophylaktische: ab Orchiektomie (ORX); postoperative: ab Osteotomie und Osteosynthese

\begin{tabular}{|c|c|c|}
\hline Gruppe & Operationen & Therapie \\
\hline nonORX & $\begin{array}{l}\text { Osteotomie und Osteosyn- } \\
\text { these }\end{array}$ & keine \\
\hline ORX & $\begin{array}{l}\text { ORX, Osteotomie und Osteo- } \\
\text { synthese }\end{array}$ & keine \\
\hline SARMT & $\begin{array}{l}\text { ORX, Osteotomie und Osteo- } \\
\text { synthese }\end{array}$ & $\begin{array}{l}\text { postoperativ Enobosarm 0,4 } \\
\text { mg/kg KG/d p.o. }\end{array}$ \\
\hline SARMP & $\begin{array}{l}\text { ORX, Osteotomie und Osteo- } \\
\text { synthese }\end{array}$ & $\begin{array}{l}\text { prophylaktisch und postoperativ } \\
\text { Enobosarm } 0,4 \mathrm{mg} / \mathrm{kg} \mathrm{KG} / \mathrm{d} \text { p.o. }\end{array}$ \\
\hline TestT & $\begin{array}{l}\text { ORX, Osteotomie und Osteo- } \\
\text { synthese }\end{array}$ & $\begin{array}{l}\text { postoperativ Testosteronpropio- } \\
\text { nat } 46,67 \mathrm{mg} / \mathrm{kg} \mathrm{KG} / \mathrm{d} \text { p.o. }\end{array}$ \\
\hline TestP & $\begin{array}{l}\text { ORX, Osteotomie und Osteo- } \\
\text { synthese }\end{array}$ & $\begin{array}{l}\text { prophylaktisch und postoperativ } \\
\text { Testosteronpropionat } 46,67 \\
\mathrm{mg} / \mathrm{kg} \mathrm{KG} / \mathrm{d} \text { p.o. }\end{array}$ \\
\hline
\end{tabular}




\subsection{Versuchsgruppengrößen zum Versuchsende}

Tabelle 7: Versuchsgruppengrößen zum Versuchsende (n: Tieranzahl zum Zeitpunkt der Tötung)

\begin{tabular}{lllllll}
\hline \multicolumn{7}{c}{ Versuchsgruppe } \\
\hline & nonORX & ORX & SARMT & SARMP & TestT & TestP \\
\hline & & & & & & \\
$\mathrm{n}$ & 12 & 8 & 7 & 9 & 5 & 9 \\
\hline
\end{tabular}

Das Versuchskollektiv hat sich im Laufe des Versuches auf Grund von postoperativen Komplikationen auf 50 Tiere reduziert. 13 Tiere verstarben direkt postoperativ bzw. direkt nach oder unter Narkose, 2 Tiere aufgrund von Störungen des Gangbildes, 15 Tiere aufgrund der Komplikation der postoperativen Schmerztherapie (Ileus) und 4 weitere Tiere wurden aufgrund eines Tumors aus dem Kollektiv entfernt. Die Genese von insgesamt sechs Todesfällen ließ sich nicht abschließend klären.

\subsection{Futteraufnahme und Wirkstoffaufnahme im Versuchsverlauf}

Die durchschnittliche tägliche Futter- bzw. Wirkstoffaufnahme eines Versuchstiers (Abbildung 8, Abbildung 9, Abbildung 10) ist nummerisch in Tabelle 8 und Tabelle 9 nachzuvollziehen. 


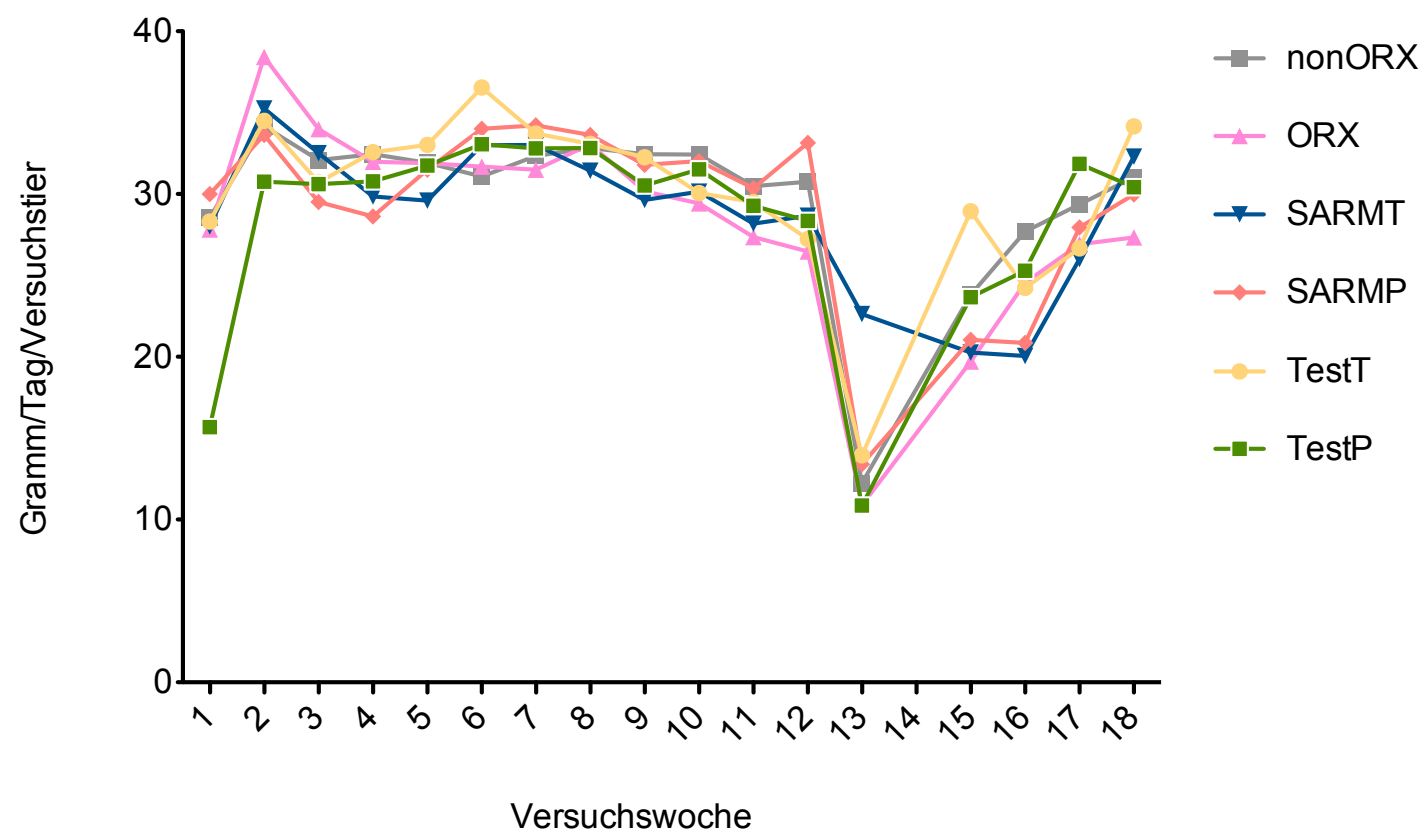

Abbildung 8: Durchschnittliche tägliche Futteraufnahme in Gramm (g) pro Versuchstier im Versuchsverlauf; für Versuchswoche 14 sind keine Messungen vorhanden

In der Woche nach der Orchiektomie wurde die Darstellung der Futteraufnahme begonnen. Es fällt auf, dass die Futteraufnahme in der ersten Woche nach der Osteotomie und Osteosynthese deutlich sank. Auf Grund von Komplikationen der postoperativen Schmerztherapie wurde für Versuchswoche 14 die Futtergabe ausgesetzt und durch die Gabe von Haferflocken, Brot, metamizolfreiem Wasser und 1-2 Guttae Herbi Colan (WDT, Garbsen, Deutschland) pro Versuchstier ersetzt. Die durchschnittliche tägliche Futteraufnahme der Versuchstiere zeigte insgesamt keine signifikanten Unterschiede zwischen den Versuchsgruppen. 


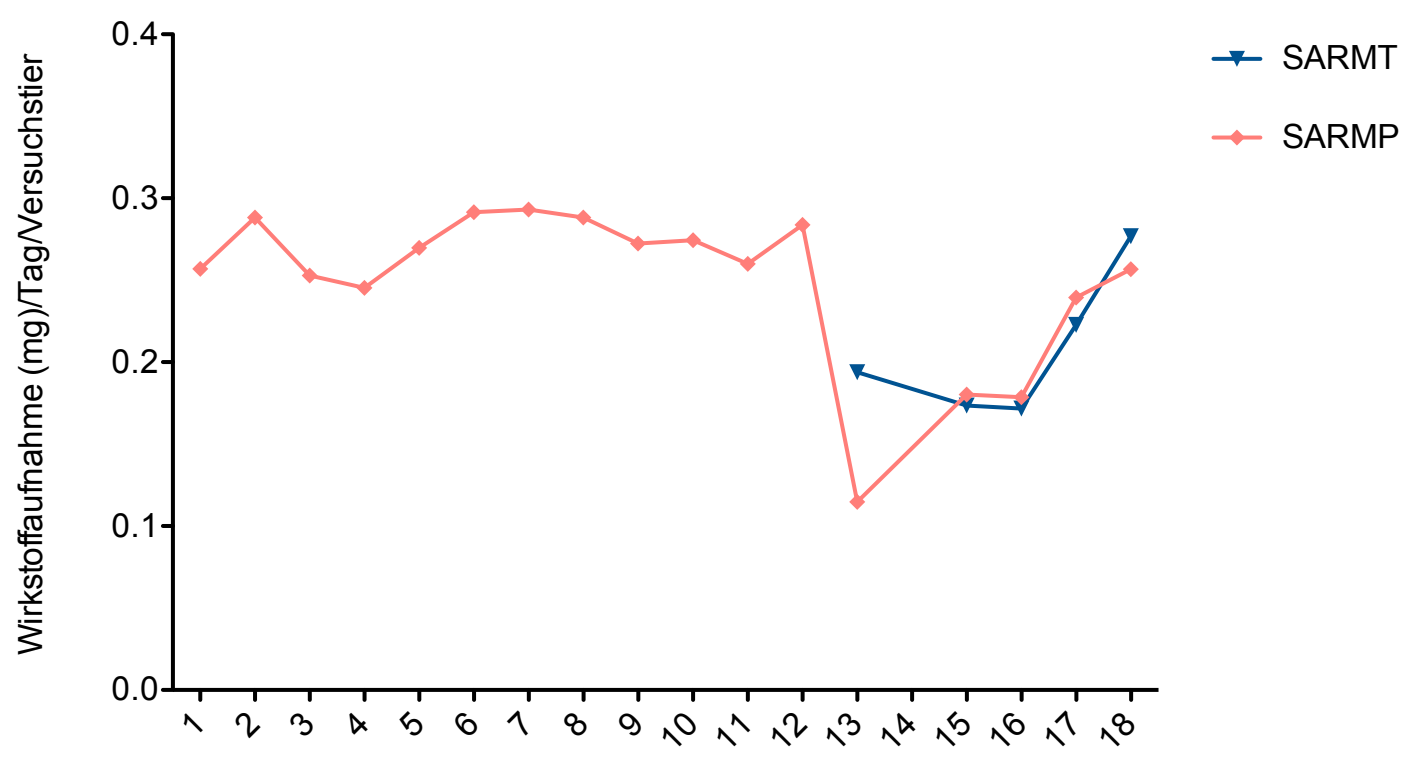

Versuchswoche

Abbildung 9: Durchschnittliche tägliche Aufnahme von Enobosarm in Milligramm (mg) pro Versuchstier im Versuchsverlauf; für Versuchswoche 14 sind keine Messungen vorhanden

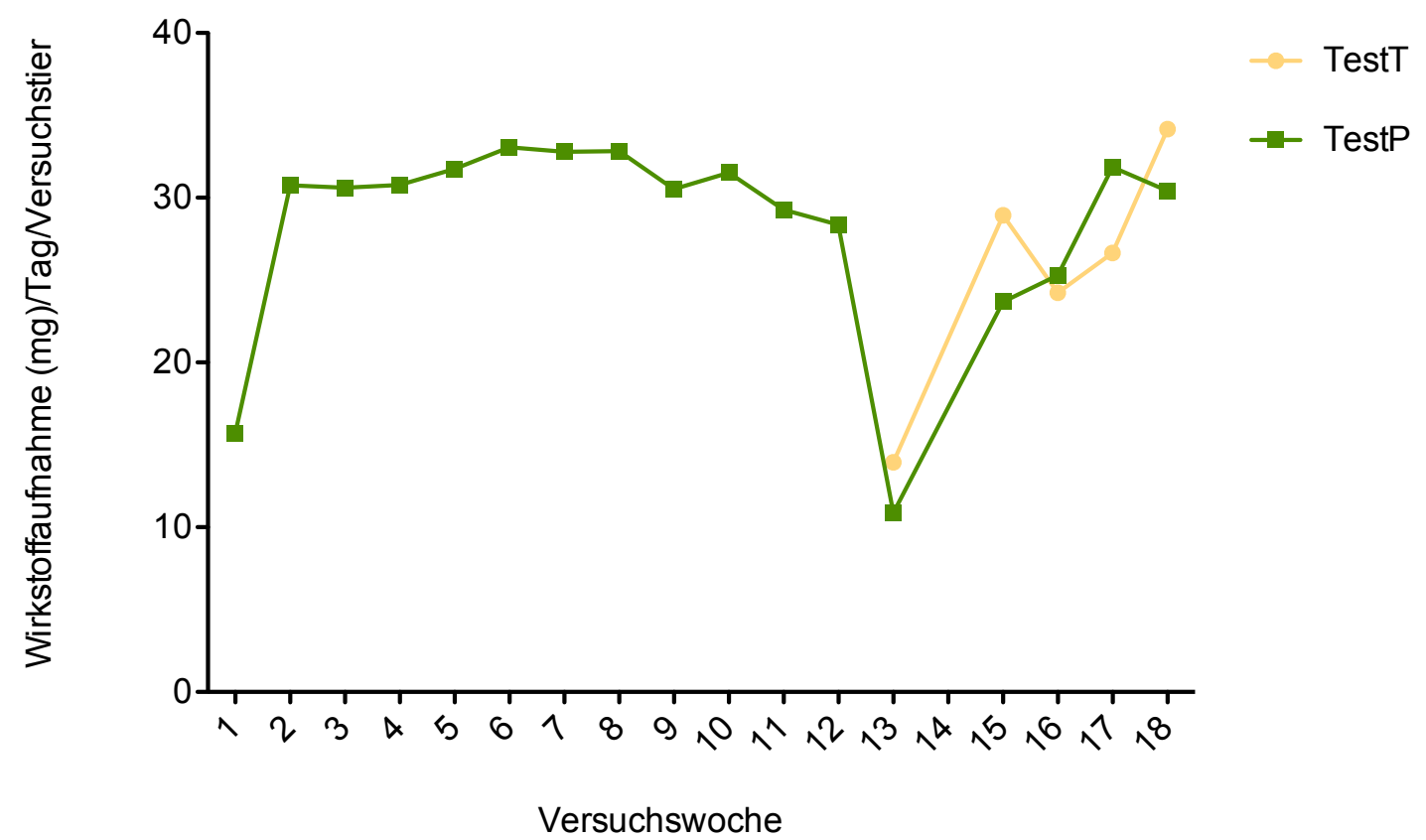

Abbildung 10: Durchschnittliche tägliche Aufnahme von Testosteronpropionat in Milligramm (mg) pro Versuchstier im Versuchsverlauf; für Versuchswoche 14 sind keine Messungen vorhanden 
In der ersten Woche nach Osteotomie und Osteosynthese zeigte sich analog zur Futteraufnahme ein deutlicher Rückgang der Aufnahme von Enobosarm und Testosteronpropionat. Das Aussetzen der Futtergabe auf Grund von Komplikationen der postoperativen Schmerztherapie in Versuchswoche 14 führte in dieser Zeit folglich zu keinen Wirkstoffaufnahmen. Zwischen den Versuchsgruppen, die jeweils Prophylaxe und Therapie bzw. nur die Therapie erhalten haben, zeigten sich keine signifikanten Unterschiede der jeweiligen Wirkstoffaufnahmen.

\subsection{Körper-, Muskel- und Prostatagewichte}

\subsubsection{Körpergewichte im Versuchsverlauf}

Die Körpergewichte der Versuchstiere wurden wöchentlich ermittelt. Im Folgenden werden die durchschnittlichen Körpergewichte im Versuchsverlauf (Abbildung 11, Tabelle 10) sowie die Körpergewichte zu den Zeitpunkten der Orchiektomie (Abbildung 12), der Osteotomie mit Osteosynthese (Abbildung 13) und der Tötung (Abbildung 14) dargestellt und beschrieben. 


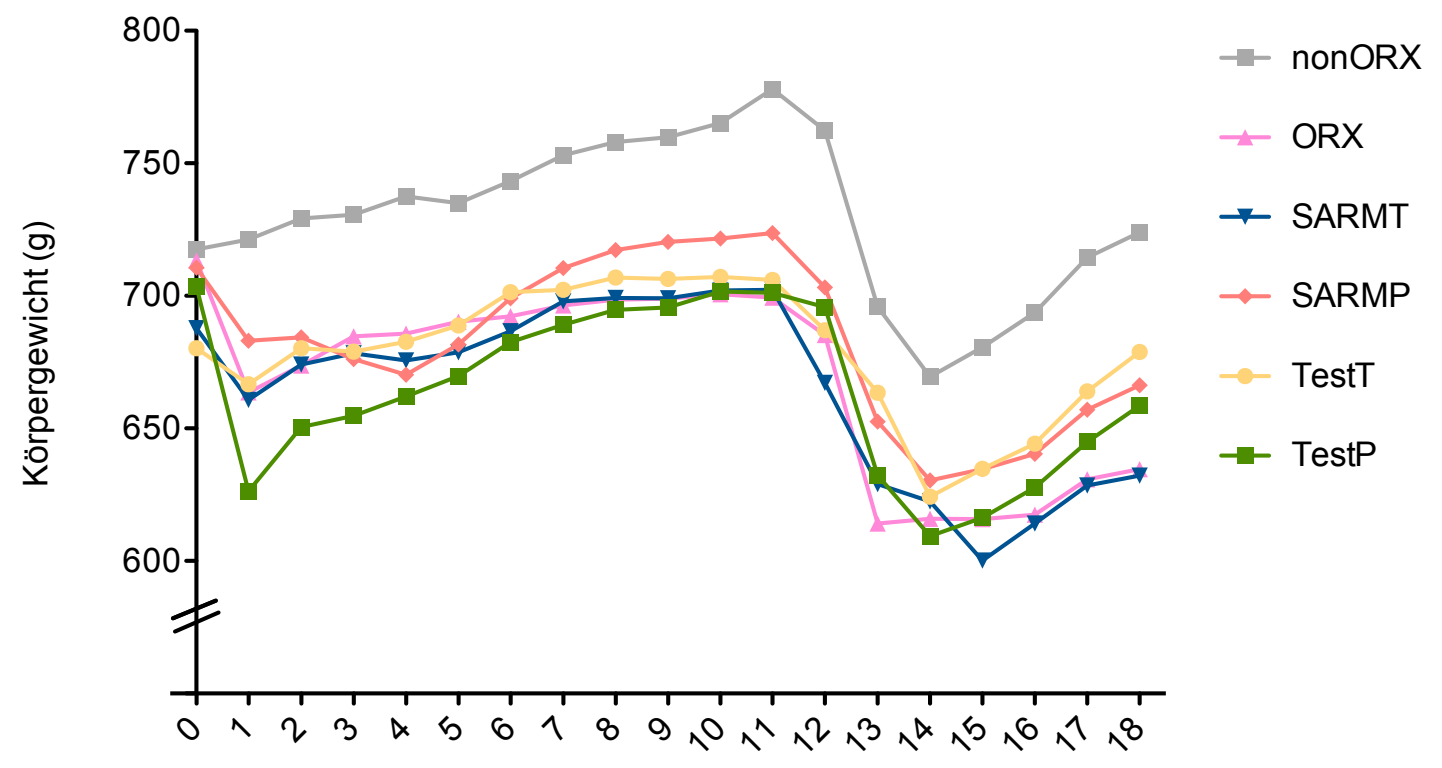

Versuchswoche

Abbildung 11: Durchschnittliche Körpergewichte in Gramm (g) im Versuchsverlauf

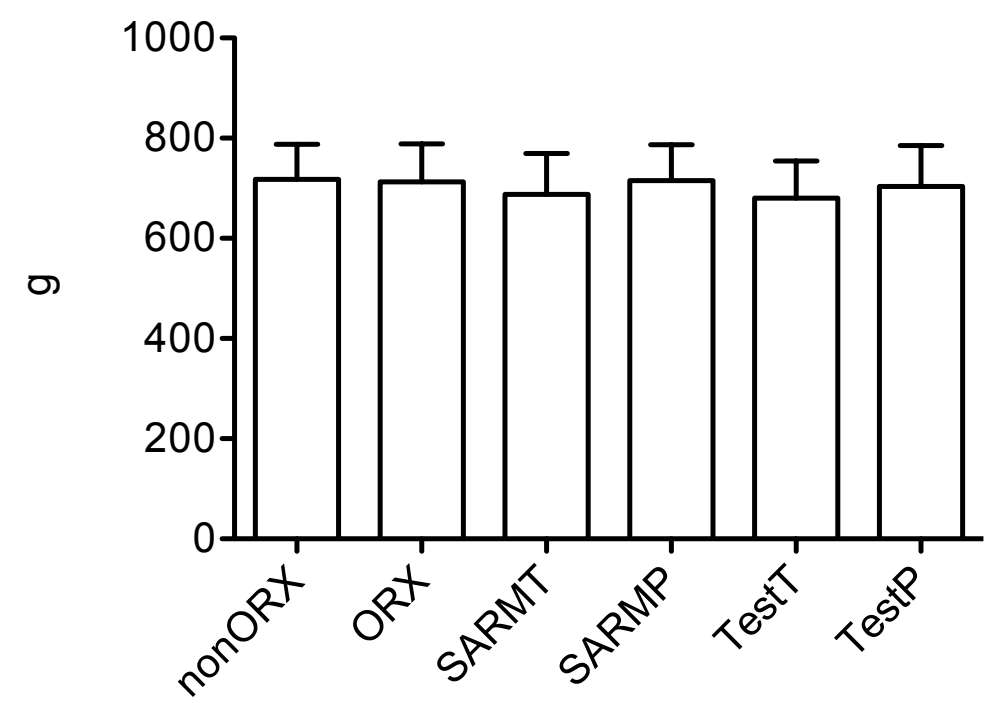

Abbildung 12: Körpergewichte in Gramm (g) zum Zeitpunkt der Orchiektomie; keine signifikanten Unterschiede 


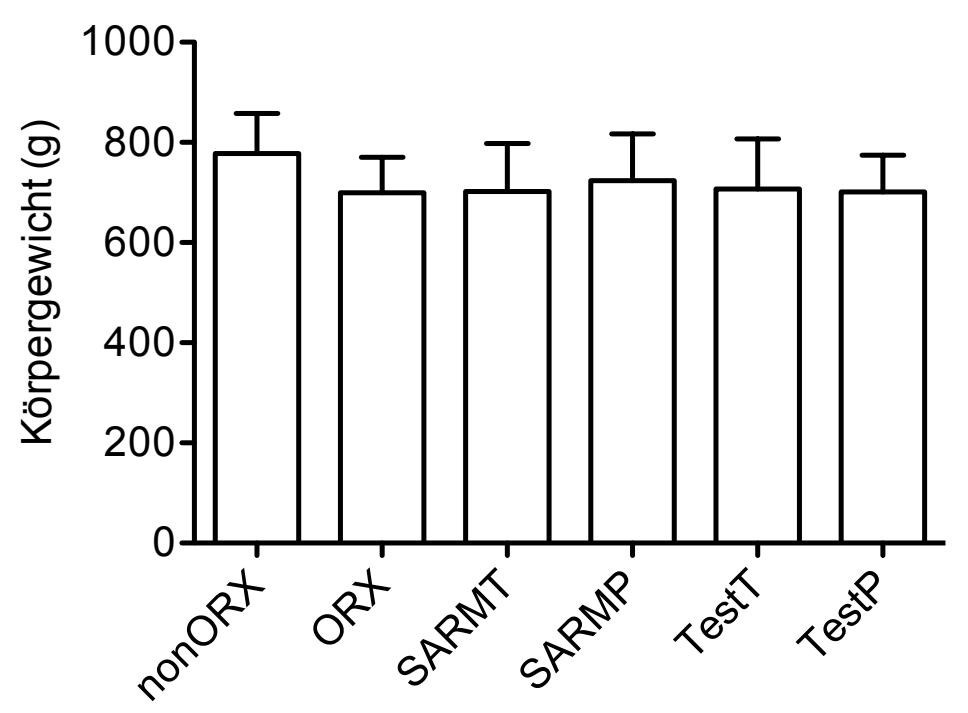

Abbildung 13: Körpergewichte in Gramm (g) zum Zeitpunkt von Osteotomie und Osteosynthese; keine signifikanten Unterschiede

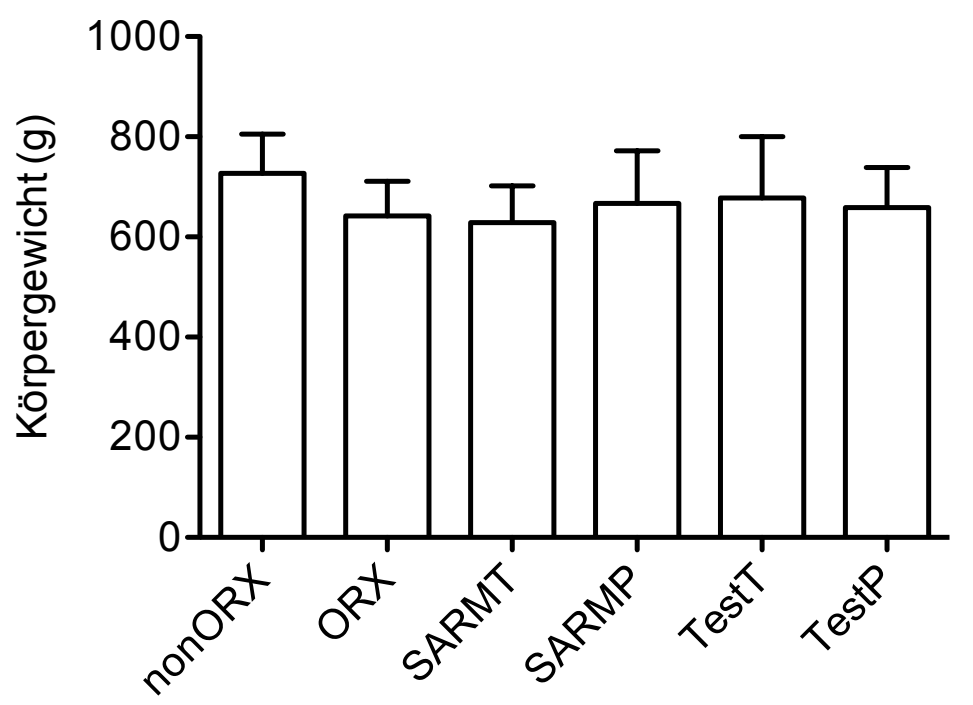

Abbildung 14: Körpergewichte in Gramm (g) zum Zeitpunkt der Tötung; keine signifikanten Unterschiede

Zum Zeitpunkt der Orchiektomie zeigten sich keine signifikanten Körpergewichtsunterschiede zwischen den Versuchsgruppen. In der Woche nach der Orchiektomie kam es innerhalb der orchiektomierten Versuchsgruppen zu einem Rückgang des durchschnittlichen Körpergewichtes, während die nonORX-Versuchstiere durchschnittlich weiter zunahmen. Es lässt sich weiter 
beobachten, dass nach Osteotomie und Osteosynthese das durchschnittliche Körpergewicht in allen Versuchsgruppen fiel und nach zwei Wochen wieder anstieg. Die weiteren Körpergewichte der Versuchsgruppen zeigten zu den oben genannten Zeitpunkten keine signifikanten Unterschiede. Das durchschnittliche Körpergewicht über den gesamten Versuchsverlauf der Versuchsgruppe nonORX war gegenüber allen anderen Versuchsgruppen signifikant erhöht (Tabelle 10).

\subsubsection{Muskelgewichte zum Versuchsende}

Die Muskeln wurden direkt nach der Tötung der Versuchstiere entnommen und gewogen. Im Folgenden werden die Gewichte der Mm. levatores anorum (Abbildung 15), gastrocnemii (Abbildung 16) und solei (Abbildung 18), sowie der Quotient Muskelgewicht/Körpergewicht (Abbildung 17, Abbildung 19) der zwei letzteren Muskeln dargestellt und beschrieben (Tabelle 11). Da die Entnahme des M. longissimus nur als Teilstück möglich war, ist kein Muskelgewicht festgestellt worden.

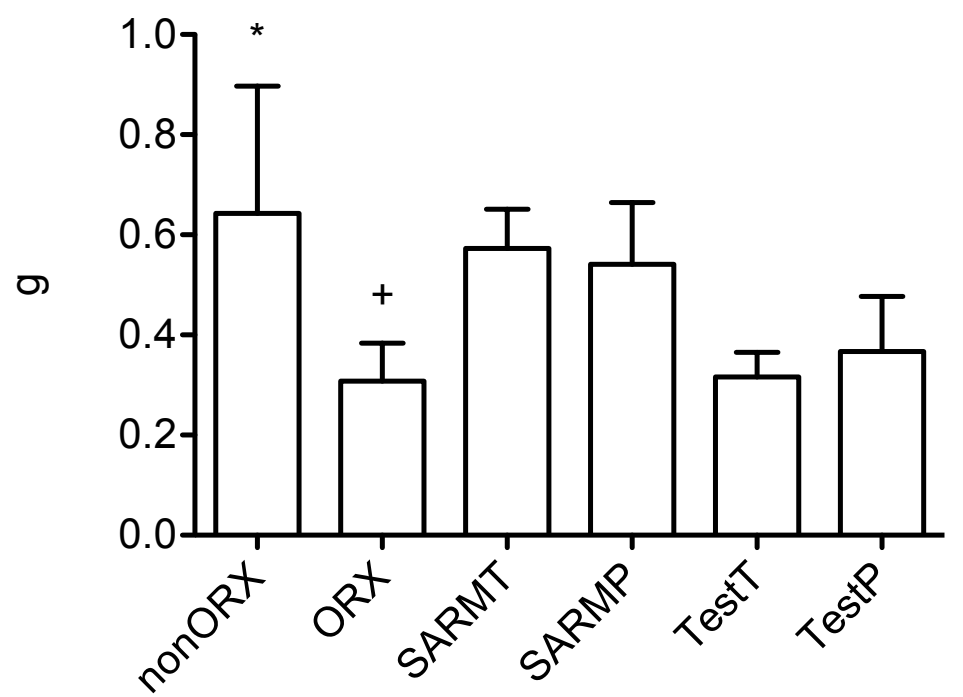

Abbildung 15: Gewichte der Mm. levatores anorum in Gramm (g) (Dunn's Multiple Comparison Test); * signifikant erhöht gegenüber ORX, TestT und TestP; + signifikant erniedrigt gegenüber SARMT und SARMP) 


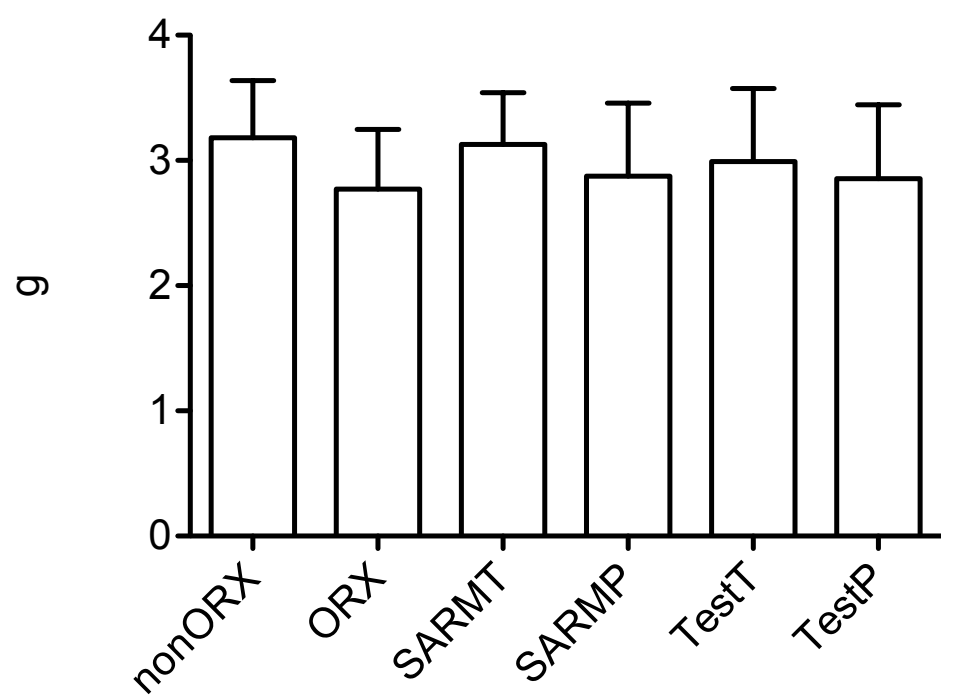

Abbildung 16: Gewichte der Mm. gastrocnemii in Gramm (g); keine signifikanten Unterschiede

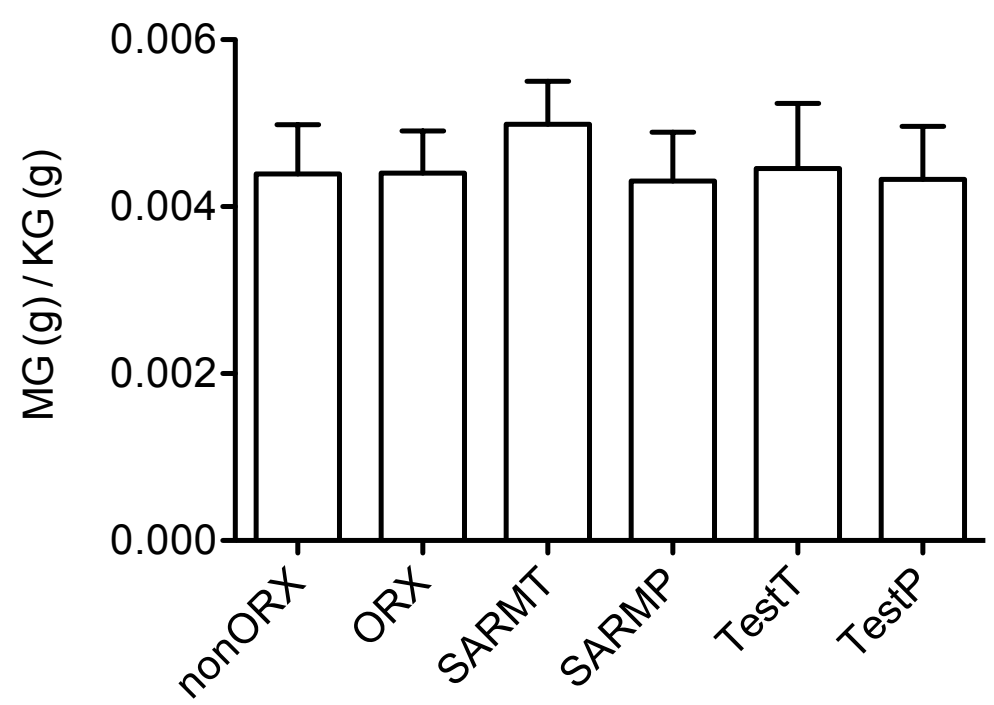

Abbildung 17: Muskelgewichte (MG) der Mm. gastrocnemii in Gramm (g) / Körpergewichte (KG) in Gramm; keine signifikanten Unterschiede 


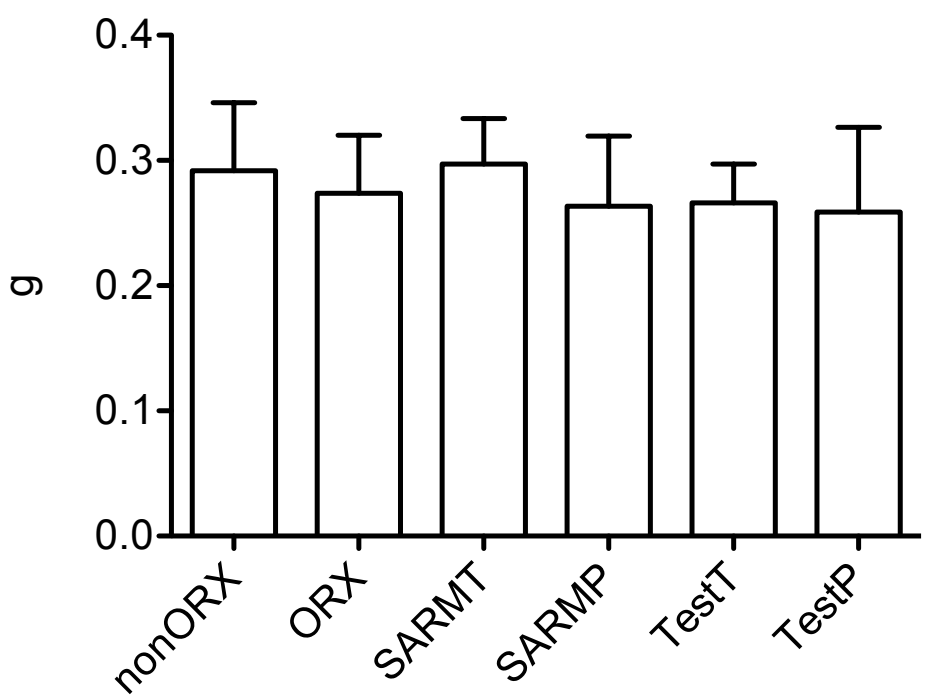

Abbildung 18: Gewichte der Mm. solei in Gramm (g); keine signifikanten Unterschiede

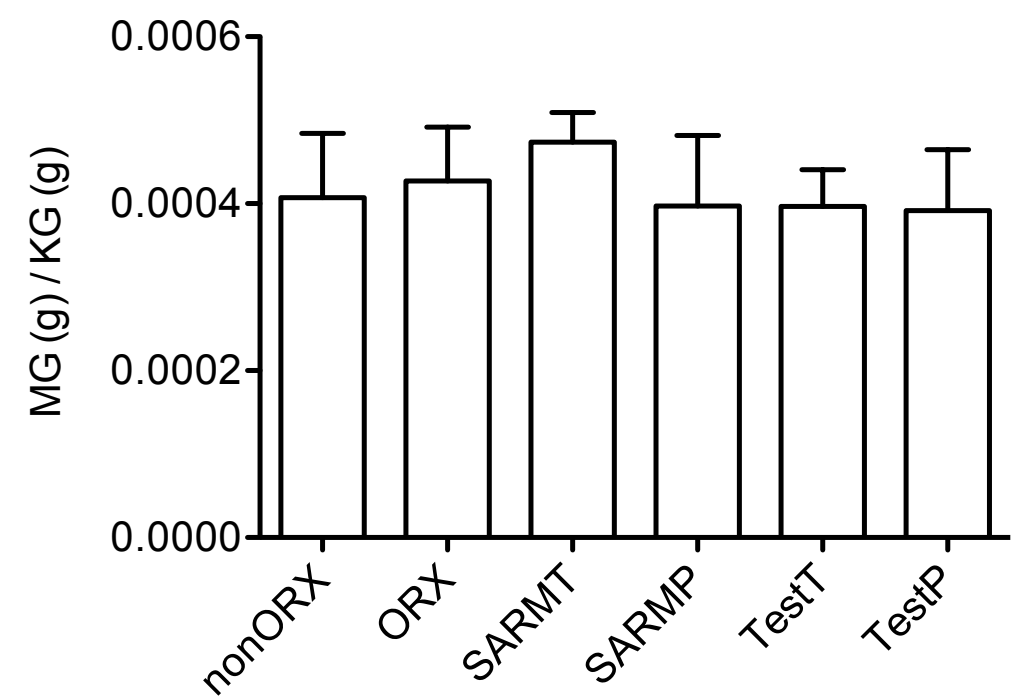

Abbildung 19: Muskelgewichte (MG) der Mm. solei in Gramm (g) / Körpergewichte (KG) in Gramm; keine signifikanten Unterschiede

Die Gewichte des $\mathrm{Mm}$. levatores anorum der Versuchsgruppe nonORX waren gegenüber denen der ORX-, TestT- und TestP-Versuchsgruppe signifikant erhöht. Die der ORX-Versuchsgruppe zeigten sich gegenüber denen der SARMTund SARMP-Versuchsgruppe signifikant erniedrigt. Ein signifikanter Unterschied zwischen den Versuchsgruppen bezüglich der Muskelgewichte der Mm. gastrocnemii und solei bestand nicht, jedoch kann eine tendenzielle Erhöhung 
der durchschnittlichen Muskelgewichte der Versuchsgruppe SARMT gegenüber denen der Versuchsgruppe ORX beobachtet werden. Diese Tendenz ist ebenfalls an den Quotienten Muskelgewicht/Körpergewicht ablesbar.

\subsubsection{Korrelation zwischen Muskel- und Körpergewichten}

Die Muskelgewichte und Körpergewichte aller Versuchstiere wurden auf Korrelation untersucht (Abbildung 20, Abbildung 21). So wird der Frage Rechnung getragen, ob bei steigendem Körpergewicht ebenfalls das Muskelgewicht steigt.

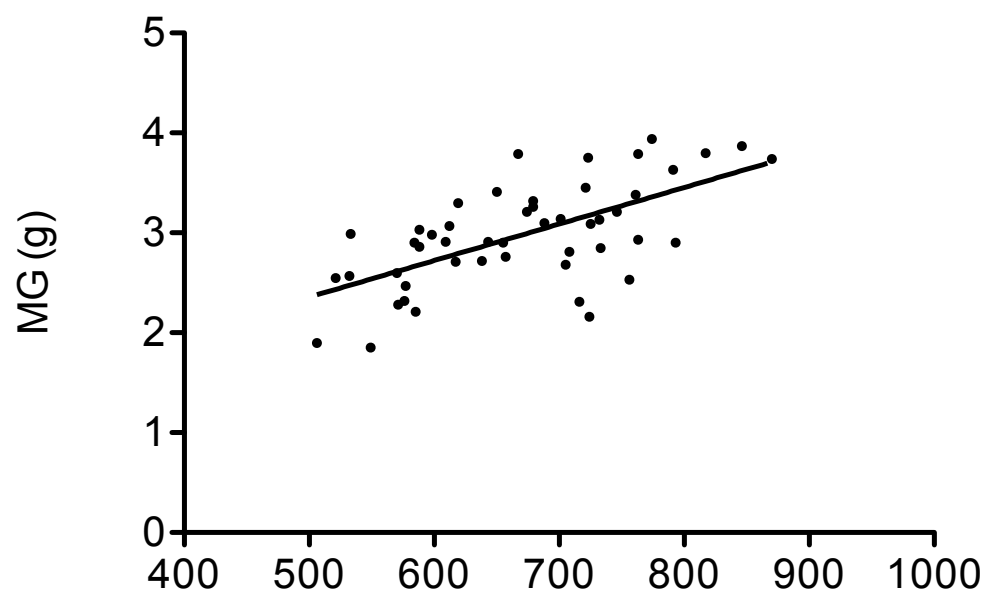

$K G(g)$

Abbildung 20: Korrelation der Körpergewichte (KG) und der Muskelgewichte (MG) der Mm. gastrocnemii aller Versuchstiere in Gramm (g) (Regressionsgrade $f(x)=0,0037 x+0,530$; Pearson $r=0,6346 ; p=<0,0001 ; R^{2}=0,4027$ ) 


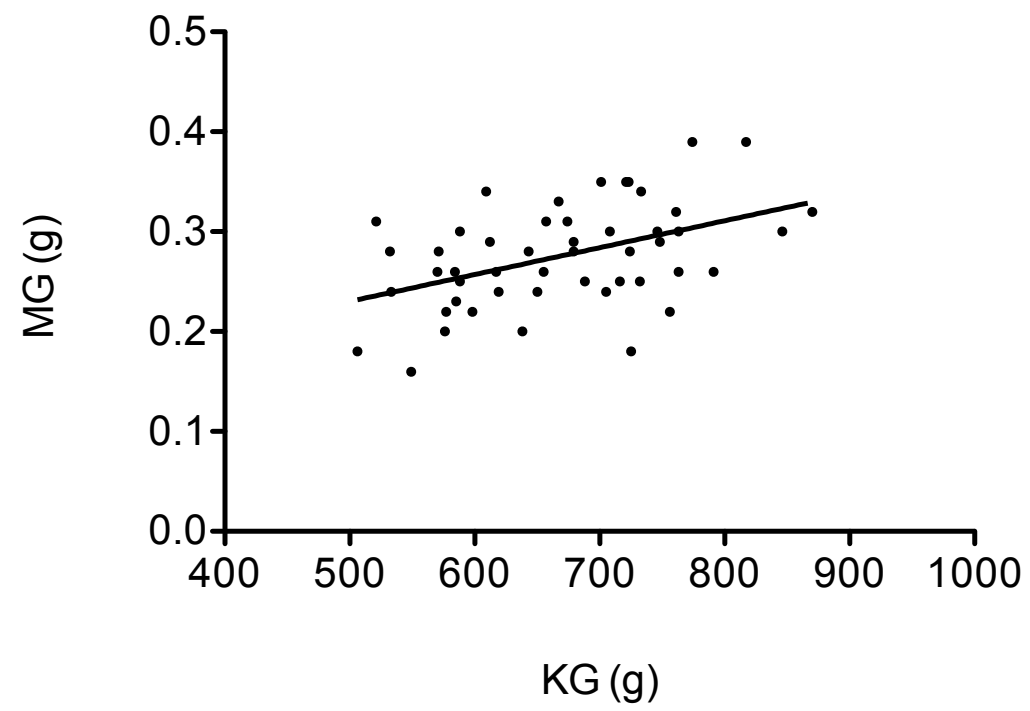

Abbildung 21: Korrelation der Körpergewichte (KG) und der Muskelgewichte (MG) der Mm. solei aller Versuchstiere in Gramm (g) (Regressionsgrade $f(x)=0,00027 x+0,096$; Pearson $r=0,4591$; $p=0,0009 ; R^{2}=0,2108$ )

Zwischen den Körpergewichten und den Gewichten der Mm. gastrocnemii bzw. Mm. solei zeigte sich eine signifikante positive Korrelation. 


\subsubsection{Prostatagewichte zum Versuchsende}

Ebenfalls wurden direkt nach der Tötung der Versuchstiere die Prostatae entnommen und gewogen (Abbildung 22, Tabelle 12).

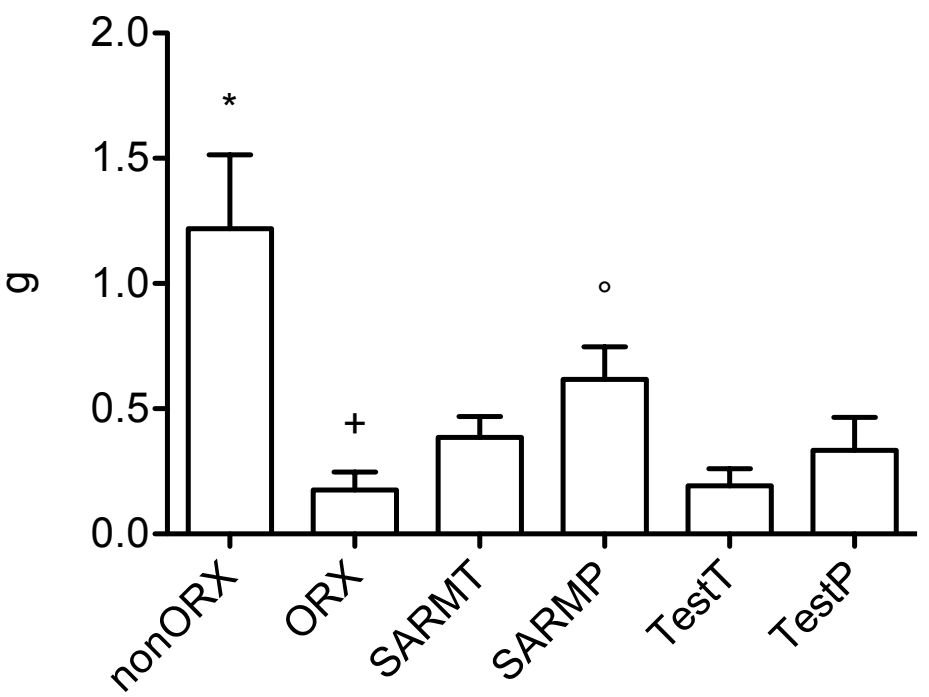

Abbildung 22: Prostatagewichte der Versuchstiere in Gramm (g) (Dunn's Multiple Comparison Test); * signifikant erhöht gegenüber ORX, SARMT, TestT und TestP; + signifikant erniedrigt gegenüber SARMP; ${ }^{\circ}$ signifikant erhöht gegenüber TestT)

Die Prostatagewichte der Versuchsgruppe nonORX zeigten sich gegenüber denen der ORX-, SARMT-, TestT- und TestP-Versuchsgruppen signifikant erhöht. Anlog verhielt es sich mit den Prostatagewichten der SARMP- gegenüber der TestT-Versuchsgruppe. Die Prostatagewichte der Versuchsgruppe ORX waren gegenüber denen der SARMP-Versuchsgruppe signifikant erniedrigt. 


\subsection{Auswertung der Amylase-PAS-Färbung}

\subsubsection{Kapillardichte}

Die Querschnitte der Mm. longissimi, gastrocnemii und solei wurden im Anschluss an die Amylase-PAS-Färbung auf das Verhältnis der Kapillaranzahl zu der Muskelzellanzahl untersucht (Abbildung 23, Abbildung 24, Abbildung 25, Tabelle 13).

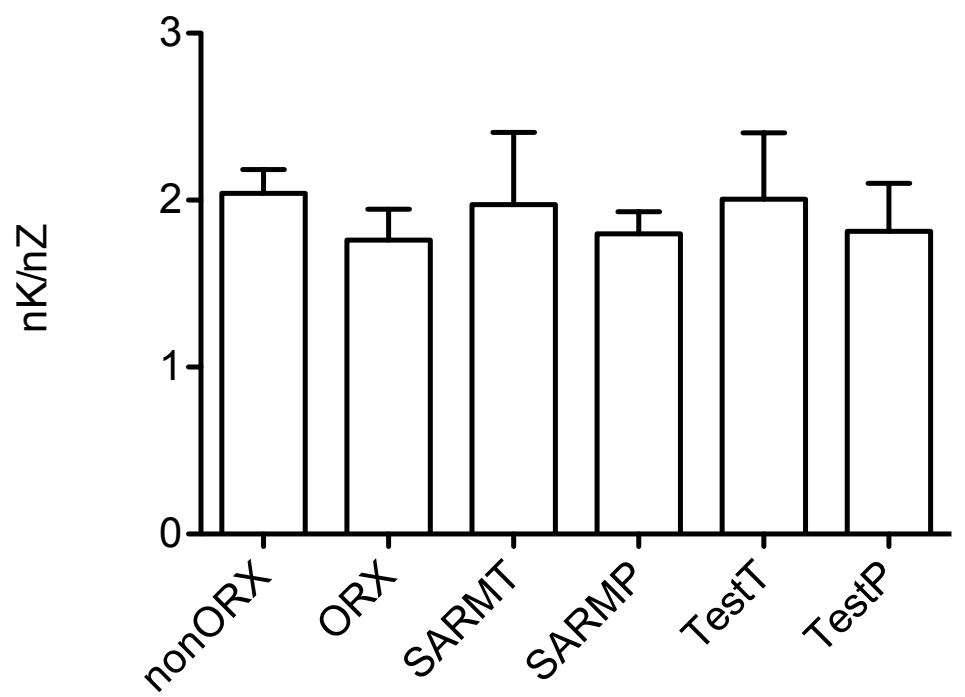

Abbildung 23: Anzahl Kapillare (nK) / Anzahl Muskelzellen ( $\mathrm{nZ}$ ) der Mm. longissimi der Versuchstiere (Dunn's Multiple Comparison Test); keine signifikanten Unterschiede 


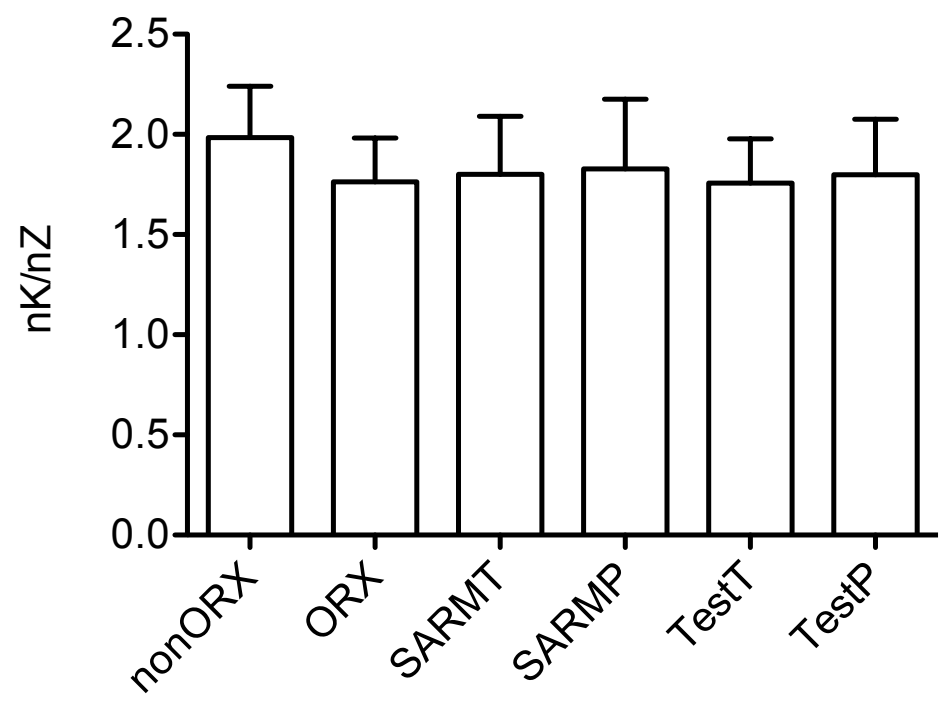

Abbildung 24: Anzahl Kapillare (nK) / Anzahl Muskelzellen (nZ) der Mm. gastrocnemii der Versuchstiere; keine signifikanten Unterschiede

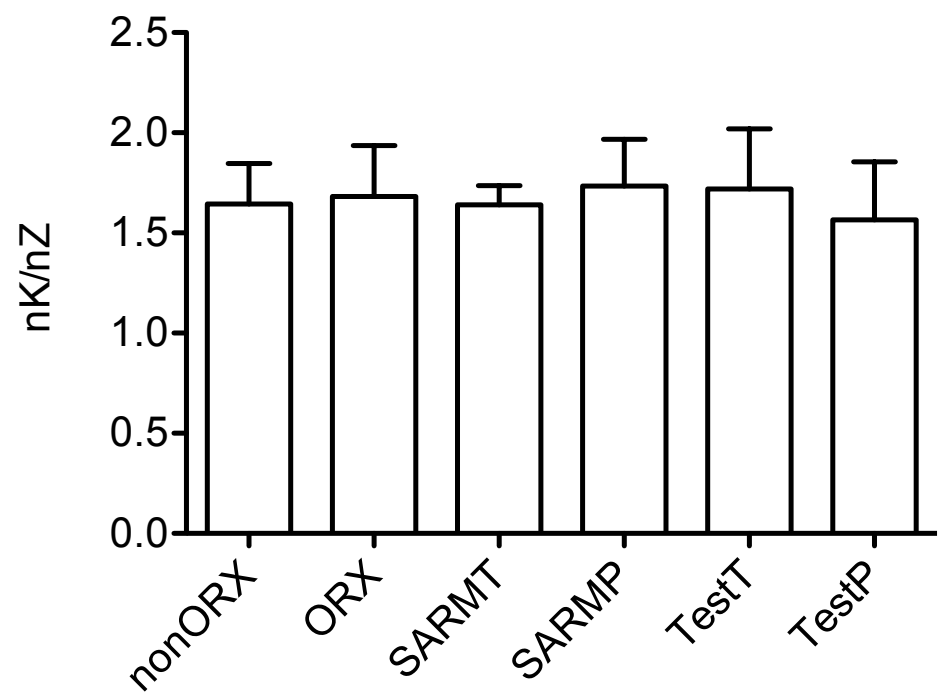

Abbildung 25: Anzahl Kapillare (nK) / Anzahl Muskelzellen (nZ) der Mm. solei der Versuchstiere; keine signifikanten Unterschiede

Die Auswertung der Amylase-PAS-Färbung bezüglich der Kapillardichte der Muskelzellen erbrachte keine signifikanten Unterschiede zwischen den Versuchsgruppen und Muskeltypen. Es lässt sich jedoch feststellen, dass die Kapillardichte der Mm. longissimi und gastrocnemii der Versuchsgruppe ORX gegenüber der von nonORX tendenziell erniedrigt ist. 


\subsection{Auswertung der ATPase-Färbung mit Diaphorase}

Durch die ATPase-Färbung mit Diaphorase wurden die Muskelzellen entsprechend ihrer Typen erkennbar. Somit konnten die Muskelzellquerschnittsflächen und die Äquivalentdurchmesser bestimmt werden. Diese wurden dann ins Verhältnis zu den Körpergewichten und den Muskelgewichten (nicht M. longissimus) der Versuchstiere gesetzt. In den Muskelquerschnitten des M. longissimus wurde zusätzlich das Verhältnis der Muskelzelltypen ausgezählt. Diese Ergebnisse werden im Folgenden für den M. longissimus, gastrocnemius und soleus dargestellt und beschrieben. Hierfür soll gelten: Unter Typ-1 wurden die oxidativen (Typ-1) und intermediären (Typ-2A) Zelltypen zusammengefasst, Typ-2 steht für den glykolytischen (Typ-2B) Zelltyp (siehe 1.2.3).

\subsubsection{M. longissimus}

\subsubsection{Auswertung der Muskelzellquerschnittsflächen}

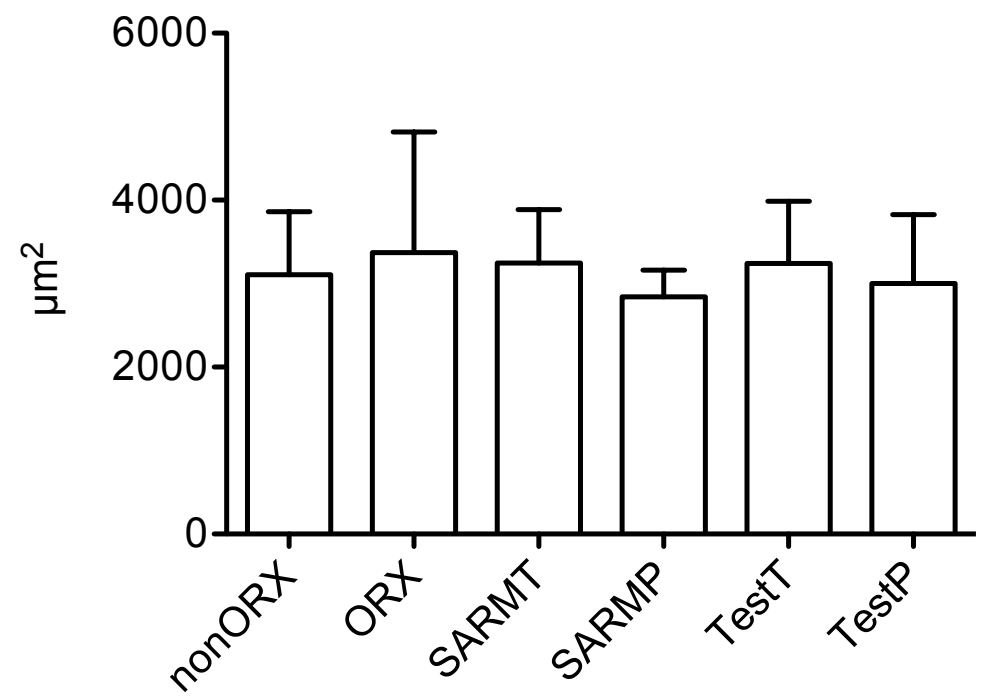

Abbildung 26: Muskelzellquerschnittsflächen, Typ-1 der Mm. longissimi der Versuchstiere in Quadratmikrometern $\left(\mu \mathrm{m}^{2}\right)$ (Dunn's Multiple Comparison Test); keine signifikanten Unterschiede 


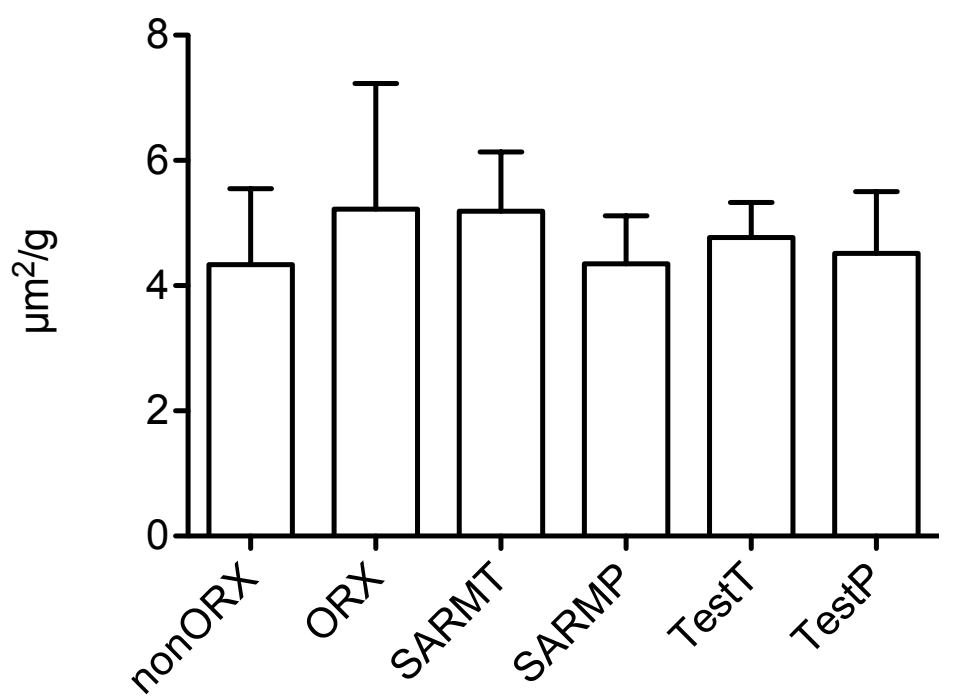

Abbildung 27: Muskelzellquerschnittsflächen, Typ-1 der Mm. longissimi der Versuchstiere in Quadratmikrometern $\left(\mu \mathrm{m}^{2}\right)$ / Körpergewichte der Versuchstiere in Gramm (g) (Dunn's Multiple Comparison Test); keine signifikanten Unterschiede

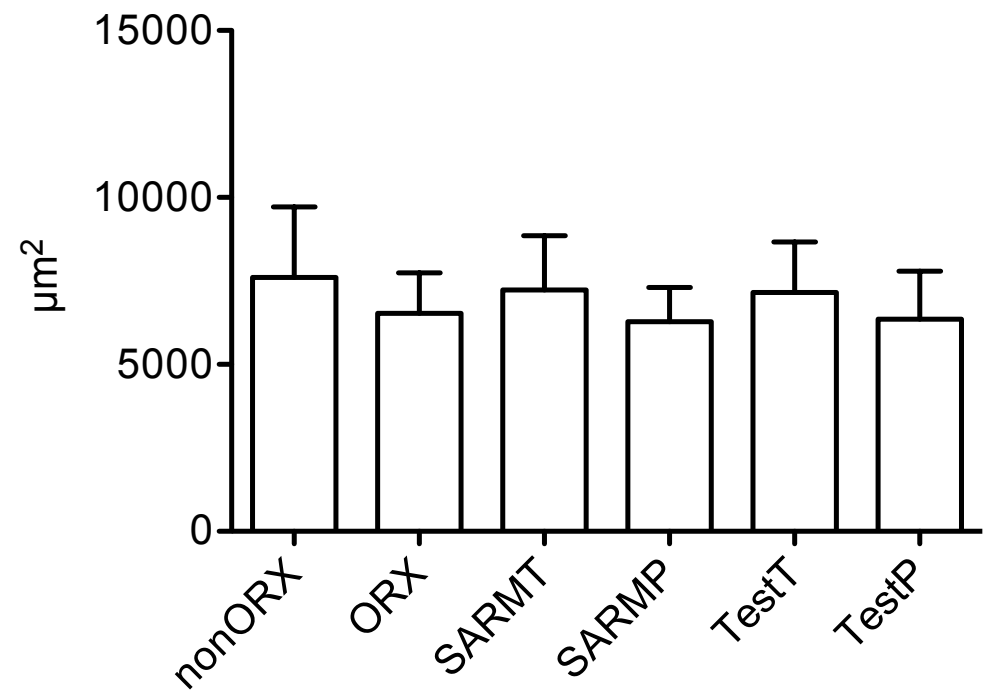

Abbildung 28: Muskelzellquerschnittsflächen, Typ-2 der Mm. longissimi der Versuchstiere in Quadratmikrometern $\left(\mu \mathrm{m}^{2}\right.$ ) (Dunn's Multiple Comparison Test); keine signifikanten Unterschiede 


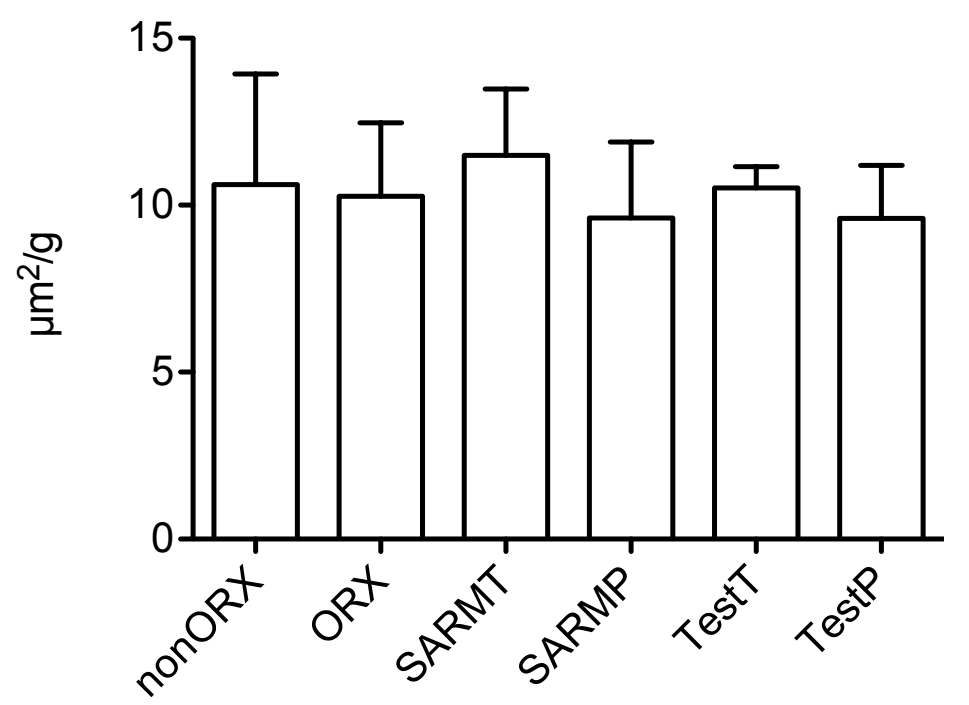

Abbildung 29: Muskelzellquerschnittsflächen, Typ-2 der Mm. Iongissimi der Versuchstiere in Quadratmikrometern $\left(\mu \mathrm{m}^{2}\right)$ / Körpergewichte der Versuchstiere in Gramm (g) (Dunn's Multiple Comparison Test); keine signifikanten Unterschiede

Die Auswertung der Muskelzellquerschnittsflächen der Typen 1 und 2 der $\mathrm{Mm}$. longissimi (Abbildung 26, Abbildung 28) sowie deren Verhältnis zum Körpergewicht (Abbildung 27, Abbildung 29) erbrachten keine signifikanten Unterschiede zwischen den Versuchsgruppen (Tabelle 14). Es lässt sich jedoch beobachten, dass die körpergewichtkorrigierten Muskelzellquerschnittsflächen beider Muskelzelltypen der Versuchsgruppen SARMT und TestT tendenziell größer als die von nonORX sind. 


\subsubsection{Auswertung der Muskelzell-Äquivalentdurchmesser}

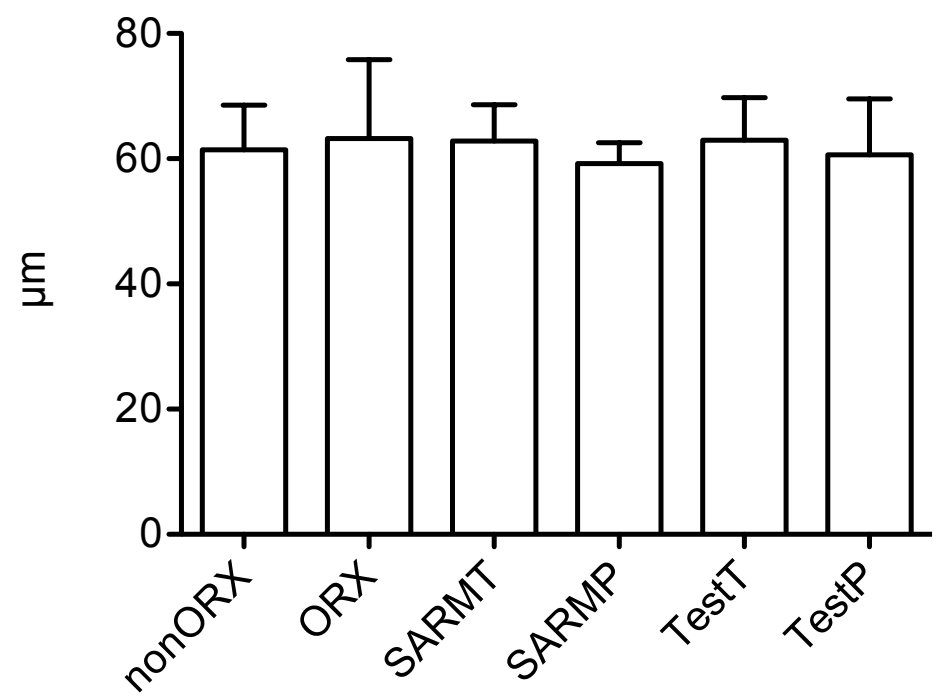

Abbildung 30: Muskelzell-Äquivalentdurchmesser, Typ-1 der Mm. longissimi der Versuchstiere in Mikrometern ( $\mu \mathrm{m})$ (Dunn's Multiple Comparison Test); keine signifikanten Unterschiede

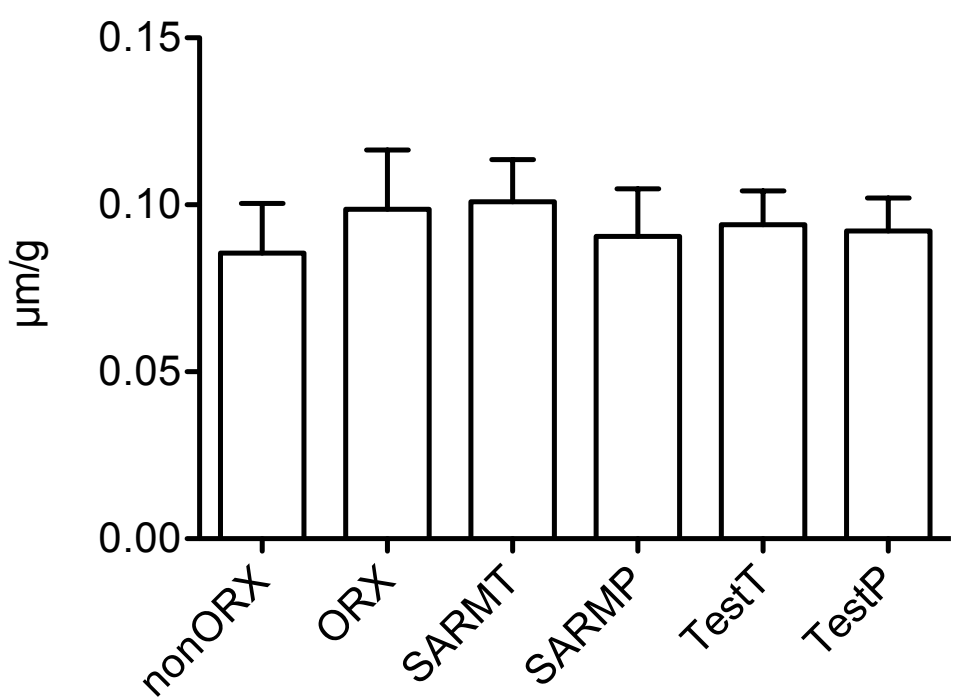

Abbildung 31: Muskelzell-Äquivalentdurchmesser, Typ-1 der Mm. longissimi der Versuchstiere in Mikrometern $(\mu \mathrm{m})$ / Körpergewichte der Versuchstiere in Gramm (g); keine signifikanten Unterschiede 


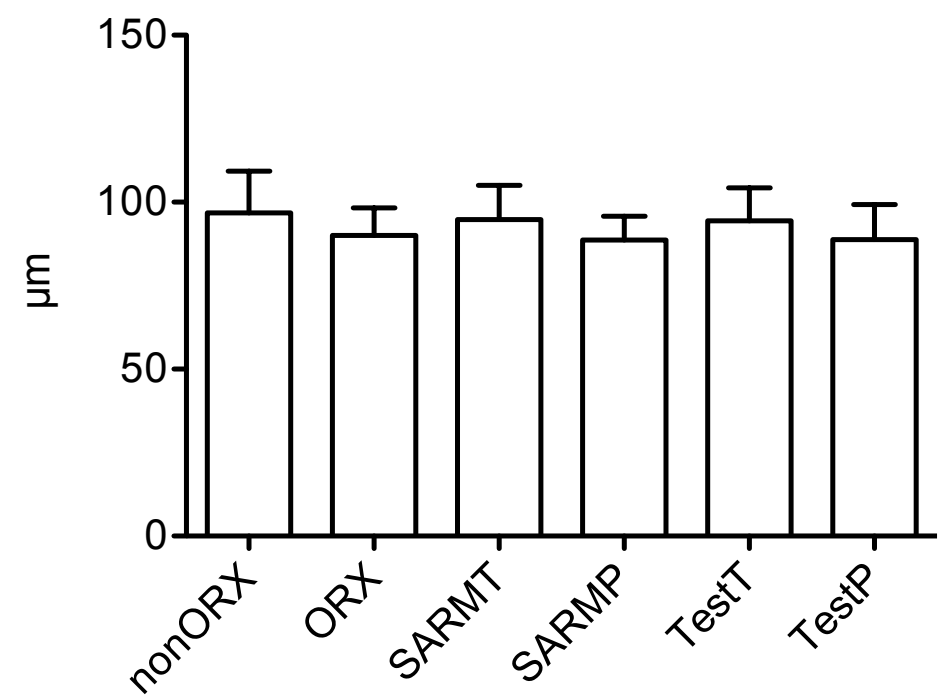

Abbildung 32: Muskelzell-Äquivalentdurchmesser, Typ-2 der Mm. longissimi der Versuchstiere in Mikrometern $(\mu \mathrm{m})$ (Dunn's Multiple Comparison Test); keine signifikanten Unterschiede

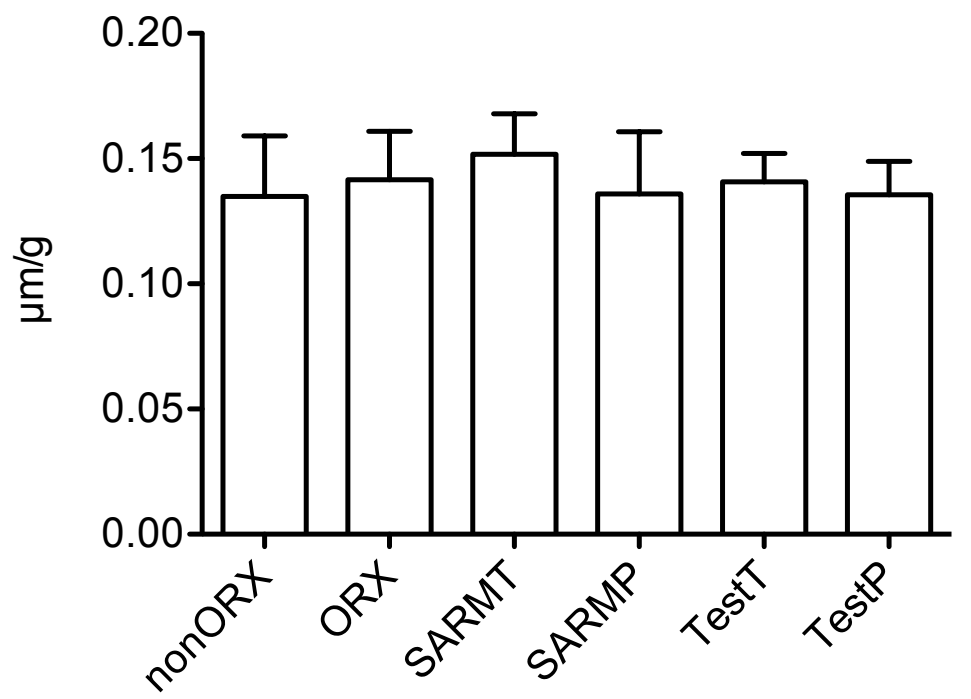

Abbildung 33: Muskelzell-Äquivalentdurchmesser, Typ-2 der Mm. Iongissimi der Versuchstiere in Mikrometern $(\mu \mathrm{m})$ / Körpergewichte der Versuchstiere in Gramm (g); keine signifikanten Unterschiede

Die Auswertung der Muskelzell-Äquivalentdurchmesser der Typen 1 und 2 der Mm. longissimi (Abbildung 30, Abbildung 32) sowie deren Verhältnis zum Körpergewicht (Abbildung 31, Abbildung 33) erbrachte keine signifikanten 
Unterschiede zwischen den Versuchsgruppen (Tabelle 15). Allerdings lässt sich erkennen, dass die körpergewichtkorrigierten Muskelwerte der Versuchsgruppe SARMT im Vergleich mit den Kontrollgruppen einen Trend in Richtung erhöhter Werte beschreiben.

\subsubsection{Verhältnisse der Muskelzelltypen}

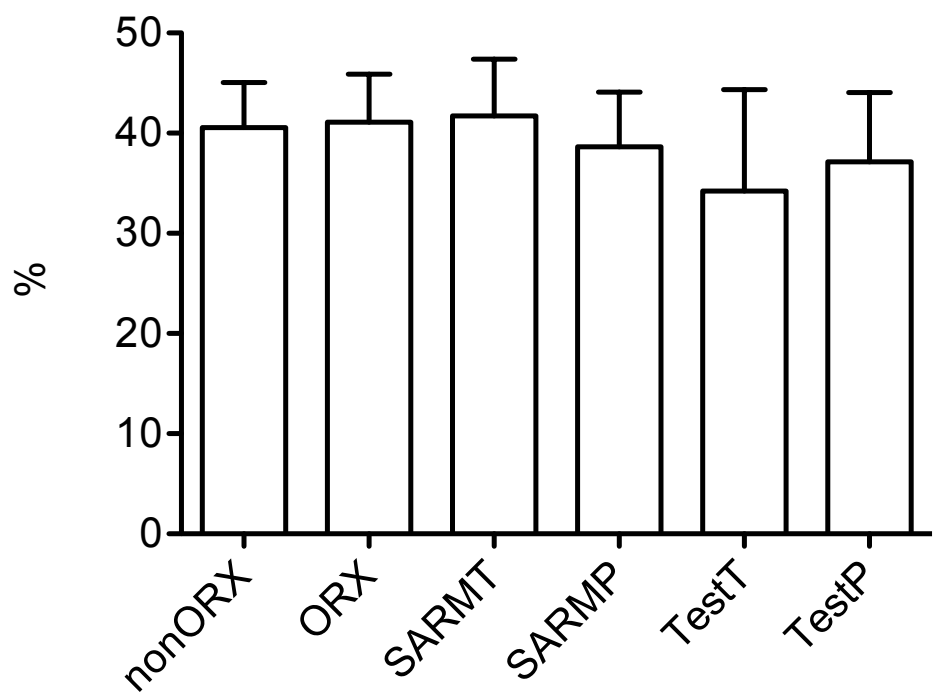

Abbildung 34: Verhältnisse der Muskelzellanzahl Typ-1 zur Gesamtmuskelzellanzahl der Mm. longissimi der Versuchstiere in Prozent (\%); keine signifikanten Unterschiede

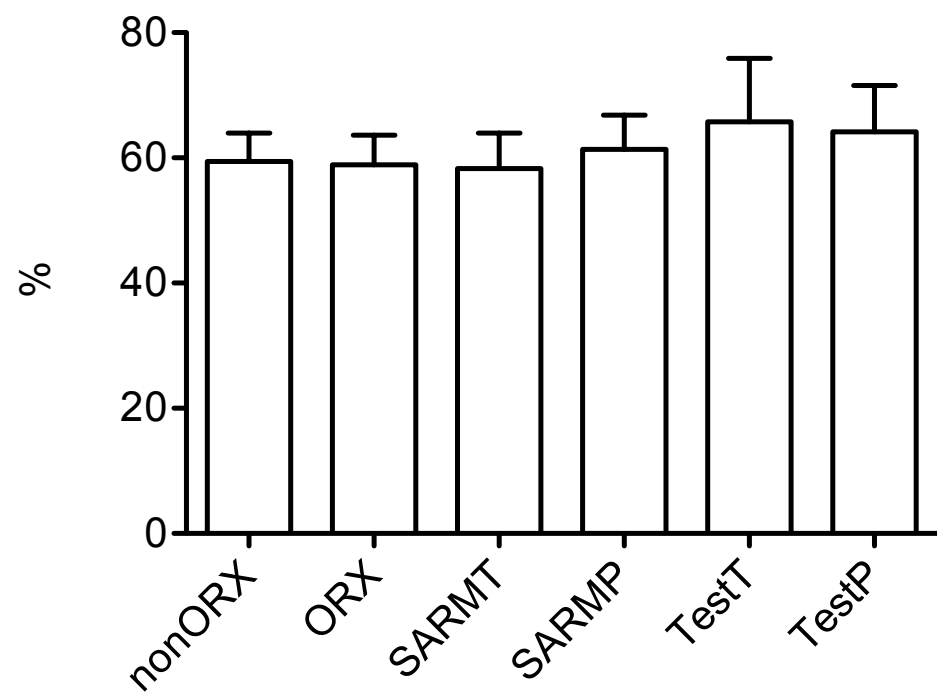

Abbildung 35: Verhältnisse der Muskelzellanzahl Typ-2 zur Gesamtmuskelzellanzahl der Mm. longissimi der Versuchstiere in Prozent (\%); keine signifikanten Unterschiede 
Die Verhältnisse der Muskelzellanzahl der Typen 1 und 2 zur Gesamtmuskelzellanzahl in $1 \mathrm{~mm}^{2}$ Muskelquerschnitt der $\mathrm{Mm}$. longissimi der Versuchstiere erbrachte keine signifikanten Unterschiede zwischen den Versuchsgruppen (Abbildung 34, Abbildung 35, Tabelle 20). Es ist indes eine Steigerung des Anteils von Typ-2 Muskelzellen in den Versuchsgruppen SARMP, TestT und TestP festzustellen, wobei die Versuchsgruppe TestT den höchsten Anteil aufweist.

\subsubsection{M. gastrocnemius}

\subsubsection{Auswertung der Muskelzellquerschnittsflächen}

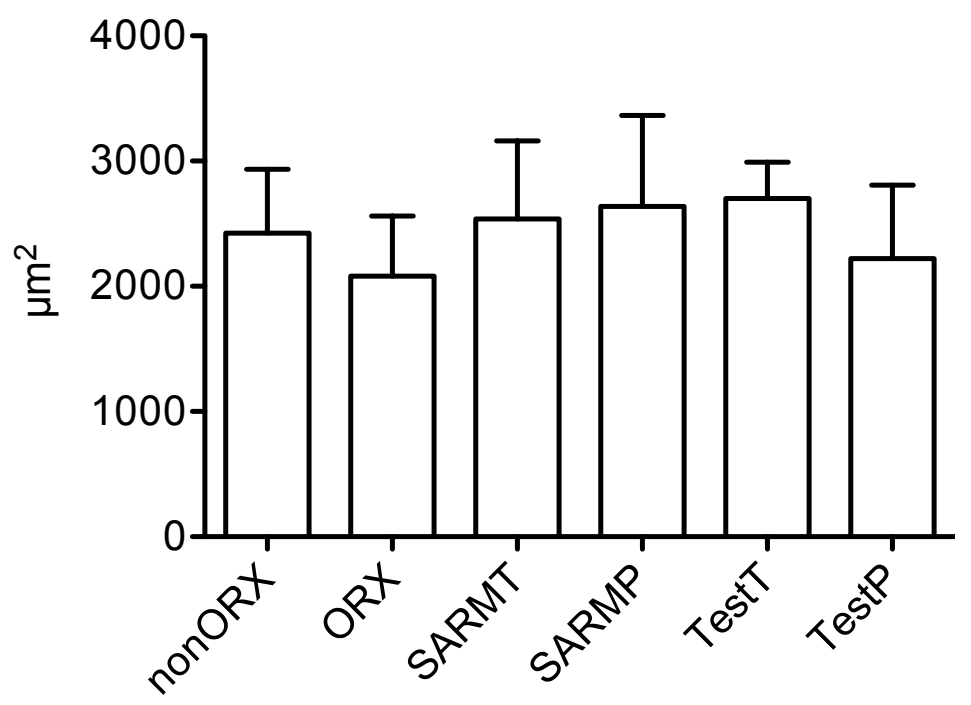

Abbildung 36: Muskelzellquerschnittsflächen, Typ-1 der Mm. gastrocnemii der Versuchstiere in Quadratmikrometern $\left(\mu \mathrm{m}^{2}\right)$; keine signifikanten Unterschiede 


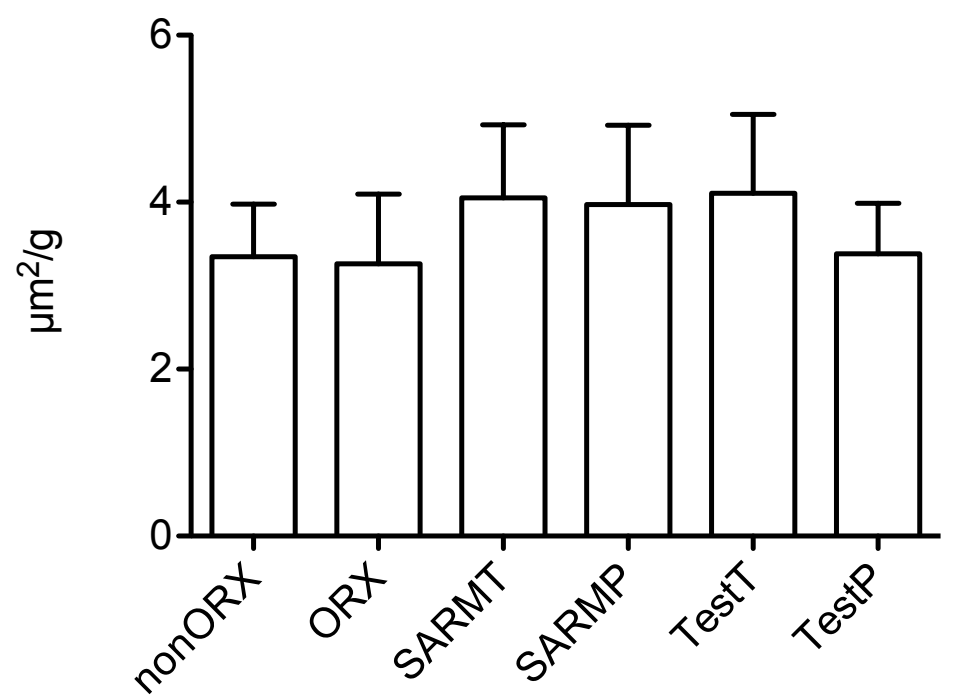

Abbildung 37: Muskelzellquerschnittsflächen, Typ-1 der Mm. gastrocnemii der Versuchstiere in Quadratmikrometern $\left(\mu \mathrm{m}^{2}\right)$ / Körpergewichte der Versuchstiere in Gramm (g); keine signifikanten Unterschiede

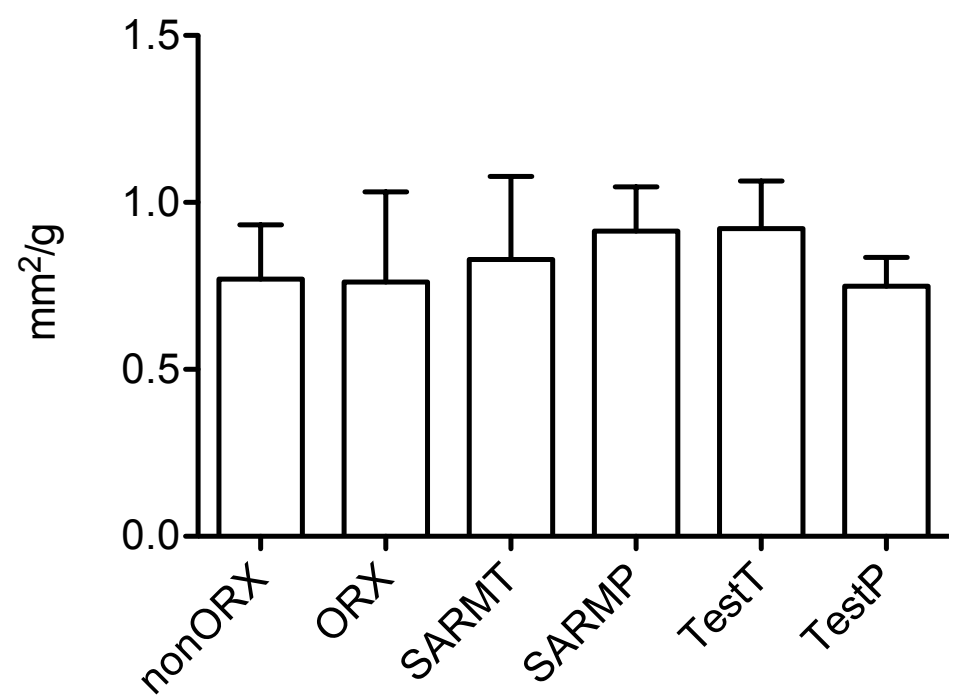

Abbildung 38: Muskelzellquerschnittsflächen, Typ-1 der Mm. gastrocnemii der Versuchstiere in Quadratmillimetern $\left(\mathrm{mm}^{2}\right)$ / Muskelgewichte der Versuchstiere in Gramm (g); keine signifikanten Unterschiede 


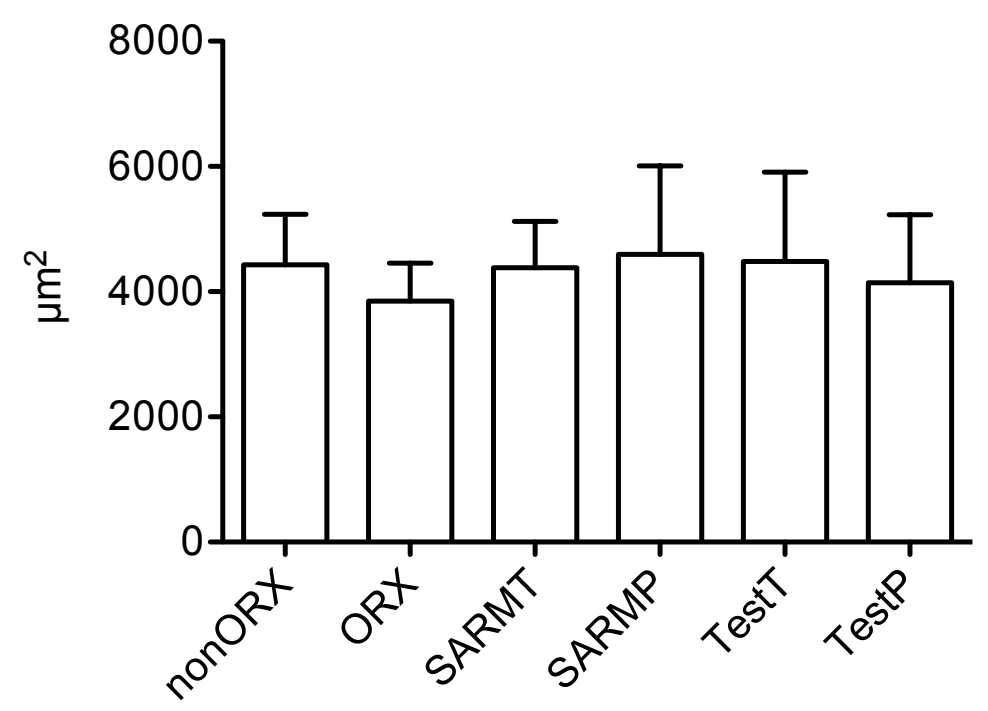

Abbildung 39: Muskelzellquerschnittsflächen, Typ-2 der Mm. gastrocnemii der Versuchstiere in Quadratmikrometern $\left(\mu \mathrm{m}^{2}\right)$; keine signifikanten Unterschiede

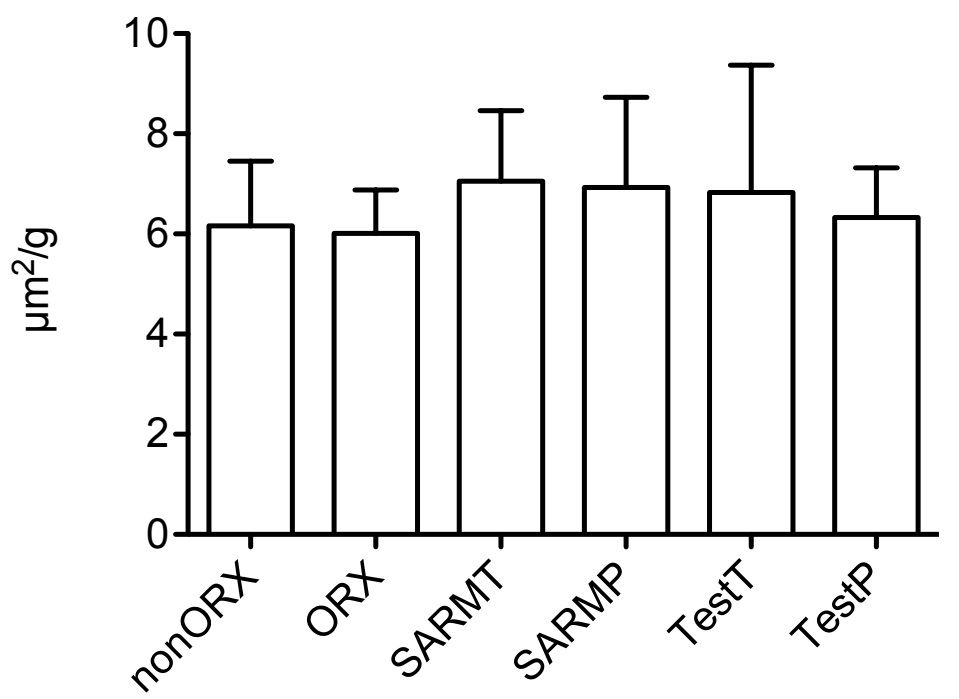

Abbildung 40: Muskelzellquerschnittsflächen, Typ-2 der Mm. gastrocnemii der Versuchstiere in Quadratmikrometern $\left(\mu \mathrm{m}^{2}\right)$ / Körpergewichte der Versuchstiere in Gramm (g); keine signifikanten Unterschiede 


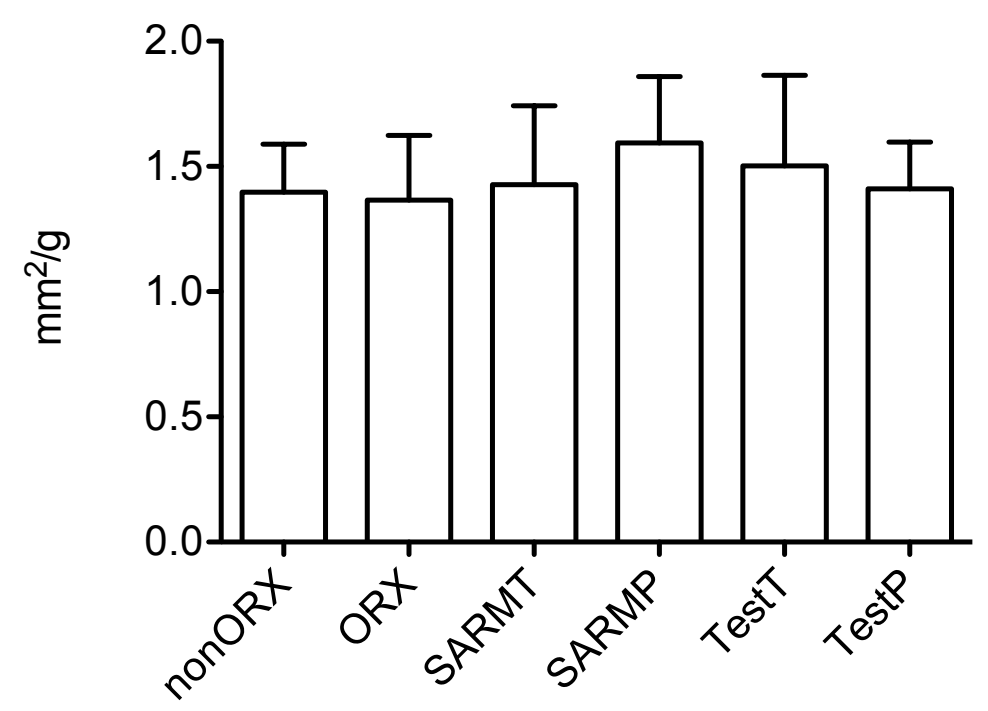

Abbildung 41: Muskelzellquerschnittsflächen, Typ-2 der Mm. gastrocnemii der Versuchstiere in Quadratmillimetern $\left(\mathrm{mm}^{2}\right)$ / Muskelgewichte der Versuchstiere in Gramm (g); keine signifikanten Unterschiede

Die Auswertung der Muskelzellquerschnittsflächen der Typen 1 und 2 der $\mathrm{Mm}$. gastrocnemii (Abbildung 36, Abbildung 39) sowie deren Verhältnis zum Körpergewicht (Abbildung 37, Abbildung 40) bzw. Muskelgewicht (Abbildung 38, Abbildung 41) ließ keine signifikanten Unterschiede zwischen den Versuchsgruppen erkennen (Tabelle 16). Der Vergleich der Versuchsgruppen nonORX und ORX demonstriert jedoch sichtbar erhöhte Werte innerhalb der nonORX-Versuchsgruppe. Im weiteren Vergleich dieser Werte mit denen der Versuchsgruppe SARMT und SARMP zeigen sich die Ergebnisse der Versuchsgruppen, welche mit Enobosarm therapiert wurden, durchweg höher. Dies lässt sich analog für die Versuchsgruppe TestT beschreiben. Die beschriebene Tendenz kann ebenfalls innerhalb der körpergewichtkorrigierten Ergebnisse beobachtet werden. 


\subsubsection{Auswertung der Muskelzell-Äquivalentdurchmesser}

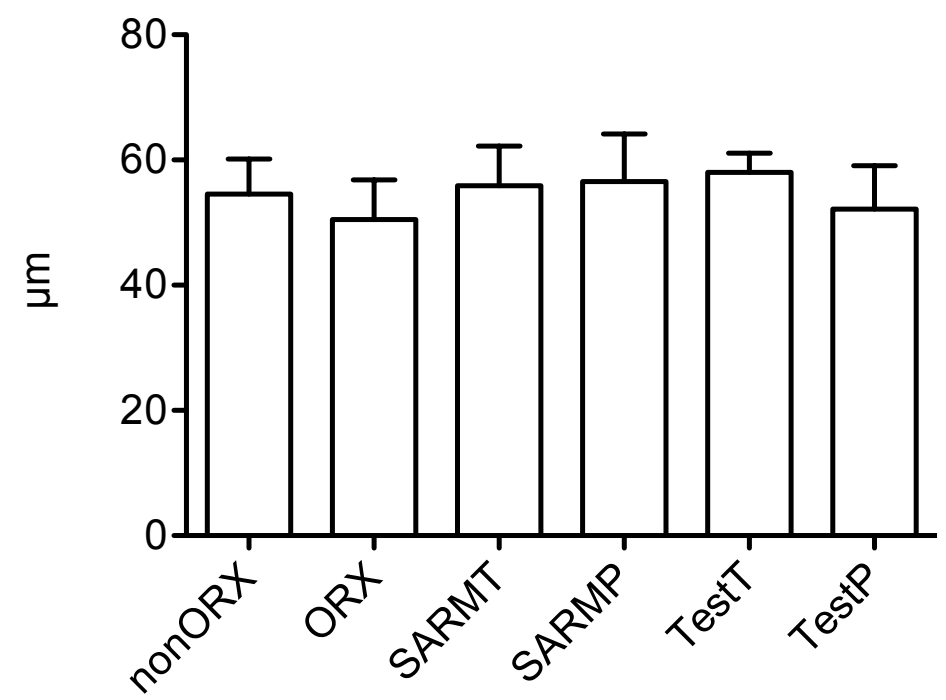

Abbildung 42: Muskelzell-Äquivalentdurchmesser, Typ-1 der Mm. gastrocnemii der Versuchstiere in Mikrometern $(\mu \mathrm{m})$; keine signifikanten Unterschiede

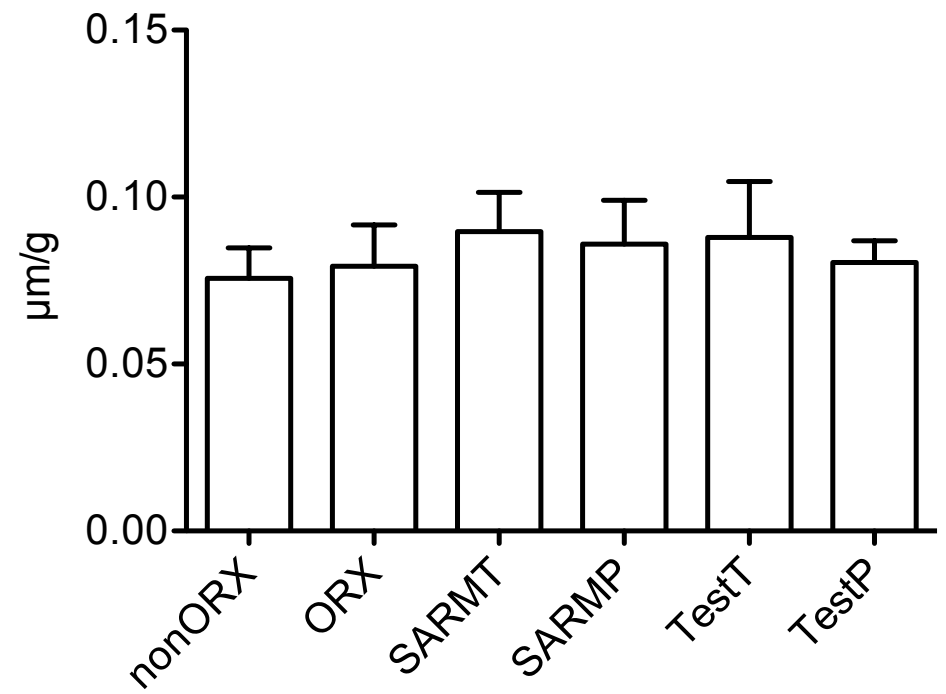

Abbildung 43: Muskelzell-Äquivalentdurchmesser, Typ-1 der Mm. gastrocnemii der Versuchstiere in Mikrometern $(\mu \mathrm{m})$ / Körpergewichte der Versuchstiere in Gramm (g); keine signifikanten Unterschiede 


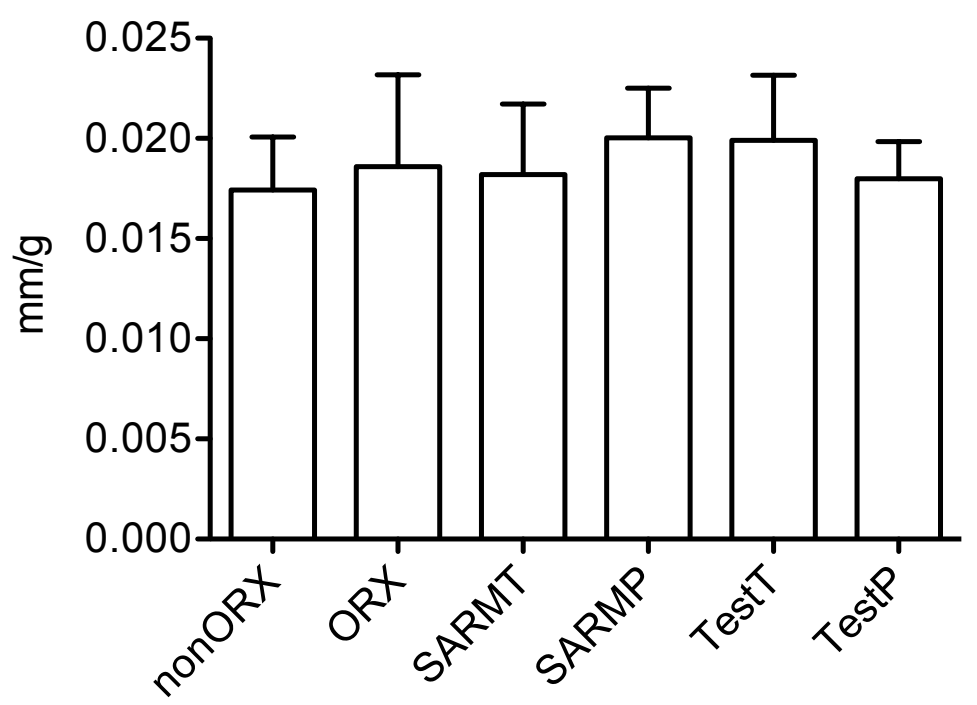

Abbildung 44: Muskelzell-Äquivalentdurchmesser, Typ-1 der Mm. gastrocnemii der Versuchstiere in Mikrometern (mm) / Muskelgewichte der Versuchstiere in Gramm (g); keine signifikanten Unterschiede

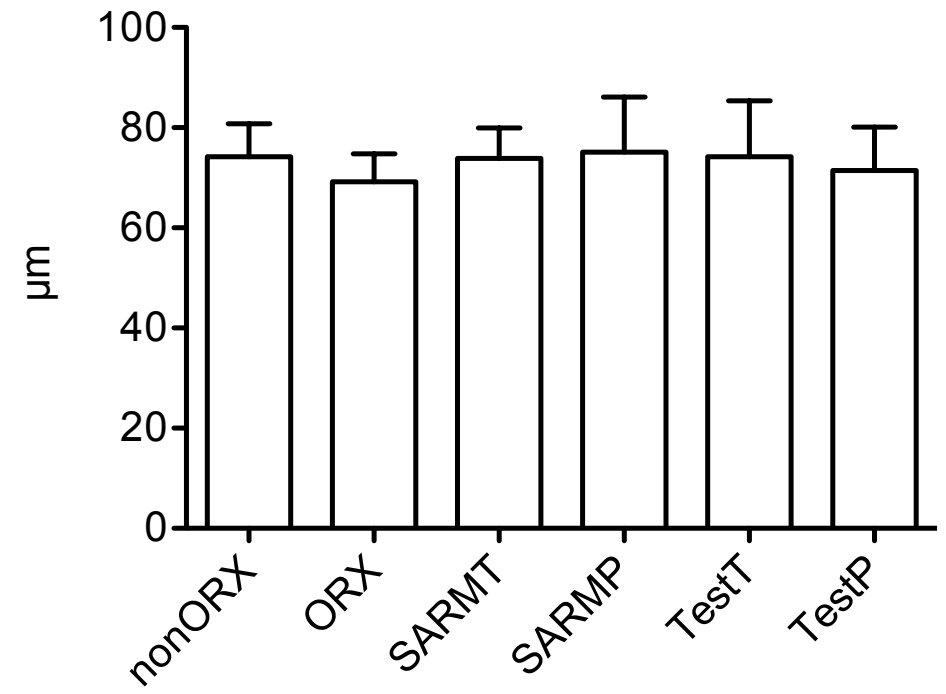

Abbildung 45: Muskelzell-Äquivalentdurchmesser, Typ-2 der Mm. gastrocnemii der Versuchstiere in Mikrometern $(\mu \mathrm{m})$; keine signifikanten Unterschiede 


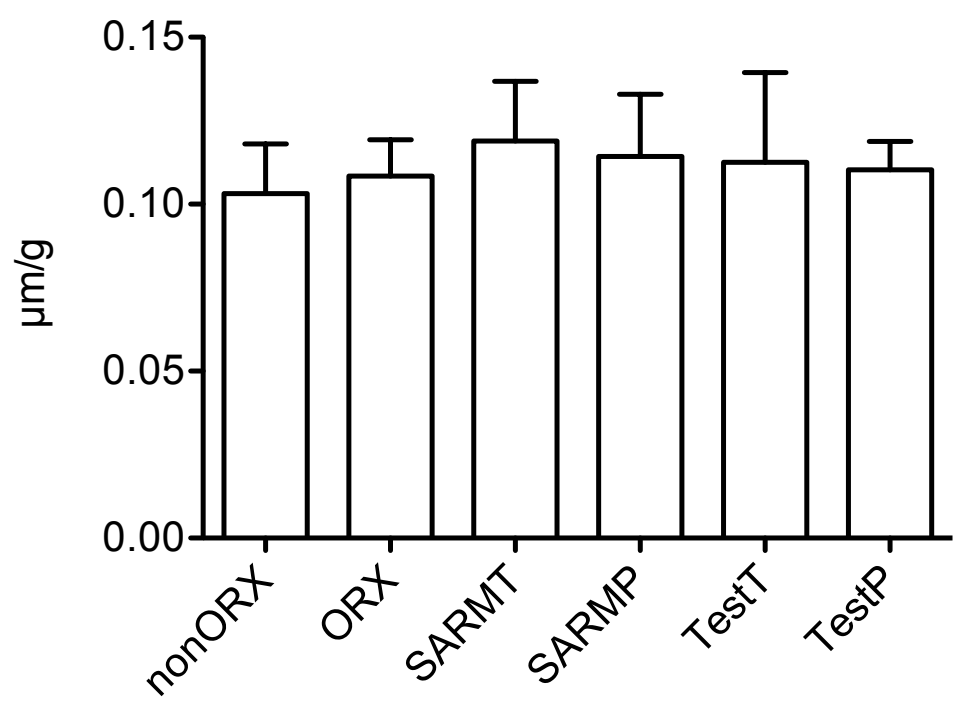

Abbildung 46: Muskelzell-Äquivalentdurchmesser, Typ-2 der Mm. gastrocnemii der Versuchstiere in Mikrometern $(\mu \mathrm{m})$ / Körpergewichte der Versuchstiere in Gramm $(\mathrm{g})$; keine signifikanten Unterschiede

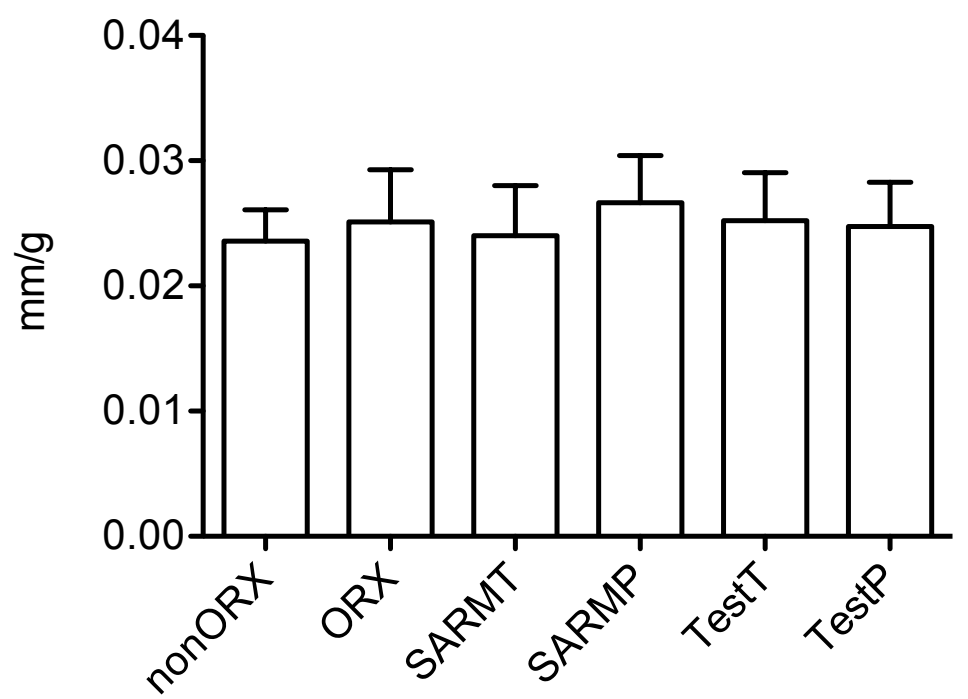

Abbildung 47: Muskelzell-Äquivalentdurchmesser, Typ-2 der Mm. gastrocnemii der Versuchstiere in Millimetern ( $\mathrm{mm}$ ) / Muskelgewichte der Versuchstiere in Gramm (g); keine signifikanten Unterschiede

Die Auswertung der Muskelzell-Äquivalentdurchmesser der Typen 1 und 2 der Mm. gastrocnemii (Abbildung 42, Abbildung 45) sowie deren Verhältnis zum Körpergewicht (Abbildung 43, Abbildung 46) bzw. Muskelgewicht (Abbildung 44, Abbildung 47) erbrachte keine signifikanten Unterschiede zwischen den 
Versuchsgruppen (Tabelle 17). Im Vergleich mit den Kontrollgruppen sind die Werte der Versuchsgruppen SARMT und SARMP erhöht. Die gleiche Beobachtung ist in Betrachtung der körpergewichtkorrigierten Werte zu machen.

\subsubsection{M. soleus}

\subsubsection{Auswertung der Muskelzellquerschnittsflächen}

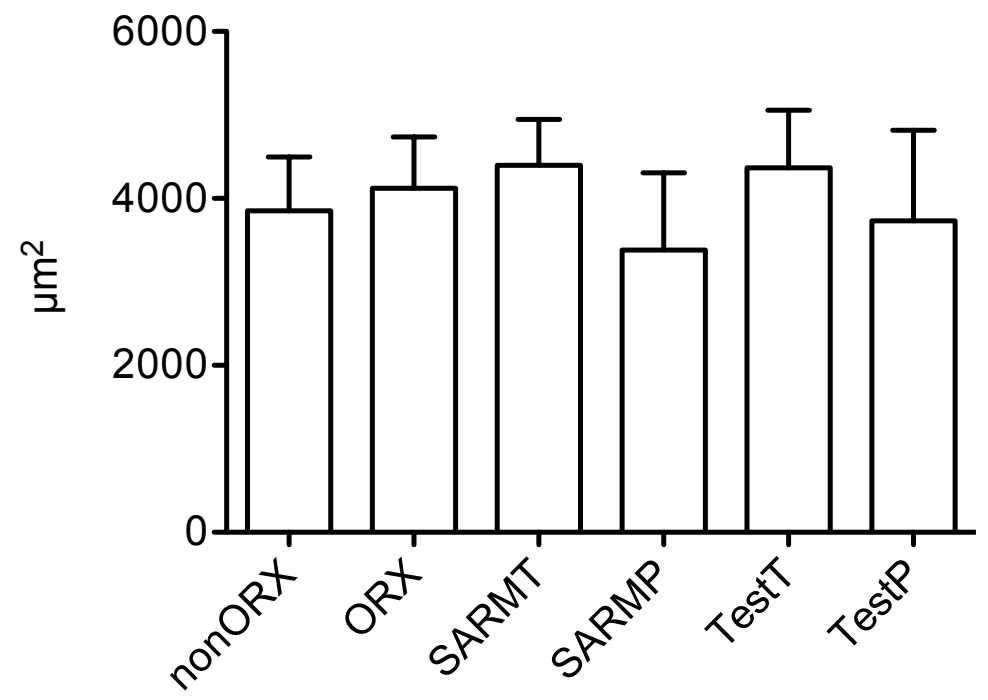

Abbildung 48: Muskelzellquerschnittsflächen, Typ-1 der Mm. solei der Versuchstiere in Quadratmikrometern $\left(\mu \mathrm{m}^{2}\right)$; keine signifikanten Unterschiede

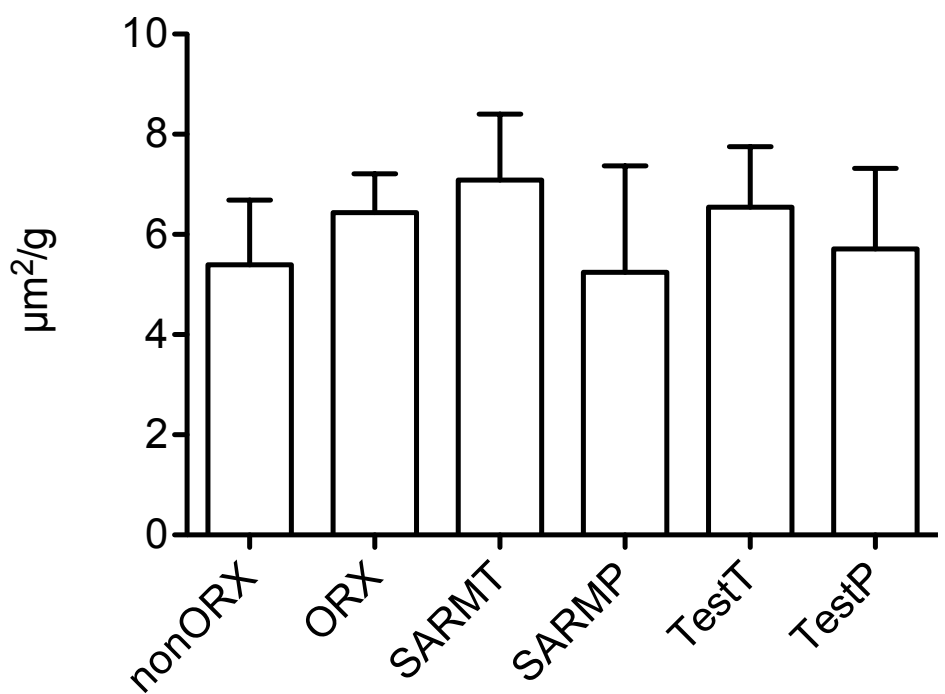

Abbildung 49: Muskelzellquerschnittsflächen, Typ-1 der Mm. solei der Versuchstiere in Quadratmikrometern $\left(\mu \mathrm{m}^{2}\right)$ / Körpergewichte der Versuchstiere in Gramm (g); keine signifikanten Unterschiede 


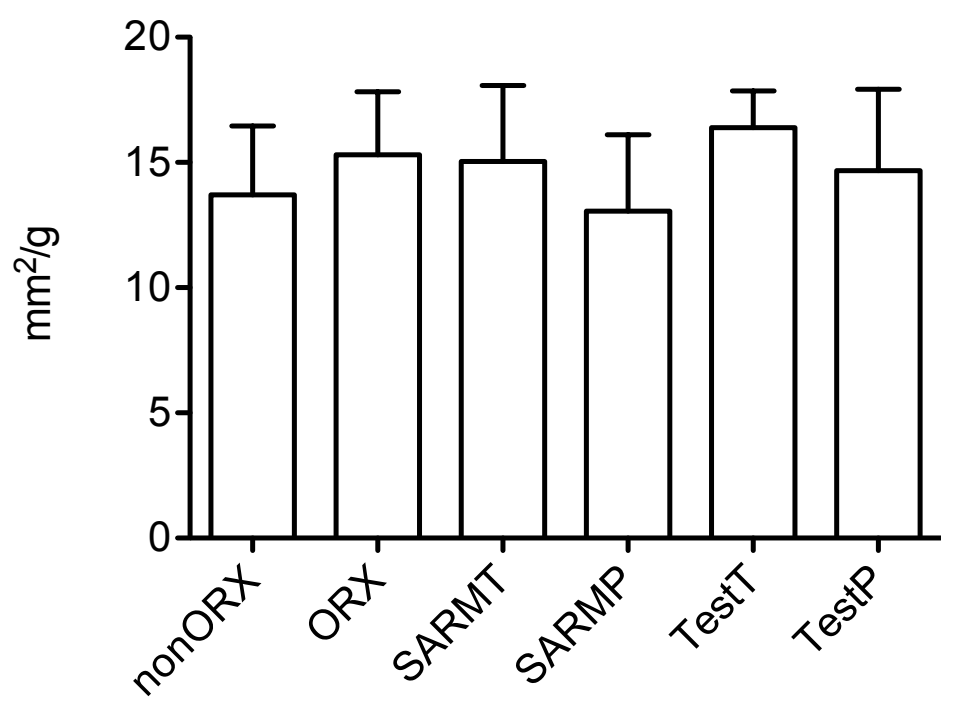

Abbildung 50: Muskelzellquerschnittsflächen, Typ-1 der Mm. solei der Versuchstiere in Quadratmillimetern $\left(\mathrm{mm}^{2}\right)$ / Muskelgewichte der Versuchstiere in Gramm (g); keine signifikanten Unterschiede

Die Auswertung der Muskelzellquerschnittsflächen des Typen $1 \mathrm{der} M m$. solei (Abbildung 48) sowie deren Verhältnis zum Körpergewicht (Abbildung 49) bzw. Muskelgewicht (Abbildung 50) erbrachte keine signifikanten Unterschiede zwischen den Versuchsgruppen (Tabelle 18). Im Vergleich der Ergebnisse der Versuchsgruppen nonORX und ORX stellen sich die Werte der ORXVersuchsgruppe erhöht dar. Die Ergebnisse der Versuchsgruppen SARMT und TestT zeigen im Vergleich zu den Kontrollgruppen eine Tendenz in Richtung höherer Werte, was ebenso im Vergleich der körpergewichtkorrigierten Werte sichtbar ist. 


\subsubsection{Auswertung der Muskelzell-Äquivalentdurchmesser}

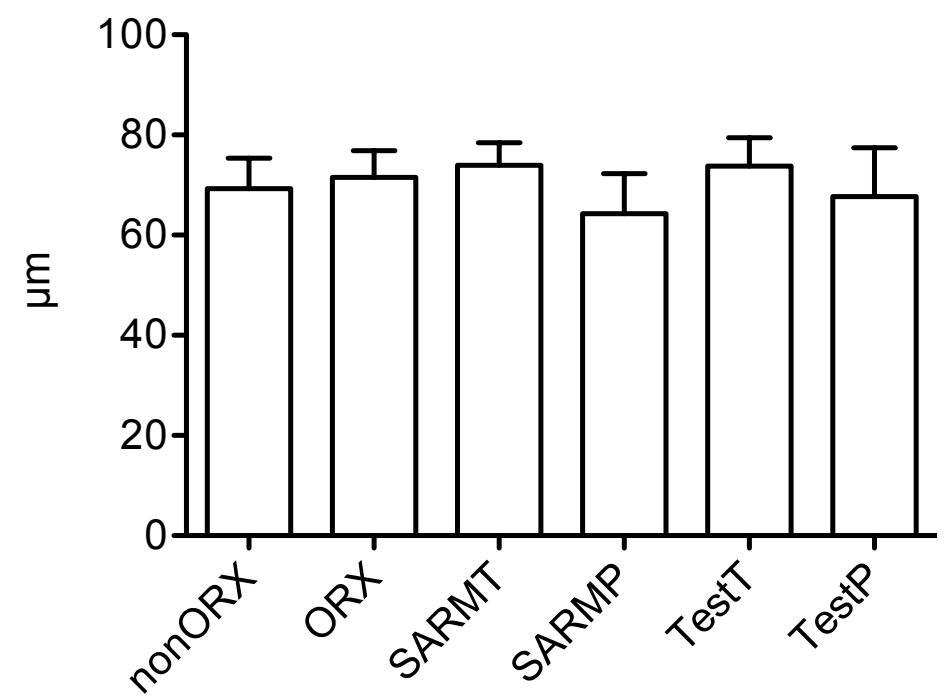

Abbildung 51: Muskelzell-Äquivalentdurchmesser, Typ-1 der Mm. solei der Versuchstiere in Mikrometern $(\mu \mathrm{m})$; keine signifikanten Unterschiede

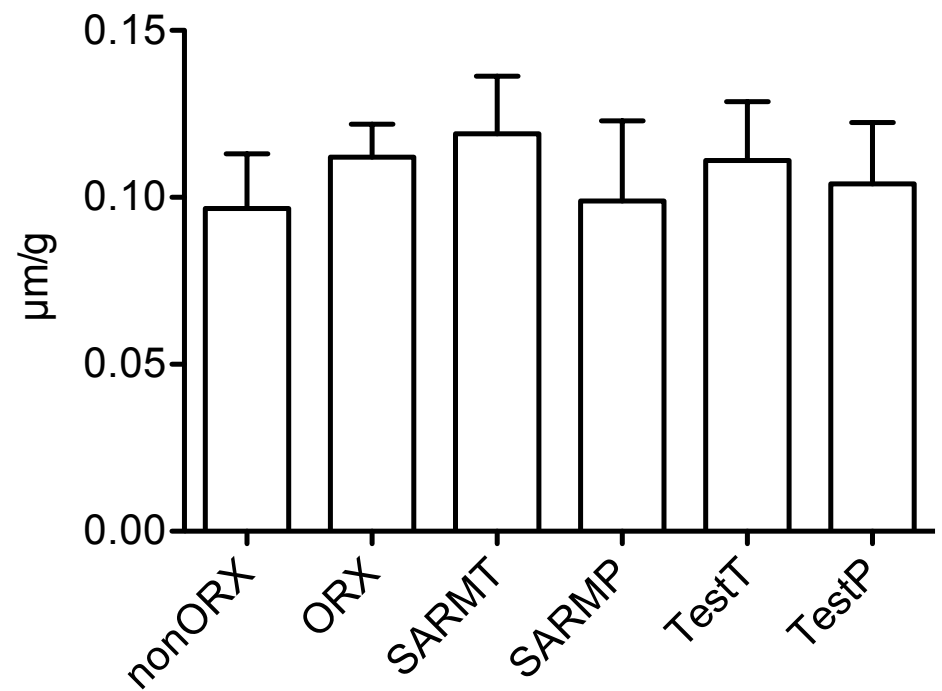

Abbildung 52: Muskelzell-Äquivalentdurchmesser, Typ-1 der Mm. solei der Versuchstiere in Mikrometern $(\mu \mathrm{m})$ / Körpergewichte der Versuchstiere in Gramm (g); keine signifikanten Unterschiede 


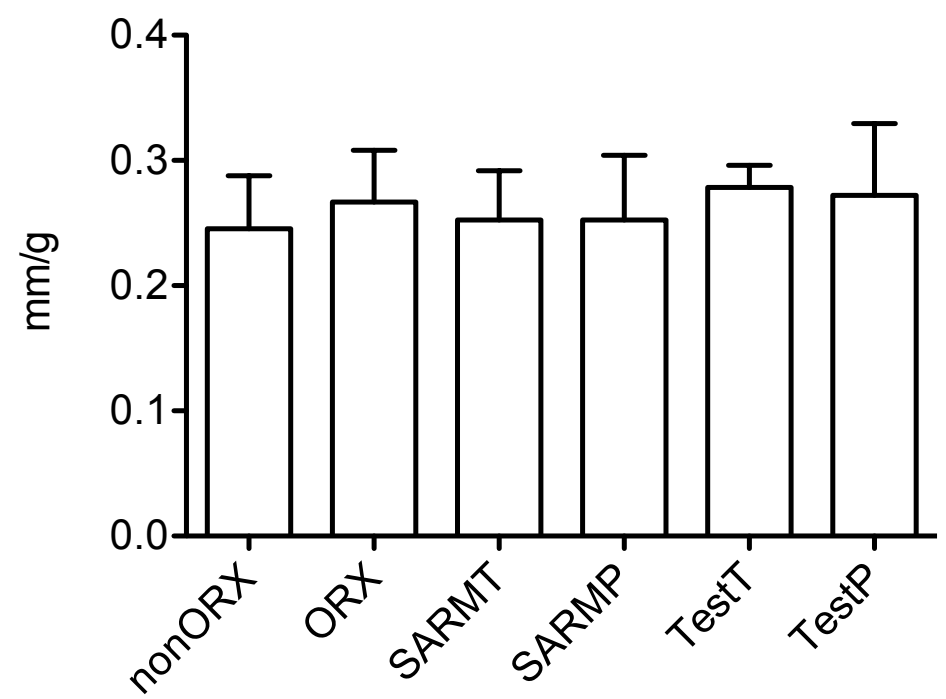

Abbildung 53: Muskelzell-Äquivalentdurchmesser, Typ-1 der Mm. solei der Versuchstiere in Mikrometern (mm) / Körpergewichte der Versuchstiere in Gramm (g); keine signifikanten Unterschiede

Die Auswertung der Muskelzell-Äquivalentdurchmesser des Typen 1 der $\mathrm{Mm}$. gastrocnemii (Abbildung 51) sowie deren Verhältnis zum Körpergewicht (Abbildung 52) bzw. Muskelgewicht (Abbildung 53) erbrachte keine signifikanten Unterschiede zwischen den Versuchsgruppen (Tabelle 19). Die Ergebnisse der Versuchsgruppe nonORX lassen im Vergleich zu denen der Versuchsgruppe ORX eine Erniedrigung erkennen. Im Vergleich der Versuchsgruppen SARMT und TestT mit den Kontrollgruppen ist hinsichtlich der Werte eine tendenzielle Erhöhung ablesbar. Dies wird durch Vergleich der Körpergewichts-korrigierten Werte unterstrichen. 


\subsection{Serum-Kreatinkinase-Werte zum Versuchsende}

Aus dem gewonnenen Blutmaterial der Versuchstiere wurden die quantitativen Werte der Kreatinkinase im Serum bestimmt (Abbildung 54, Tabelle 21).

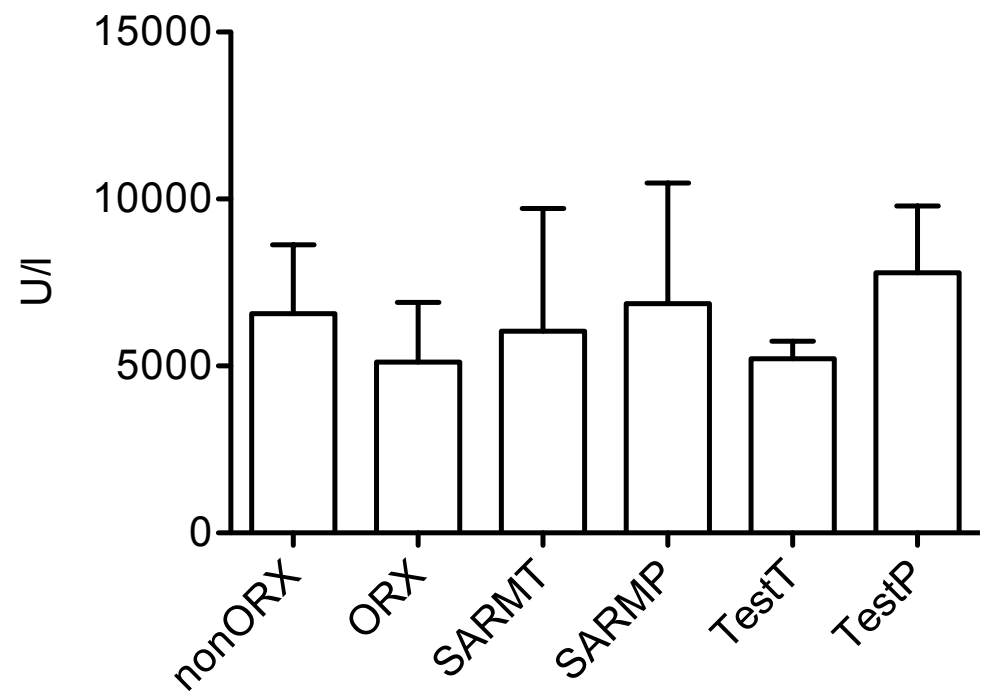

Abbildung 54: Kreatinkinase-Werte der Versuchstiere im Serum in Units/Liter (U/I) (Dunn's Multiple Comparison Test); keine signifikanten Unterschiede

Es zeigten sich keine signifikanten Unterschiede zwischen den SerumKreatinkinase-Werten der Versuchsgruppen. Es sind jedoch auffällig große Standardabweichungen innerhalb der Versuchsgruppen zu bemerken. 


\section{Diskussion}

\subsection{Körpergewichte, Muskelgewichte und Futteraufnahme}

In der Versuchswoche nach der Orchiektomie nahmen die orchiektomierten Versuchstiere zunächst durchschnittlich an Körpergewicht ab, während die nonORX-Versuchstiere durchschnittlich weiter zunahmen. Im weiteren Verlauf bis hin zur Osteotomie und Osteosynthese nahm das durchschnittliche Körpergewicht der orchiektomierten Versuchstiere wieder zu. Dazu passend fällt auf, dass die Futteraufnahme mit dem Zeitpunkt des Anstiegs der durchschnittlichen Körpergewichte ebenfalls anstieg. Der postoperative Körpergewichtsrückgang sowie der darauf folgende analoge Anstieg von Futteraufnahme und Körpergewicht konnte schon in anderen Versuchen beobachtet werden (Borst et al. 2007; Komrakova et al. 2011).

Bezüglich des durchschnittlichen Körpergewichtsverlaufes zeigten andere Versuche zum einen, dass Sprague-Dawley-Ratten mit einem Alter von acht Monaten zwar ihre finale Körperlänge erreicht haben, jedoch bis in das durchschnittliche Alter von 522 Tagen an Körpergewicht zunehmen (Berg und Harmison 1957). Zum anderen konnte in weiteren Versuchen gezeigt werden, dass die Orchiektomie eine weitere Zunahme der Körpermasse nicht unterbindet (Brown et al. 2001; Frese et al. 2011). Auch stand den Versuchstieren Futter sowie Trinkwasser ad libitum zur Verfügung. In Zusammenschau dieser Erkenntnisse und der Versuchsergebnisse ist der durchschnittliche Körpergewichtsverlauf bis zur Osteotomie und Osteosynthese nachvollziehbar.

Die durchschnittlichen Körpergewichte aller Versuchsgruppen sowie die durchschnittlichen Futteraufnahmen gingen nach Osteotomie und Osteosynthese deutlich zurück. Die durchschnittlichen präoperativen Körpergewichte wurden frühestens zwischen einer und zwei Wochen vor Versuchsende erreicht. Eine ähnliche Dynamik wurde in vorläufigen Versuchen beschrieben und ist in erster 
Linie auf postoperative Analgetika-Therapie sowie verminderte Aktivität und Regenerationsprozesse zurückzuführen (Komrakova et al. 2011; Rechholz 2017). Jedoch zeigte sich der Körpergewichtsrückgang in diesem Versuch vergleichsweise deutlicher. Hinzu kam, dass postoperativ 23 \% der Versuchstiere verstarben, was in einer minimalen Versuchsgruppengröße von fünf Ratten resultierte. Die Verluste sind am ehesten auf die multimodale Schmerztherapie (Buprenorphin s.c. und Metamizol p.o.) zurückzuführen, welche in diesem Versuch von den zuständigen Tierärzten neu eingeführt wurde. Diese verursachte aller Wahrscheinlichkeit nach die durch Obduktion bestätigten paralytischen Ilei. Es lässt sich vermuten, dass Buprenorphin einen postoperativen Ileus begünstigt oder gar ausgelöst hat (Behm und Stollman 2003). Zudem könnte das Trinkwasser durch den Zusatz von Metamizol geschmacklich dahingehend verändert worden sein, dass die Versuchstiere weniger zu sich nahmen. Eine konsekutive Dehydratation könnte eine bestehende Ileus-Symptomatik verstärkt haben. Zukünftig sollte die Eignung der Schmerzmittelkombination von Buprenorphin s.c. und Metamizol p.o. für den postoperativen Gebrauch weiter kritisch beurteilt werden und gegebenenfalls auf bewährte Analgetika-Protokolle zurückgegriffen werden (Stürmer et al. 2009; Komrakova et al. 2011; Komrakova et al. 2016).

Die durchschnittliche Wirkstoffaufnahme von Enobosarm entsprach weitestgehend der Zieldosis von 0,4 mg/kg KG/d. Lediglich in den ersten drei Wochen nach Osteotomie und Osteosynthese wurde die Zieldosis auf Grund der verminderten Futteraufnahme nicht erreicht. Mit Ausnahme der ersten postoperativen Woche kam es zu einer maximalen Abweichung von 0,07 mg/kg KG/d. Testosteronpropionat wurde durchschnittlich noch konsequenter aufgenommen. Hier zeigten sich ausschließlich in der ersten postoperativen Woche nach Orchiektomie sowie Osteotomie und Osteosynthese negative Abweichungen von der Zieldosis $46,67 \mathrm{mg} / \mathrm{kg} \mathrm{KG} / \mathrm{d}$. Die Wirkstoffaufnahmen waren insgesamt befriedigend. Darüber hinaus stellt der orale Applikationsweg eine nicht-invasive und schonende Therapiemethode für die Versuchstiere dar und resultiert in hinreichenden Wirkstoffkonzentrationen (Stuermer et al. 2009). 
Das durchschnittliche Gewicht der Mm. levatores anorum als etablierter Indikator für androgensensible anabole Prozesse zeigt unter anderem die Wirksamkeit von Orchiektomie bzw. applizierten Therapien (Eisenberg und Gordan 1950; Hershberger et al. 1953). Beispielhaft dafür ist der signifikante Unterschied der durchschnittlichen Muskelgewichte zwischen intakter (nonORX) und orchiektomierter (ORX) Versuchsgruppe. Letztere wies durchschnittlich signifikant erniedrigte $M$. levator ani-Gewichte auf. Ein antianaboler Effekt bzw. eine Androgendeprivation durch die Orchiektomie kann somit angenommen werden (Freyberger et al. 2007). Die durchschnittlichen M. levator ani-Gewichte der Versuchsgruppen, welche Enobosarm als Therapie (SARMT) oder zusätzlich als Prophylaxe (SARMP) erhielten, zeigten sich nahezu gleich denen der nonORXVersuchsgruppe und gegenüber der ORX-Versuchsgruppe signifikant erhöht. Es kann also von einer anabolen Wirksamkeit der Substanz Enobosarm ausgegangen werden. Der Effekt von Enobosarm auf den M. levator ani wurde in der Literatur bereits beschrieben und wird durch diesen Versuch bekräftigt (Narayanan et al. 2008).

Obwohl eine Wiederherstellung der M. levator ani-Gewichte auf ein Niveau der nonORX-Versuchsgruppe zu erwarten gewesen wäre (Eisenberg und Gordan 1950; Hershberger et al. 1953), blieben die M. levator ani-Gewichte der Versuchsgruppen TestT und TestP deutlich hinter denen der Versuchsgruppen nonORX, SARMT und SARMP zurück. Es bleibt die Vermutung, dass die orale Applikation von Testosteronpropionat gegebenenfalls nicht zu den erwünschten Wirkstoffkonzentrationen im Serum geführt hat. Es wäre sinnvoll, zukünftig laborchemische Kontrollen durchzuführen (Stuermer et al. 2009).

Ebenfalls ablesen lässt sich die anabole Wirksamkeit von Enobosarm an den erhöhten durchschnittlichen Gewichten der Mm. gastrocnemii und solei der Versuchsgruppe SARMT gegenüber denen von ORX. Weiter sollte beachtet werden, dass die Gewichte der Mm. gastrocnemii und solei positiv mit den Körpergewichten der Versuchstiere korrelierten. Eine derartige Korrelation konnte bereits in vorangegangenen Versuchen beobachtet werden (Komrakova 
et al. 2016). Es kann also angenommen werden, dass mit steigendem Körpergewicht auch die Muskelgewichte steigen. Betrachtet man nun die durch die individuellen Körpergewichte relativierten Muskelwerte, also die Quotienten aus Muskelgewicht und Körpergewicht, so lässt sich die Tendenz höherer durchschnittlicher Muskelgewichte der Versuchsgruppe SARMT noch deutlicher feststellen. Diese Tendenz zeigt sich nicht nur im Vergleich mit der Versuchsgruppe ORX, sondern mit allen verbleibenden Versuchsgruppen - ein weiteres Indiz für die anabole Wirksamkeit von Enobosarm.

\subsection{Prostatagewichte}

Das Prostatagewicht eines Versuchstieres kann sowohl als Indikator für den Erfolg der durchgeführten Orchiektomie als auch für die androgene Wirkung bzw. Selektivität einer Therapie dienen (Hershberger et al. 1953; Frese et al. 2011). Die Orchiektomie bei Ratten führt erfahrungsgemäß zu einer Abnahme der Prostatagewichte (Borst und Conover 2006; Borst et al. 2007). Dies stimmt mit den Beobachtungen dieses Versuches überein. Die durchschnittlichen Prostatagewichte der Versuchsgruppen ORX, SARMT, TestT und TestP waren gegenüber denen der Versuchsgruppe nonORX signifikant erniedrigt. Dies kann als Bestätigung für eine erfolgreiche Orchiektomie angesehen werden. Es kann weiter vermutet werden, dass eine kurzzeitige Therapie mit Enobosarm eine befriedigende androgene Selektivität bezüglich der Prostata entfaltet. Die signifikante Erhöhung der Prostatagewichte der Versuchsgruppe SARMP gegenüber denen der ORX und TestT Versuchsgruppen weist allerdings darauf hin, dass eine ausreichende androgene Selektivität der längerfristigen Enobosarm-Therapie hinsichtlich der Prostata in diesem Fall nicht gegeben ist.

Interessanterweise zeigten die durchschnittlichen Prostatagewichte der Versuchsgruppen TestT und TestP nicht die erwarteten Zunahmen (Hershberger et al. 1953; Negro-Vilar 1999; Omwancha und Brown 2006). Besonders für die Versuchsgruppe TestT gilt, dass eine Aktivität von Testosteronpropionat anhand 
erhöhter Prostatagewichte nicht feststellbar war. Mutmaßlich ist der Zeitraum von sechs Wochen nicht ausreichend, um einen messbaren Effekt zu generieren. Jedoch blieben auch das durchschnittliche Prostatagewicht der Versuchsgruppe TestP gegenüber dem von nonORX erniedrigt. Dies ließe erneut vermuten, dass trotz ausreichender Wirkstoffaufnahme eine insuffiziente Wirkstoffkonzentration erreicht wurde. Zum anderen wäre denkbar, dass die TestosteronpropionatApplikation für die hier veranschlagten Zeiträume tatsächlich keine nennenswerten Einflüsse auf die Prostata nimmt. Es gibt Hinweise auf befriedigend niedrigen Einfluss von Testosteron auf das Prostatagewebe des Menschen für einen Zeitraum von zumindest sechs Monaten (Marks et al. 2006). Im Falle des Ausschlusses eines Prostatakarzinoms könnte eine Testosteronapplikation möglicherweise ohne negative Effekte auf die Prostata durchgeführt werden (Holyoak et al. 2008; Roddam et al. 2008). Das Wachstum der Prostata könnte darüber hinaus durch exogene Testosteronzufuhr sogar aufgehalten oder reversiert werden (Pechersky et al. 2002). Um eine therapeutische Anwendbarkeit von Enobosarm sowie Testosteron hinsichtlich Prostatapathologien möglicher zu machen, sollten Erkenntnisse aus längerfristigen Versuchen gesammelt werden. Der Effekt von Enobosarm auf das Prostatagewebe wurde in maßgebenden klinischen Studien ausschließlich anhand der Serumkonzentration des PSA beurteilt und als unbedenklich beurteilt (Dalton et al. 2011; Dobs et al. 2013). Nicht nur, dass die PSA-Konzentration im Serum keinen klar definierten oberen Grenzwert hat (Thompson et al. 2004), sondern besonders hinsichtlich der in diesem Versuch beobachteten unzureichenden androgenen Selektivität der 18-wöchigen Therapie, sollte in zukünftigen Versuchen eine differenzierte Beurteilung des Prostatagewebes bedacht werden. Abschließend sollte festgehalten werden, dass die Applikation von Enobosarm sowie Testosteronpropionat in diesem Versuch zumindest für einen kurzfristigen Einsatz befriedigend niedrige durchschnittliche Prostatagewichte erzielt hat. 


\subsection{Kapillardichte}

Die Kapillardichte der Muskelzellen, also das Verhältnis der Kapillaren zu Muskelzellen, wurde untersucht, um zu erforschen, ob die verschiedenen Behandlungen der Versuchsgruppen einen Einfluss die Kapillardichte nehmen. Sarkopenie geht mit einer Einschränkungen der Mikrozirkulation innerhalb der Muskulatur einher und könnte so $\mathrm{zu}$ Muskelmassenverlust und Muskelfunktionseinschränkungen beitragen (Wang et al. 2014). Auch kommt es bei Muskelmassen- und Muskelkraftverlust im Alter, im Vergleich zu gesunden jungen Menschen, zu einem Rückgang der Kapillardichte von etwa 25 \% (Rogers und Evans 1993). Ein positiver Einfluss auf die Mikrozirkulation, im Sinne einer Steigerung der Kapillardichte, könnte also einen positiven Einfluss auf die Gesundheit der Skelettmuskulatur nehmen.

Die Untersuchung der Kapillardichte erbrachte keine Erkenntnisse hinsichtlich signifikanter Unterschiede zwischen den Versuchsgruppen und Muskeln. Es lassen sich jedoch Tendenzen ablesen. So ist im Vergleich der Versuchsgruppen nonORX und ORX eine verringerte Kapillardichte in den Mm. longissimi und gastrocnemii der Versuchsgruppe ORX zu sehen. In den $M m$. solei zeigen sich die Werthöhen allerdings umgekehrt. In einem vorangegangenen Versuch, der im annähernd gleichen zeitlichen Rahmen stattfand, zeigte die Orchiektomie ebenso keinen homogenen Effekt auf die Kapillardichte der Muskelzellen. Es konnte lediglich eine signifikante Erhöhung der Kapillardichte in den Mm. gastrocnemii der orchiektomierten Ratten im Vergleich zu intakten Ratten beobachtet werden, was sich durch die hier vorliegenden Daten aber nicht reproduzieren lässt (Komrakova et al. 2011). In Betrachtung der Kapillardichte der Mm. longissimi ließe sich die Beobachtung anstellen, dass in den Versuchsgruppen SARMT und TestT annähernd die durchschnittliche Kapillardichte der nonORXVersuchsgruppe erreicht wurde. Die verbleibenden Versuchsgruppen ORX, SARMP und TestP blieben hingegen sichtbar unter diesen Werten. Eine Übertragbarkeit dieser Tendenz auf die Untersuchungen der Mm. gastrocnemii und 
solei ist dementgegen nicht möglich. Aus diesen Beobachtungen lässt sich folglich kein klarer Schluss bezüglich möglicher positiver Auswirkungen von Enobosarm auf die Kapillardichte von den hier untersuchten Skelettmuskelzellen ziehen.

In der Literatur gibt es keine Hinweise auf Untersuchungen der Kapillardichte unter SARMs-Einfluss. Damit bleiben die vorliegenden Ergebnisse der Enobosarm-Applikation vorerst ohne wissenschaftliche Referenzen. Es ist jedoch beschrieben, dass die Kapillardichte der Skelettmuskulatur im Zuge von Testosteronmangel im Alter deutlich zurückgeht (Ambrose 2015), aber durch die Applikation von androgenen Steroiden wie Testosteron gesteigert werden kann (Yu et al. 2014). Experimentelle Untersuchungen anhand von Rattenmodellen für Myokardinfarkte zeigen einen steigernden Einfluss von Testosteron auf die Kapillardichte des Myokards (Chen et al. 2012; Gonçalves et al. 2014). In Anbetracht der nicht zu vernachlässigenden Rolle, welche die Kapillardichte in der Pathophysiologie der Sarkopenie spielt (Siparsky et al. 2014), und der vorliegenden teilweise positiven Effekte von kurzfristiger Enobosarm- und Testosteronpropionat-Applikation auf die Kapillardichte der Skelettmuskulatur der Ratte, wäre es wünschenswert, den Einfluss der hier verwendeten Substanzen auf die Kapillardichte der Muskulatur weiter zu untersuchen.

Die Kapillardichte des Skelettmuskels kann veränderten Bedingungen angepasst werden, so zum Beispiel einer erhöhten muskulären Aktivität (Hudlická 1985). Es konnte weiter gezeigt werden, dass die adaptive Kapazität von Rattenmuskeln auch im Alter gegeben bleibt. Um einen Effekt messen zu können, könnte jedoch ein insgesamt längerer Zeitraum benötigt werden als der in diesem Versuch veranschlagte. Auch scheint eine gesteigerte Aktivität, beispielsweise in Form von Ausdauertraining, eine maßgebende Rolle innerhalb der Mikrozirkulation der Skelettmuskulatur zu spielen (Farrar et al. 1981; Kovanen und Suominen 1987; Gonçalves et al. 2014). Neuere Untersuchungen beschreiben weiter, dass Muskelbeanspruchung und Scherkräfte einen wichtigen Part in der adaptiven 
Veränderung von Mikrozirkulation bzw. der Angiogenese haben (Badr et al. 2003; Egginton 2011).

Insgesamt lässt sich also diskutieren, ob ein möglicher Einfluss der hier untersuchten Therapieansätze auf die Kapillardichte der Skelettmuskelzellen nicht erst durch die Miteinbeziehung gezielt gesteigerter muskulärer Aktivität demaskiert werden könnte. Des Weiteren ist zu bemerken, dass es postoperativ möglicherweise zu einer eingeschränkten Aktivität der Versuchstiere und somit zu einer verminderten Muskelbeanspruchung kam. Jedoch ist dem zu entgegnen, dass eine stabile Osteosynthese der Femora durchgeführt wurde, welche in Kombination mit der durchgeführten Analgetika-Therapie eine schnelle postoperative Belastbarkeit nach sich zog. Um jedoch die Angiogenese der Muskelkapillaren unter etwaigem Wirkstoffeinfluss genauer untersuchen zu können, böte sich ein Versuchsmodell an, welches gezielte muskuläre Beanspruchung der Versuchstiere integriert.

\subsection{Muskelzellquerschnittsflächen und Muskelzell- Äquivalentdurchmesser}

Die Muskelzellquerschnittsflächen und Muskelzell-Äquivalentdurchmesser wurden untersucht um der Frage nachzugehen, ob und wenn ja welchen Einfluss die verschiedenen Behandlungen der Versuchsgruppen auf die drei untersuchten Muskeln hatten. Um den etwaigen individuellen Einfluss der Körper- und Muskelgewichte der Versuchstiere auf die erhobenen Parameter zu relativieren, wurden diese ins Verhältnis zu Körper- bzw. Muskelgewicht gesetzt und ausgewertet. In vorangegangenen Studien zeigten sich Unterschiede deutlicher, nachdem sie um die individuellen Körper- und Muskelgewichte korrigierten worden waren (Komrakova et al. 2011; Ammon 2015).

Vergleicht man die Muskelzellquerschnittsflächen und Muskelzell-Äquivalentdurchmesser der intakten (nonORX) mit denen der orchiektomierten (ORX) Versuchstiere, lassen sich keine signifikanten Unterschiede beschreiben. 
Tendenzen sind allerdings innerhalb der Auswertungen eines Muskels zu erkennen. Die durchschnittlichen Werte der untersuchten Parameter beider Muskelzelltypen der $\mathrm{Mm}$. gastrocnemii der Versuchsgruppe nonORX sind tendenziell größer als die der ORX Versuchsgruppe. Dieses Verhältnis lässt sich für die Mm. solei in umgekehrter Weise beschreiben. Für den M. longissimus lassen sich keine derartig eindeutigen Tendenzen ableiten. Bezüglich der Auswirkung von Orchiektomie auf die hier besprochenen Parameter beobachteten Komrakova et al. in einem vergleichbaren Versuch ebenfalls keine signifikanten Unterschiede. Insgesamt wurde jedoch eine Abnahme der Parameter in der orchiektomierten Versuchsgruppe festgestellt (Komrakova et al. 2011). Des Weiteren beschrieben Borst et al. eine signifikante Abnahme der Muskelzellquerschnittsflächen im M. soleus sowie M. extensor digitorum longus von fünf Monate alten Ratten acht Wochen nach Orchiektomie (Borst et al. 2007). Andererseits konnten Sinnesael et al. acht Wochen nach der Orchiektomie von elf Monate alten Ratten keinen Effekt der Orchiektomie auf die Muskelquerschnittsflächen des M. soleus sowie des M. tibialis anterior feststellen (Sinnesael et al. 2011). Der M. tibialis anterior ließe sich im Übrigen hinsichtlich seiner Muskelzelltypkonfiguration mit der des M. gastrocnemius vergleichen (Armstrong und Phelps 1984). Zusammenfassend hatte die Orchiektomie auf die hier besprochenen Muskelparameter einen heterogenen Effekt. In Betrachtung dieser Erkenntnis sollte berücksichtigt werden, wie unterschiedlich die An- oder Abwesenheit von Androgenen auf verschiedene Muskeln wirken kann (Lubischer und Bebinger 1999; Dubois et al. 2015).

Für die Versuchsgruppe SARMT, welche Enobosarm über sechs Wochen verabreicht bekam, ergeben sich bemerkenswerte Tendenzen. Gegenüber den Versuchsgruppen ORX sowie nonORX sind die durchschnittlichen Muskelzellquerschnittsflächen und Muskelzell-Äquivalentdurchmesser beider Muskelzelltypen (M. soleus nur Typ 1) aller drei untersuchter Muskeln erhöht. Diese Tendenz wird in Betrachtung der durch die Körpergewichte korrigierten Werte ausnahmslos wahrnehmbar. Die durchschnittlichen Mittelwerte der 
Versuchsgruppe SARMP, welche Enobosarm zusätzlich zur bereits erwähnten Therapie, als Prophylaxe für zwölf Wochen erhielt, zeigen eine analoge Tendenz, jedoch nur für Untersuchung der Mm. gastrocnemii.

Die Einbettung dieser Ergebnisse in die wissenschaftliche Literatur bereitet Mühe, da weder Muskelzellquerschnittsflächen noch Muskelzell-Äquivalentdurchmesser unter SARM-Therapie bislang untersucht wurden. Die einzige Ausnahme bieten Dalbo et al. mit der Untersuchung von Muskelzellquerschnittsflächen in Mm. levatores anorum orchiektomierter Ratten unter Trenbolon-Applikation. Die Substanz Trenbolon könnte hinsichtlich Wirkungsmechanismus sowie Wirkungsprofil mit SARMs vergleichbar sein (Yarrow et al. 2010). Der Versuch erbrachte schließlich eine signifikante Zunahme der Muskelzellquerschnittsflächen im Vergleich zu nicht therapierten Versuchsgruppen (Dalbo et al. 2017). Da der M. levator ani aber äußerst zuverlässig auf myotrophe Substanzen reagiert (Eisenberg und Gordan 1950), bietet er den hier untersuchten Muskeln kein optimales Pendant. Grundsätzlich ist also die Vergleichbarkeit der Versuche eingeschränkt. Aber auch wenn die nur bedingte Vergleichbarkeit der Versuche $\mathrm{zu}$ einer diffizilen Verbindung der Versuchsergebnisse führte, soll dennoch darauf hingewiesen werden, dass die hier beobachteten Tendenzen im Vergleich mit bereits publizierten Daten nicht allein stehen. Darüber hinaus muss bemerkt werden, dass die hier besprochenen Tendenzen mit einer durchschnittlichen Muskelgewichtszunahme einhergingen und somit von einer hypertrophierenden Wirkung von Enobosarm ausgegangen werden kann. Dies ließe sich auch für den M. levator ani vermuten und sollte zukünftig komparabel ausgewertet werden.

Auch die Auswertung der Ergebnisse der Versuchsgruppen TestT und TestP erbrachte keine signifikanten Unterschiede im Vergleich aller Gruppen zu einander. Es lassen sich indes Tendenzen für die Versuchsgruppe TestT ableiten, welche über einen Zeitraum von sechs Wochen Testosteronpropionat erhielt. Wie auch für die Versuchsgruppe SARMT beschrieben, kommt es im Vergleich zu den Versuchsgruppen ORX sowie nonORX tendenziell zu einer Zunahme der 
Muskelzellquerschnittsflächen und Muskelzell-Äquivalentdurchmesser beider Muskelzelltypen (M. soleus nur Typ-1) der drei untersuchten Muskeln. Diese Zunahme wird von allen Werten bekräftigt, die um Körpergewicht und Muskelgewicht korrigiert wurden. Derartige Erkenntnisse wurden schon in anderen Versuchen gemacht. So schlussfolgerten Sinha-Hikim et al. aus Untersuchungen junger Männer, dass die Muskelzellquerschnittsflächen beider hier besprochener Muskelzelltypen infolge von Testosteronapplikation ebenfalls bedeutend zunahmen. Dabei korrelierten die Flächenzunahmen signifikant mit den gemessenen Testosteronkonzentrationen im Serum (Sinha-Hikim et al. 2002).

Zusammenfassend lässt sich sagen, dass die sechswöchigen Therapien mit Enobosarm sowie Testosteronpropionat einen positiven Effekt auf die durchschnittlichen Muskelzellquerschnittsflächen zeigten. Wenn man nun die tendenzielle Zunahme der durchschnittlichen Muskelgewichte der Versuchsgruppe SARMT im Vergleich zu denen von ORX miteinbezieht, lässt sich grundlegend auf eine therapeutisch bedingte Muskelhypertrophie schließen. Mit dem Skelettmuskelmassen- und kraftverlust als den zwei grundlegenden Pathologien der Sarkopenie (Cruz-Jentoft et al. 2010) wäre zumindest dem Skelettmuskelmassenverlust eine mögliche therapeutische Intervention geboten. Ob indes die beobachtete Zunahme der Skelettmuskelmasse mit einem Kraftgewinn einhergeht sollte in zukünftigen Versuchen erforscht werden.

\subsection{Muskelzelltypverhältnis des $M$. longissimus}

Die Literatur gibt Hinweise, dass es im Zuge von Muskelatrophie zu einem „shift“ von schnellen Muskelzelltypen, also Typ-2A und Typ-2B, hin zu langsamen Muskelzelltypen, also Typ-1, kommt (Larsson et al. 1993; Ciciliot et al. 2013). Untersuchungen des $M$. plantaris der männlichen Ratte zeigen, dass es mit fortschreitendem Alter zu einer Abnahme von Typ-2A und einer Zunahme von Typ-1-Muskelzellen kommt (Holloszy et al. 1991). Des Weiteren wurde im Vergleich zu jungen Menschen festgestellt, dass es im Alter nicht nur zu einem 
Rückgang, sondern auch zu verminderten Muskelzellquerschnittsflächen von Typ-2 Muskelzellen kommt. Die Anzahl und Muskelzellquerschnittsflächen der Typ-1 Muskelzellen blieben hingegen kaum beeinflusst (Lexell 1995).

In diesem Versuch konnte eine Veränderung des prozentualen Verhältnisses der Muskelzelltypen des M. longissimus im Vergleich der Versuchsgruppe nonORX zu ORX, als sarkopenisches Modell, nicht festgestellt werden. Interessanterweise konnte beobachtet werden, dass in den Versuchsgruppen SARMP, TestT und TestP weniger Typ-1 und mehr Typ-2 Muskelzellen vorkamen als in den anderen Versuchsgruppen. Es könnte also vermutet werden, dass eine längerfristige Therapie mit Enobosarm sowie eine kurz- und längerfristige Testosteronpropionat-Therapie einer Verhältnisänderung der Muskelzelltypen von schnell zu langsam entgegenwirken könnte. Ähnliches fiel bei Untersuchungen von Holmäng et al. auf. Dort kam es bei weiblichen ovariektomierten Ratten unter Testosterontherapie ebenfalls $\mathrm{zu}$ einer prozentualen Verringerung von langsamen Typ-1- sowie einer Zunahme von schnellen Typ-2-Muskelzellen (Holmäng et al. 1990). Es sollte jedoch nicht vergessen werden, dass sich Muskeln bezüglich ihrer Muskelzelltypverhältnisse stark voneinander unterscheiden (Armstrong und Phelps 1984). Auch die Muskelveränderungen im Alter zeigen sich dahingehend unterschiedlich, dass Muskeln, deren Aufgabe hauptsächlich im Tragen von Gewicht liegt, eher den hier besprochenen Verhältniswechsel der Muskelzelltypen erfahren als Muskeln, die kein Gewicht $\mathrm{zu}$ tragen haben (Holloszy et al. 1991). Es ist also kaum möglich die Untersuchung des M. longissimus auf andere Muskeln oder das gesamte muskuläre System zu übertragen. Eine potentielle therapeutische Anwendbarkeit der hier beschriebenen Erkenntnisse bleibt vorerst ungewiss und bedarf weiterer Forschung. 


\subsection{Enobosarm}

Es stellt sich die Frage, ob im gesamtwissenschaftlichen Kontext die Wahl von Enobosarm als Testsubstanz sinnvoll war, und welche Alternativen, im Besonderen für die zukünftige Forschung, bestehen.

Enobosarm ist der bis dato einzige SARM, welcher in klinischen Studien hinsichtlich einer Anwendbarkeit zur Verbesserung von Muskelmasse und -kraft sowie der körperlicher Leistungsfähigkeit (Crawford et al. 2016) klinische PhaseIII-Studien erreicht und durchlaufen hat (Narayanan et al. 2018). Es ist jedoch zu erwähnen, dass diesbezüglich weitere Forschung von der durchführenden Firma GTx Incorporated (heute Oncternal Therapeutics), unter anderem aufgrund einer nicht ausreichend nachweisbaren Verbesserung der körperlichen Leistungsfähigkeit, mittlerweile bis auf weiteres eingestellt wurde (Garber 2016). Enobosarm wird weiterhin in klinischen Studien zur Anwendbarkeit bei Stressinkontinenz und androgenrezeptor-positivem Brustkrebs untersucht (Narayanan et al. 2018).

Vergleichbare Substanzen für selbigen potentiellen Anwendungsbereich sind beispielsweise LGD-4033, MK-0773, GLPG0492 oder GSK2881078. Diese befinden sich in unterschiedlichen Stadien der Erforschung was Gegenüberstellung nur bedingt zulässt. LGD-4033 (auch Ligandrol oder VK5211) zeigte in einer 21tägigen klinischen Phase-I-Studie eine angemessene Verträglichkeit, Sicherheit sowie eine signifikante Erhöhung von Muskelmasse und -kraft (Basaria et al. 2013). Im ovarektomierten Rattenmodell konnte mit LGD-4033 eine verbesserte Muskelkapillarisierung und erhöhte Muskelquerschnittsfläche, bei jedoch nicht konsistenten Ergebnissen bezüglich des Uterusgewicht erzielt werden (Carstens et al. 2018). Der steroidale SARM MK-0773 (auch PF-05314882) wurde bereits in einer klinischen Phase-IIa-Studie über 6 Monate an weiblichen Probanden untersucht, wobei sich zwar eine Zunahme der Muskelmasse aber keine Steigerung der Muskelkraft messen ließ. Auch kam es bei einer nicht zu vernachlässigenden Anzahl von Probanden zu einer Erhöhung der Lebertransaminasen 
(Papanicolaou et al. 2013). GLPG0492 (auch DT-200) wurde erfolgreich, im Sinne von Selektivität, Eindämmung von Muskelmassenverlust und gesteigerter körperlicher Leistungsfähigkeit, anhand von durch Immobilisation verursachter Muskelatrophie in Ratten (Blanqué et al. 2014) und an einem Mausmodell für die Duchenne-Muskeldystrophie (Cozzoli et al. 2013) untersucht. Das jüngst untersuchte SARM GSK2881078 ließ in klinischen Phase I-Studien eine vertretbare Verträglichkeit, Sicherheit sowie eine Vermehrung von Muskelmasse erkennen (Clark et al. 2017; Neil et al. 2018) und befindet sich in weiterführender Erforschung hinsichtlich einer möglichen Verbesserung von Muskelkraft und -funktion bei Probanden mit einer chronisch obstruktiven Lungenerkrankung als Grunderkrankung (NCT03359473) (Furrer und Handschin 2019).

Allen genannten SARMs ist eine angemessene Verträglichkeit und Sicherheit gemein. MK-0773 unterscheidet sich im Besonderen von den anderen SARMs, da es steroidal und somit nur eingeschränkt vergleichbar ist. Generell sind Versuche am Tiermodell rar, was Vergleiche mit den vorliegenden Ergebnissen nur bedingt zulässt. Interessant ist, dass LGD-4033 ähnlich zu hier vorliegenden Ergebnissen bereits nach einer kurzfristigen Applikationsdauer zu positiven Ergebnissen führte, was künftig zunächst eine Konzentration auf die kurzfristige Anwendbarkeit bei akuten Krankheitsbildern, wie beispielsweise funktionelle Einschränkungen nach Immobilisation, befürworten ließe (Basaria et al. 2013). Für das Feld der Sarkopenie wären sicherlich unmittelbar vergleichende Untersuchungen der vielversprechendsten Substanzen vorteilhaft, da anhand der aktuellen Erkenntnisse nicht eindeutig zu sagen ist, welche der Substanzen für zukünftige Forschungsarbeiten zu bevorzugen wäre. Eine Entscheidung für eine Substanz hinsichtlich zukünftige Versuche bleibt im Endeffekt komplex, da diese vor allem unter Berücksichtigung der Fragestellung zu treffen ist.

Zum Zeitpunkt des Versuches war Enobosarm der klinisch weitestgehend erforschte SARM und, angesichts der damals publizierten Erkenntnisse, vielversprechend hinsichtlich der Verbesserung der Muskelgesundheit. Alles in allem lässt sich die Wahl von Enobosarm als Testsubstanz als sinnvoll einstufen. Die 
Tatsache, dass Enobosarm bezüglich einer Anwendbarkeit bei Sarkopenie klinisch aktuell nicht weiter erforscht wird, lässt sich nicht nur auf die fehlende Verbesserung der körperlichen Leistungsfähigkeit in der klinischen Phase-IIIStudien zurückführen. Andere Faktoren, wie das Fehlen von spezifischen, ggf. globalen, Richtlinien für klinische Studien (Fearon et al. 2015), die Erforschung neuer klinischer Indikationen (Dalton 2017) sowie nicht zu vernachlässigende finanzielle Aspekte (Garber 2016) spielen ebenfalls eine Rolle.

\subsection{Serum-Kreatinkinase-Werte}

Die Aktivitätsmessung der Kreatinkinase im Serum kann verwendet werden um Muskelschäden zu detektieren. Die physiologisch intrazellulär vorkommende Kreatinkinase gelangt unter anderem durch Membrandefekte der Muskelzellen in den Blutkreislauf und wird so im Serum messbar (Sinert et al. 1994; Magal et al. 2010). Die Messwerte eignen sich jedoch nur zur Beurteilung des Vorhandenseins von Muskelschäden. Um eine suffiziente Aussage über das Ausmaß von Muskelschäden sowie die Funktionalität der Muskulatur zu treffen, sind sie jedoch nicht brauchbar (Fridén und Lieber 2001).

Der durchschnittliche Normwert der Aktivität von Kreatinkinase männlicher Ratten sei mit $444 \mathrm{U} / \mathrm{l}$ angenommen (Zur 2005). In Betrachtung der vorliegenden Ergebnisse fällt auf, dass die Messwerte und auch die Standardabweichungen deutlich oberhalb dieser Norm liegen (maximaler Variationskoeffizient: 60,7 \%; Minimum aller Gruppen: 2327 U/1; Maximum aller Gruppen: 14373 U/l; Mean aller Gruppen: 5997 U/1). In vorangegangenen Versuchen zeigten sich die Werte ebenfalls deutlich erhöht (Kling 2015; Rechholz 2017). Dass nun derart erhöhte Werte wiederholt auf eine Muskelschädigung zurückzuführen wären, erscheint unwahrscheinlich. Zum einen, da die Bewegungsmuster der Versuchstiere im Vorfeld der Tötung keine Auffälligkeiten zeigten. Zum anderen, weil die Muskulatur nach der Tötung makroskopisch und im Rahmen der vorliegenden Ergebnisse mikroskopisch unauffällig erschien. Im Besonderen jedoch, da die 
augenscheinlichste Parallele zwischen den Versuchen die Art der Blutgewinnung durch Dekapitation ist. Bei der Dekapitation kommt es zu einer tödlichen Verletzung des Körpergewebes. Die im Anschluss aus dem Rattenkörper gewonnene Blutprobe dürfte unter anderem auch intrazelluläre Bestandteile muskulärer Zellen enthalten. Es könnte also am ehesten durch die Art der Blutgewinnung zu den abnormal erhöhten Werten gekommen sein. Auch wenn mit der gleichen Behandlung aller Versuchstiere eine Vergleichbarkeit der Werte bestehen bleibt, so sind die Messwerte auf Grund der Erkenntnisse über die angewendete Blutgewinnung in diesem Fall kaum zur Beurteilung der Rattenmuskulatur zu verwenden.

Für möglichst zuverlässige Messwerte könnte also andere Arten der Blutgewinnung eine entscheidende Rolle spielen und sollten für weitere Versuche berücksichtigt werden. So ist es möglich die Vena cava superior von Ratten unter adäquater Anästhesie zu punktieren (Jekl et al. 2005). Dabei könnte ein solcher Zugang darüber hinaus als permanente Blutgewinnungsmöglichkeit genutzt werden (Moslen et al. 1988). Die Punktion der Vena saphena magna (Hem et al. 1998) sowie der Schwanzvene (Morton et al. 1993) stellen weitere verlässliche Methoden zur möglichst atraumatischen Blutgewinnung dar. Für die terminale Blutgewinnung gelten die retrobulbäre Punktion der Orbita sowie die kardiale Punktion als adäquate Methoden (Izumi et al. 1993; Morton et al. 1993; Beeton et al. 2007). Generell gilt, dass eine situationsentsprechende Gewöhnung der Versuchstiere im Vorfeld geplanter Eingriffe die gemessene Aktivität von Kreatinkinase reduziert und somit zu zuverlässigeren Messwerten führen könnte (Lefebvre et al. 1992).

\subsection{Ratte als Modell}

In diesem Versuch wurde die Spezies Rattus norvegicus als Modell für die Spezies Homo sapiens gewählt. In wissenschaftlichem Kontext wird die so genannte Wanderratte seit 1856 zu experimentellen Zwecken genutzt. Die ersten Indizien 
gezielter Züchtung stammen aus Deutschland aus dem Jahr 1877 (Lindsey und Baker 2005). Seit dieser Zeit hat sich die Verwendung der Ratte als Versuchstier weltweit verbreitetet (Jacob 1999) und ist als Modell für menschliche Erkrankungen etabliert (Aitman et al. 2008; Iannaccone und Jacob 2009). In diesem Fall wurde durch die Durchführung einer Orchiektomie ein, auf Androgendeprivation basierendes, Krankheitsmodell der männlichen Osteoporose verursacht. Die Orchiektomie gilt als ein langjährig etabliertes Verfahren, um eine osteoporotische Stoffwechsellage in männlichen Ratten hervorzurufen (Wink und Felts 1980; Turner et al. 1989; Blouin et al. 2008; Ryu et al. 2015). Darüber hinaus wurde die Orchiektomie synergistisch verwendet, um eine sarkopenische Stoffwechsellage der Versuchstiere herbeizuführen. Multiple Versuche konnten belegen, dass die Orchiektomie zu einem signifikanten Rückgang der fettfreien Körpermasse führt (Vanderschueren et al. 2000; Moreau et al. 2001). In puncto Definition und Diagnostik von Sarkopenie dient die Ermittlung der fettfreien Körpermasse weitverbreitetet und stellt somit einen validen Parameter für die Feststellung einer Sarkopenie dar (Cruz-Jentoft et al. 2010; Fielding et al. 2011; Crawford et al. 2016). In Anlehnung an das Hershberger essay als Test anaboler Aktivität androgener Substanzen, dient die hier durchgeführte Untersuchung von Prostata und $M$. levator ani der Ratte als noch heute gültiges Verfahren (Hershberger et al. 1953; Freyberger et al. 2007). Unter Einbeziehung dieser Erkenntnisse lässt sich schlussfolgern, dass mit der Wahl des Tiermodells der Ratte eine im wissenschaftlichen Sinne adäquate Entscheidung getroffen wurde.

\subsection{Schlussfolgerung}

Die Applikation des SARMs Enobosarm über unterschiedlich lange Zeiträume zeigte heterogene Effekte auf die Skelettmuskulatur der orchiektomierten Ratte. Die relativ kurzzeitige Applikation über sechs Wochen hatte eine tendenzielle Zunahme von Muskelgewicht sowie Muskelzellquerschnittsfläche zur Folge. Anhand der Untersuchung des M. levator ani und der Prostata konnte weiter gezeigt werden, dass Enobosarm selbst bei dieser kurzen Applikationsdauer zum 
einen eine gut messbare anabole Wirkung entfaltet und zum anderen eine zufriedenstellende Selektivität gegenüber der Prostata besitzt. Die langfristige Applikation über 18 Wochen zeigte hingegen nur in der Betrachtung des M. gastrocnemius positive Auswirkungen auf Muskelgewicht und Muskelzellquerschnittsfläche. Die androgene Aktivität in Bezug auf die Prostata blieb unbefriedigend. Im Zuge der langfristigen Therapie konnte lediglich ein tendenziell positiver Einfluss auf das Muskelzelltypverhältnis (des M. longissimus) beobachtet werden. Insgesamt konnten unter Enobosarm-Applikation keine nennenswerten Tendenzen bezüglich Futteraufnahme, Körpergewicht und Kapillardichte beobachtet werden. Um auf eine sichere langfristige Anwendbarkeit zur Therapie von Sarkopenie wie auch von Osteoporose hinzuarbeiten (Girgis 2015), sollte die Applikation von geringeren Enobosarm-Dosen erforscht werden (Dalton et al. 2011).

Die sechswöchige Testosteronpropionat-Applikation zeigte ebenfalls einen positiven Einfluss auf die Muskelzellquerschnittsfläche. Ein verhältnismäßig geringer Effekt auf das Prostatagewicht sowie den M. levator ani wirft die Frage auf, ob über die orale Applikation ausreichende Wirkstoffkonzentrationen erreicht wurden oder ob die Anwendbarkeit von Testosteron und dessen Einfluss auf die androgendeprivierte Prostata gegebenenfalls neu evaluiert werden sollte (Bassil et al. 2009). Den sechs sowie 18-wöchigen TestosteronpropionatApplikationen war ein positiver Effekt auf das Muskelzelltypverhältnis gemein. Das Körpergewicht, weitere Muskelgewichte und die Kapillardichte blieben unter Testosteronpropionat-Applikation tendenzlos.

Zusammenfassend lässt sich festhalten, dass die Applikation von Enobosarm sowie Testosteronpropionat für eine kurzfristige Dauer vorteilhafte Effekte auf die Skelettmuskulatur in punkto Muskelzellquerschnittsfläche und für Enobosarm zusätzlich in puncto Muskelgewicht zeigten und gleichzeitig zufriedenstellende Ergebnisse hinsichtlich Prostatagewicht lieferten. Diese Ergebnisse weisen auf ein mögliches therapeutisches Potential hin, welches Gegenstand weiterer Forschungen sein sollte. Dahingehend wäre eine mögliche 
Synergie von Substanzwirkung und muskulären Trainings von besonderem Interesse (Egginton 2011; Cruz-Jentoft et al. 2014). Die erhoffte selektive Wirkung von Enobosarm (Cilotti und Falchetti 2009; Dalton et al. 2011; Dobs et al. 2013) sowie eindeutig positive Einflüsse auf die Skelettmuskulatur konnten im Rahmen der langfristigen Applikation nicht erzielt werden. 


\subsection{Zusammenfassung}

Osteoporose und Sarkopenie sind eng miteinander assoziierte Erkrankungen, welche zusammengenommen unser muskuloskelettales System betreffen. Lange als weibliche Erkrankungen erforscht, wurden nun die möglichen therapeutischen Auswirkungen des selektiven Androgenrezeptor-Modulators (SARMs) Enobosarm auf das muskuloskelettale System am osteoporotischen Modell der orchiektomierten Ratte untersucht. In dieser Arbeit wird ausschließlich die Forschung hinsichtlich der Skelettmuskulatur behandelt.

Der Versuch begann mit der beidseitigen Orchiektomie. Nach zwölf Wochen wurden alle Versuchstiere einer beidseitigen Osteotomie des Femurs mit anschließender stabiler Plattenosteosynthese unterzogen. Nach weiteren sechs Wochen wurden die Versuchstiere schließlich der Wissenschaft geopfert. Zu Versuchsbeginn wurden sechs Versuchsgruppen aus 90 Versuchstieren gebildet: 1. (nonORX): nicht orchiektomiert; 2. (ORX): orchiektomiert; 3. (SARMT): orchiektomiert + Enobosarm, 0,4 mg/kg KG/d p.o., für die letzten sechs Wochen; 4. (SARMP): orchiektomiert + Enobosarm, 0,4 mg/kg KG/d p.o., für 18 Wochen; 5. (TestT): orchiektomiert + Testosteronpropionat, 46,67 mg/kg KG/d p.o., für die letzten sechs Wochen; 6. (TestP): orchiektomiert + Testosteronpropionat, 46,67 mg/kg KG/d p.o., für 18 Wochen. Die Körpergewichte der Versuchstiere und die verzehrten Futtermengen wurden wöchentlich erhoben.

Post mortem wurden die Mm. longissimi, gastrocnemii und solei histologisch präpariert und mikroskopisch ausgewertet. Es wurden die Ratio von Typ-1- zu Typ-2-Muskelzellen, die Muskelzellquerschnittsflächen und -äquivalentdurchmesser sowie die Kapillardichte bestimmt. Darüber hinaus wurden die Aktivität der Kreatinkinase im Serum, die Muskelgewichte, einschließlich des M. levator ani, und die Prostatagewichte ermittelt.

Tendenziell zeigte sich, dass eine kurzfristige Therapie mit Enobosarm sowie Testosteronpropionat (SARMT, TestT) vorteilhafte Auswirkungen auf die Skelettmuskulatur der orchiektomierten Ratte hat, ohne dabei das 
Prostatagewicht nennenswert $\mathrm{zu}$ erhöhen. Eine längerfristige Therapie mit Enobosarm (SARMP) führte hingegen zu erhöhten Prostatagewichten und wirkte nicht eindeutig vorteilhaft auf die Skelettmuskulatur.

Für eine langfristige Anwendbarkeit von Enobosarm sollte die Applikation von geringeren Dosen erforscht werden. Darüber hinaus wäre eine synergistische Wirkung von Substanz und muskulärem Training denkbar und sollte ebenfalls zukünftig berücksichtigt werden.

\subsection{Summary}

Osteoporosis and sarcopenia are closely related diseases, which together affect our musculoskeletal system. Long researched as female diseases, the potential therapeutic effects of the selective androgen receptor modulator (SARMs) Enobosarm on the musculoskeletal system were now investigated using the osteoporotic model of the orchiectomized rat. This thesis deals exclusively with research on skeletal muscles.

The experiment commenced with bilateral orchiectomy. After twelve weeks, all experimental animals underwent bilateral femoral osteotomy followed by stable plate osteosynthesis. After an additional six weeks, the animals were finally sacrificed to science. At the beginning of the experiment, 90 animals were divided into six groups: 1. (nonORX): non-orchiectomized; 2. (ORX): orchiectomized; 3. (SARMT): orchiectomized + Enobosarm, $0.4 \mathrm{mg} / \mathrm{kg} \mathrm{BW} / \mathrm{d}$ p.o., for the last six weeks; 4. (SARMP): orchiectomized + Enobosarm, $0.4 \mathrm{mg} / \mathrm{kg}$ BW/d p.o., for 18 weeks; 5. (TestT): orchiectomized + testosterone propionate, $46.67 \mathrm{mg} / \mathrm{kg}$ BW/d p.o., for the last six weeks; 6. (TestT): orchiectomized + testosterone propionate, $46.67 \mathrm{mg} / \mathrm{kg} \mathrm{BW} / \mathrm{d}$ p.o., for 18 weeks. The body weights of the test animals and the quantities of food consumed were recorded weekly. The Mm. longissimi, gastrocnemii and solei were histologically prepared post mortem and microscopically evaluated. The ratio of type 1 to type 2 muscle cells, the muscle cell cross-sectional surfaces and equatorial diameters as well as the 
capillary density were determined. The activity of creatine kinase in serum, the muscle weights, including $M$. levator ani, and prostate weights were also determined.

Short-term treatment with Enobosarm and testosterone propionate (SARMT, TestT) tended to have beneficial effects on the skeletal muscles of the orchiectomized rat without significantly increasing the weight of the prostate. On the other hand, longer-term therapy with Enobosarm (SARMP) led to increased prostate weights and did not have a clearly beneficial effect on skeletal muscles. For long-term applicability of Enobosarm, the application of lower doses should be investigated. Furthermore, a synergistic effect of substance and muscular training would be conceivable and should also be considered in the future. 


\section{$5 \quad$ Anhang}

\subsection{Färbeprotokoll der Amylase-PAS-Färbung}

Wird im Folgenden keine Temperatur angegeben, herrschte Raumtemperatur.

1. Fixierung, 60 Min.

Senkrecht in den Küvetten stehend, wurden die Objektträger mit einem Gemisch aus Chloroform, Ethanol und Essigsäure bei $4{ }^{\circ} \mathrm{C}$ fixiert.

2. Spülen mit Aqua destillata (Aqua dest.) 10 x 5 Sek.

3. Amylase, $25 \mathrm{Min}$.

In Aqua dest. gelöste Amylase wird in die Küvetten gegeben und bei $37^{\circ} \mathrm{C}$ inkubiert.

4. Spülen mit Aqua dest. 10 x 5 Sek.

5. Perijodsäure, 30 Min.

Perijodsäure in Aqua dest. wurde hinzugefügt.

6. Spülen mit Aqua dest. 10 x 5 Sek.

7. Schiff-Reagenz, ca. 2 Min.

Nun wurde das Schiff-Reagenz in die Küvetten gefüllt. Unter ständiger Sichtkontrolle wurde der Färbeprozess kontrolliert. Die Färbung durfte nicht über ein zartes Rosa hinausgehen, welches nach 1-2 Min erreicht war. Man bedenke, dass die sichtbare Färbung fast ausschließlich durch Zellwände zustande kommt, welche nur einen Teil des Präparatvolumens ausmachen. Eine zu starke Einfärbung konnte eine spätere Auswertung vereiteln. Nicht zu spät wurde das Reagenz abgegossen.

8. Kaliumdisulfidlösung, 30 Min.

Zehn prozentige Kaliumdisulfidlösung wurde zusammen mit Aqua dest. und Salzsäure in die Küvetten gegeben. 
9. Leitungswasser, 10 Min.

Die Küvetten wurden mit fließendem Leitungswasser begossen.

Daraufhin wurden die Objektträger mindestens für fünf Minuten in Aqua dest. gelagert. Anschließend konnten die fertigen Färbungen mit Deckgläsern (Menzel Gläser, 24x48 mm \#1) konserviert werden. Dazu wurde ein wassergelöster Kleber (Aquatex ${ }^{\circledR}$, Merck KGaA) auf die Feinschnitte getropft und mit einem Deckglas belegt. Zwischen den Gläsern entstandene Blasen konnten durch externen Druck mit einem Spatel entfernt werden. $\mathrm{Zu}$ guter Letzt wurden die Objektträger in waagerechter Position für mindestens 48 Stunden getrocknet.

\subsection{Färbeprotokoll der ATPase-Färbung mit Diaphorase}

Wird im Folgenden keine Temperatur angegeben, herrschte Raumtemperatur.

1. Fixierung nach Meijer (Meijer 1970), 1 Min.

Die Lösung, bestehend aus Paraformaldehyd, Kalziumchloriddihydrat, Saccharose und Aqua dest. wurde nach pH-Einstellung auf 6,3-6,6 in die Küvetten gegeben.

2. Spülung mit Aqua dest., 2 x 5 Min.

3. Diaphorase-Inkubation, 60 Min.

Die Objektträger wurden hierzu waagerecht in Feuchtekammern gelegt und mit einer Lösung aus NADH-Dinatriumsalz, Phosphatpuffer, Nitroblautetrazoliumchlorid und Aqua dest. benetzt. Anschließend wurden diese bei $37^{\circ} \mathrm{C}$ inkubiert. 4. Spülung mit Aqua dest., 15 Min.

Wieder senkrecht in den Küvetten stehend, wurden die Objektträger erneut mit Aqua dest. gespült. 
5. Saure Vorinkubation, 15 Min.

Anschließend wurde eine Lösung aus Kalziumchloridstammlösung, Eisessig und Aqua dest. auf einen pH-Wert von 4,2 eingestellt und in die Küvetten gegeben.

6. Tris-Kalziumchloridlösung, 2 Min.

Tris(hydroxymethyl)-aminomethan, Kalziumchloridstammlösung und Aqua dest. werden gemeinsam auf einen $\mathrm{pH}$-Wert von 7,8 eingestellt und in die Küvetten gegeben.

7. ATPase-Inkubation, $30 \mathrm{Min}$.

Zur Inkubation bei $37{ }^{\circ} \mathrm{C}$ wurde eine Lösung aus Kaliumchlorid, ATP, Glycinpuffer und Kalziumchloridstammlösung eingesetzt.

8. Spülung mit Kalziumchloriddihydrat plus Aqua dest., 3 x 45 Sek.

9. Kobaltchloridlösung, 2 Min.

Anschließend an die Spülung wurde eine Lösung aus Kobaltchlorid und Aqua dest. auf die Objektträger gegeben.

10. Spülung mit Aqua dest., 3 x 45 Sek.

11. Ammoniumsulfidlösung, 2 Min.

Ammoniumsulfid in Aqua dest. wurde unter dem Abzug in die Küvetten gegeben.

12. Leitungswasser, $10 \mathrm{Min}$.

Zuletzt wurden die Küvetten mit fließendem Leitungswasser begossen und bis zur Versorgung mit Deckgläsern (siehe 5.1) in Aqua dest. gelagert. 


\subsection{Ansätze der Färbeprotokolle}

Im Folgenden werden die Ansätze, wenn nicht anders angegeben, zur Bestückung einer Glasküvette mit einem Fassungsvermögen von $60 \mathrm{ml}$, entsprechend den Nummerierungen der Färbeprotokolle, aufgeführt. Wenn die Lösungen auf Grund ihrer Lagerfähigkeit nicht schon vorläufig - und in teilweise größeren Mengen - angesetzt werden konnten (v), wurden sie für die Färbungen neu (n) angesetzt.

\subsubsection{Amylase-PAS-Färbung}

1. Fixierungslösung (n)

Ethanol (Merck KgaA)

$43 \mathrm{ml}$

Chloroform (Merck KgaA)

$8 \mathrm{ml}$

Essigsäure (Merck KgaA)

$2,7 \mathrm{ml}$

$\underline{\text { 3. Amylaselösung (n) }}$

Amylase (Sigma-Aldrich) $185 \mathrm{mg}$

Aqua dest. $60 \mathrm{ml}$

5. Perijodsäure (n)

Perijodsäure (Carl Roth GmbH + Co. KG) 0,8 g

Aqua dest. $60 \mathrm{ml}$

7. Schiff's Reagenz (v) (Carl Roth GmbH + Co. KG) 60 ml

8. Kaliumdisulfidlösung (v)

Aqua dest.

Kaliumdisulfidlösung (10 \%, Merck KgaA)

$\mathrm{HCl}(1 \mathrm{~N}$, Merck KgaA)
$600 \mathrm{ml}$

$30 \mathrm{ml}$

$30 \mathrm{ml}$ 


\subsubsection{ATPase-Färbung mit Diaphorase}

\section{$\underline{1 . \text { Fixierungslösung (n) }}$}

Paraformaldehyd (Carl Roth $\mathrm{GmbH}+\mathrm{Co} . \mathrm{KG}) \quad$ 0,6 g

Kalziumchloriddihydrat

$0,588 \mathrm{~g}$

(Fluka Chemie GmbH, Buchs, Schweiz)

Saccharose

$3,6 \mathrm{~g}$

(AppliChem GmbH, Darmstadt, Deutschland)

Aqua dest.

$60 \mathrm{ml}$

Aqua dest. wurde zuletzt hinzugefügt. Kurz vor Einsatz der Lösung wurde der pH-Wert auf 6,3-6,6 titriert. Hierzu wurde Natronlauge (Carl Roth GmbH + Co. KG) bzw. HCl (Merck KgaA) verwendet.

3.1 Diaphorase-Inkubationslösung (n) (500 $\mu \mathrm{l} /$ Präparat)

NADH-Dinatriumsalz (AppliChem $\mathrm{GmbH}$ ) $12 \mathrm{mg}$

Phosphatpuffer $(0,1 \mathrm{M}, \mathrm{pH} \mathrm{7,4)} \quad 2,08 \mathrm{ml}$

Nitroblautetrazoliumchlorid $\quad 2,6 \mathrm{ml}$

(Carl Roth GmbH + Co. KG)

Aqua dest.

$3,12 \mathrm{ml}$

\subsection{Phosphatpuffer (v)}

Lösung 1:

primäres Natriumphosphat

$18,8 \mathrm{~g}$

(0,1 M, Merck KgaA)

Aqua dest.

Lösung 2:

sekundäres Natriumphosphat $17,8 \mathrm{~g}$

$(0,1 \mathrm{M}$, Merck KgaA)

Aqua dest. 
15,9 ml von Lösung 1 plus 84,1 ml von Lösung 2 ergeben $100 \mathrm{ml}$ Phosphatpuffer. Die Einstellung auf den pH-Wert 7,4 wird durch Titrieren mit Lösung 1 (pHWert-Senkung) oder Lösung 2 (pH-Wert-Erhöhung) vorgenommen.

$\underline{3.3 \text { Nitroblautetrazoliumchlorid (v) }}$

Nitroblautetrazoliumchlorid $\quad 40 \mathrm{mg}$

(Carl Roth GmbH + Co. KG)

Aqua dest. $\quad 40 \mathrm{ml}$

5. Lösung für saure Vorinkubation (n)

Kalziumchloridstammlösung $\quad 6,67 \mathrm{ml}$

Eisessig (Merck KgaA) 0,27 ml

Aqua dest. $\quad 60 \mathrm{ml}$

Das Titrieren auf den pH-Wert 4,2 erfolgte, wie schon beschrieben, kurz vor Benutzung.

$\underline{5.1 \text { Kalziumchloridstammlösung (v) }}$

Kalziumchloridhydrat (Fluka Chemie $\mathrm{GmbH}$ ) $\quad 6,62 \mathrm{~g}$

Aqua dest. $250 \mathrm{ml}$

6. Tris-Kalziumchloridlösung (n)

Tris(hydroxymethyl)-aminomethan $\quad 0,74 \mathrm{~g}$

(Carl Roth GmbH + Co. KG)

Kalziumchloridstammlösung $\quad 6,1 \mathrm{ml}$

Aqua dest. $55 \mathrm{ml}$

Das Titrieren auf den pH-Wert 7,8 erfolgte, wie schon beschrieben, kurz vor Benutzung. 
7. ATPase Inkubationslösung (n)

Kaliumchlorid (Merck KgaA) $226 \mathrm{mg}$

ATP (Carl Roth GmbH + Co. KG) 93 mg

Glycinpuffer $55 \mathrm{ml}$

Kalziumchloridstammlösung $\quad 6,1 \mathrm{ml}$

Die Kalziumchloridstammlösung wurde zuletzt hinzugegeben. Das Titrieren auf den $\mathrm{pH}$-Wert 9,4 erfolgte, wie schon beschrieben, kurz vor Benutzung. Die Lösung wurde bei $37^{\circ} \mathrm{C}$ gelagert.

\subsection{Glycinpuffer (v)}

Glycinstammlösung $125 \mathrm{ml}$

Natronlauge (0,4 M Carl Roth GmbH + Co. KG) $42 \mathrm{ml}$

Aqua dest.

bis auf $500 \mathrm{ml}$ aufgefüllt

Anschließend das Titrieren, wie schon beschrieben, auf den pH-Wert 9,4.

\subsubsection{Glycinstammlösung (v)}

Glycin (AppliChem GmbH) $\quad$ 7,51 g

Aqua dest. $250 \mathrm{ml}$

Anschließend erfolgte das Titrieren, wie schon beschrieben, auf den $\mathrm{pH}$-Wert 9,4 .

8. Kalziumchloriddihydrat (v)

Kalziumchloriddihydrat (Sigma-Aldrich) $\quad 10 \mathrm{~g}$

Aqua dest.

11

9. Kobaltchloridlösung (n)

Kobaltchlorid (AppliChem $\mathrm{GmbH}) \quad 1,2 \mathrm{~g}$

Aqua dest. $\quad 60 \mathrm{ml}$

11. Ammoniumsulfidlösung (n)

Ammoniumsulfid (Merck KgaA) $\quad 0,08 \mathrm{ml}$

Aqua dest. $\quad 60 \mathrm{ml}$ 


\subsection{Tabellarische Darstellungen relevanter Daten}

\subsubsection{Futteraufnahme und Wirkstoffaufnahme im}

\section{Versuchsverlauf}

Tabelle 8: Durchschnittliche tägliche Futteraufnahmen (Mean) und Standardabweichungen (SD) in Gramm pro Versuchstier im Versuchsverlauf

\begin{tabular}{|c|c|c|c|c|c|c|c|}
\hline \multirow{2}{*}{\multicolumn{2}{|c|}{ Versuchswoche }} & \multicolumn{6}{|c|}{ Versuchsgruppe } \\
\hline & & \multirow{2}{*}{$\begin{array}{l}\text { nonORX } \\
28,53\end{array}$} & \multirow{2}{*}{$\begin{array}{l}\text { ORX } \\
27,83\end{array}$} & \multirow{2}{*}{$\begin{array}{l}\text { SARMT } \\
28,02\end{array}$} & \multirow{2}{*}{$\begin{array}{l}\text { SARMP } \\
30,00\end{array}$} & \multirow{2}{*}{$\begin{array}{l}\text { TestT } \\
28,31\end{array}$} & \multirow{2}{*}{$\begin{array}{l}\text { TestP } \\
15,67\end{array}$} \\
\hline 1 & Mean & & & & & & \\
\hline & $\mathrm{SD}$ & 1,49 & 3,60 & 3,86 & 3,20 & 4,59 & 10,42 \\
\hline \multirow[t]{2}{*}{2} & Mean & 34,15 & 38,43 & 35,26 & 33,64 & 34,49 & 30,75 \\
\hline & $\mathrm{SD}$ & 1,82 & 6,31 & 2,51 & 4,24 & 3,06 & 5,10 \\
\hline \multirow[t]{2}{*}{3} & Mean & 32,09 & 33,99 & 32,51 & 29,52 & 30,73 & 30,60 \\
\hline & $\mathrm{SD}$ & 1,35 & 2,36 & 4,27 & 3,99 & 5,38 & 6,57 \\
\hline \multirow[t]{2}{*}{4} & Mean & 32,46 & 31,99 & 29,86 & 28,63 & 32,57 & 30,78 \\
\hline & $\mathrm{SD}$ & 1,57 & 2,21 & 5,60 & 5,86 & 4,76 & 5,15 \\
\hline \multirow[t]{2}{*}{5} & Mean & 31,91 & 31,91 & 29,60 & 31,50 & 33,01 & 31,76 \\
\hline & $\mathrm{SD}$ & 2,53 & 2,30 & 5,27 & 3,70 & 3,05 & 3,09 \\
\hline \multirow[t]{2}{*}{6} & Mean & 31,07 & 31,69 & 32,99 & 34,02 & 36,56 & 33,07 \\
\hline & $\mathrm{SD}$ & 1,54 & 3,00 & 2,99 & 2,84 & 2,26 & 4,62 \\
\hline \multirow[t]{2}{*}{7} & Mean & 32,34 & 31,51 & 33,01 & 34,22 & 33,72 & 32,80 \\
\hline & $\mathrm{SD}$ & 1,54 & 3,00 & 2,73 & 3,05 & 1,70 & 4,90 \\
\hline \multirow[t]{2}{*}{8} & Mean & 30,86 & 33,07 & 31,44 & 33,64 & 33,08 & 32,84 \\
\hline & $\mathrm{SD}$ & 3,48 & 1,90 & 2,26 & 1,51 & 1,28 & 3,70 \\
\hline \multirow[t]{2}{*}{9} & Mean & 32,44 & 30,18 & 29,64 & 31,79 & 32,25 & 30,52 \\
\hline & $\mathrm{SD}$ & 1,29 & 2,99 & 3,34 & 1,27 & 4,87 & 3,25 \\
\hline \multirow[t]{2}{*}{10} & Mean & 32,42 & 29,44 & 30,15 & 32,03 & 30,07 & 31,53 \\
\hline & $\mathrm{SD}$ & 2,04 & 2,69 & 2,26 & 1,56 & 2,11 & 4,14 \\
\hline \multirow[t]{2}{*}{11} & Mean & 30,48 & 27,37 & 28,18 & 30,36 & 29,50 & 29,27 \\
\hline & SD & 2,32 & 2,54 & 2,33 & 1,89 & 3,34 & 3,51 \\
\hline \multirow[t]{2}{*}{12} & Mean & 30,76 & 26,47 & 28,66 & 33,14 & 27,23 & 28,36 \\
\hline & $\mathrm{SD}$ & 3,20 & 2,03 & 8,21 & 5,75 & 1,67 & 3,71 \\
\hline \multirow[t]{2}{*}{13} & Mean & 12,23 & 10,89 & 22,64 & 13,39 & 13,95 & 10,87 \\
\hline & $\mathrm{SD}$ & 1,58 & 2,66 & 12,24 & 2,38 & 4,81 & 3,61 \\
\hline \multirow[t]{2}{*}{14} & Mean & 0,00 & 0,00 & 0,00 & 0,00 & 0,00 & 0,00 \\
\hline & $\mathrm{SD}$ & 0,00 & 0,00 & 0,00 & 0,00 & 0,00 & 0,00 \\
\hline \multirow[t]{2}{*}{15} & Mean & 23,81 & 19,71 & 20,25 & 21,04 & 28,94 & 23,67 \\
\hline & SD & 0,13 & 3,55 & 2,42 & 2,71 & 18,59 & 5,01 \\
\hline
\end{tabular}


Versuchsgruppe

\begin{tabular}{|c|c|c|c|c|c|c|c|}
\hline \multicolumn{2}{|c|}{ Versuchswoche } & nonORX & ORX & SARMT & SARMP & TestT & TestP \\
\hline \multirow[t]{2}{*}{16} & Mean & 23,74 & 24,55 & 20,06 & 20,86 & 24,23 & 25,29 \\
\hline & $\mathrm{SD}$ & 1,83 & 9,38 & 0,57 & 2,59 & 3,87 & 4,90 \\
\hline \multirow[t]{2}{*}{17} & Mean & 29,37 & 26,91 & 26,00 & 27,95 & 26,65 & 31,86 \\
\hline & $\mathrm{SD}$ & 1,11 & 3,29 & 1,15 & 2,45 & 2,87 & 6,06 \\
\hline \multirow[t]{2}{*}{18} & Mean & 31,04 & 27,34 & 32,31 & 29,98 & 34,16 & 30,43 \\
\hline & SD & 3,19 & 2,80 & 2,88 & 2,58 & 1,30 & 1,45 \\
\hline
\end{tabular}


Tabelle 9: Durchschnittliche tägliche Wirkstoffaufnahme (Mean) und Standardabweichungen (SD) in Milligramm pro Versuchstier im Versuchsverlauf

\begin{tabular}{|c|c|c|c|c|c|}
\hline \multirow{2}{*}{\multicolumn{2}{|c|}{ Versuchswoche }} & \multicolumn{4}{|c|}{ Versuchsgruppe } \\
\hline & & SARMT & SARMP & TestT & TestP \\
\hline \multirow[t]{2}{*}{1} & Mean & - & 0,26 & - & 15,67 \\
\hline & SD & - & 0,03 & - & 10,42 \\
\hline \multirow[t]{2}{*}{2} & Mean & - & 0,29 & - & 30,75 \\
\hline & SD & - & 0,04 & - & 5,10 \\
\hline \multirow[t]{2}{*}{3} & Mean & - & 0,25 & - & 30,60 \\
\hline & $\mathrm{SD}$ & - & 0,03 & - & 6,57 \\
\hline \multirow[t]{2}{*}{4} & Mean & - & 0,25 & - & 30,78 \\
\hline & $\mathrm{SD}$ & - & 0,05 & - & 5,15 \\
\hline \multirow[t]{2}{*}{5} & Mean & - & 0,27 & - & 31,76 \\
\hline & $\mathrm{SD}$ & - & 0,03 & - & 3,09 \\
\hline \multirow[t]{2}{*}{6} & Mean & - & 0,29 & - & 33,07 \\
\hline & SD & - & 0,02 & - & 4,62 \\
\hline \multirow[t]{2}{*}{7} & Mean & - & 0,29 & - & 32,80 \\
\hline & $\mathrm{SD}$ & - & 0,03 & - & 4,90 \\
\hline \multirow[t]{2}{*}{8} & Mean & - & 0,29 & - & 32,84 \\
\hline & SD & - & 0,01 & - & 3,70 \\
\hline \multirow[t]{2}{*}{9} & Mean & - & 0,27 & - & 30,52 \\
\hline & $\mathrm{SD}$ & - & 0,01 & - & 3,25 \\
\hline \multirow[t]{2}{*}{10} & Mean & - & 0,27 & - & 31,53 \\
\hline & $\mathrm{SD}$ & - & 0,01 & - & 4,14 \\
\hline \multirow[t]{2}{*}{11} & Mean & - & 0,26 & - & 29,27 \\
\hline & $\mathrm{SD}$ & - & 0,02 & - & 3,51 \\
\hline \multirow[t]{2}{*}{12} & Mean & - & 0,28 & - & 28,36 \\
\hline & $\mathrm{SD}$ & - & 0,05 & - & 3,71 \\
\hline \multirow[t]{2}{*}{13} & Mean & 0,19 & 0,11 & 13,95 & 10,87 \\
\hline & SD & 0,10 & 0,02 & 4,81 & 3,61 \\
\hline \multirow[t]{2}{*}{14} & Mean & 0,00 & 0,00 & 0,00 & 0,00 \\
\hline & SD & 0,00 & 0,00 & 0,00 & 0,00 \\
\hline \multirow[t]{2}{*}{15} & Mean & 0,17 & 0,18 & 28,94 & 23,67 \\
\hline & $\mathrm{SD}$ & 0,02 & 0,02 & 18,59 & 5,01 \\
\hline \multirow[t]{2}{*}{16} & Mean & 0,17 & 0,18 & 24,23 & 25,29 \\
\hline & $\mathrm{SD}$ & 0,00 & 0,02 & 3,87 & 4,90 \\
\hline \multirow[t]{2}{*}{17} & Mean & 0,22 & 0,24 & 26,65 & 31,86 \\
\hline & SD & 0,01 & 0,02 & 2,87 & 6,06 \\
\hline \multirow[t]{2}{*}{18} & Mean & 0,28 & 0,26 & 34,16 & 30,43 \\
\hline & SD & 0,02 & 0,02 & 1,30 & 1,45 \\
\hline
\end{tabular}




\subsubsection{Körper-, Muskel- und Prostatagewichte}

Tabelle 10: Durchschnittliche Körpergewichte (Mean) und Standardabweichungen (SD) der Versuchstiere in Gramm im Versuchsverlauf ( ${ }^{*}$ signifikant erhöht gegenüber allen andern Gruppen)

\begin{tabular}{|c|c|c|c|c|c|c|c|}
\hline \multirow[b]{2}{*}{ Versuchswoche } & & \multicolumn{6}{|c|}{ Versuchsgruppe } \\
\hline & & nonORX & ORX & SARMT & SARMP & TestT & TestP \\
\hline \multirow[t]{2}{*}{1} & Mean & 721 & 664 & 661 & 683 & 667 & 626 \\
\hline & SD & 70 & 57 & 81 & 63 & 65 & 66 \\
\hline \multirow[t]{2}{*}{2} & Mean & 729 & 674 & 674 & 684 & 680 & 650 \\
\hline & SD & 71 & 54 & 80 & 67 & 77 & 56 \\
\hline \multirow[t]{2}{*}{3} & Mean & 731 & 685 & 678 & 676 & 679 & 655 \\
\hline & SD & 73 & 60 & 88 & 84 & 85 & 63 \\
\hline \multirow[t]{2}{*}{4} & Mean & 738 & 686 & 676 & 670 & 683 & 662 \\
\hline & SD & 76 & 57 & 99 & 103 & 94 & 68 \\
\hline \multirow[t]{2}{*}{5} & Mean & 735 & 690 & 679 & 682 & 689 & 670 \\
\hline & $\mathrm{SD}$ & 86 & 60 & 101 & 103 & 92 & 63 \\
\hline \multirow[t]{2}{*}{6} & Mean & 743 & 692 & 687 & 699 & 701 & 683 \\
\hline & SD & 77 & 62 & 86 & 89 & 85 & 60 \\
\hline \multirow[t]{2}{*}{7} & Mean & 753 & 696 & 698 & 710 & 702 & 689 \\
\hline & SD & 80 & 63 & 88 & 82 & 85 & 63 \\
\hline \multirow[t]{2}{*}{8} & Mean & 758 & 699 & 699 & 717 & 707 & 695 \\
\hline & SD & 81 & 66 & 91 & 82 & 87 & 68 \\
\hline \multirow[t]{2}{*}{9} & Mean & 760 & 699 & 699 & 720 & 706 & 696 \\
\hline & SD & 80 & 67 & 92 & 82 & 93 & 70 \\
\hline \multirow[t]{2}{*}{10} & Mean & 765 & 701 & 702 & 722 & 707 & 702 \\
\hline & SD & 85 & 68 & 91 & 86 & 94 & 72 \\
\hline \multirow[t]{2}{*}{11} & Mean & 778 & 699 & 702 & 724 & 706 & 701 \\
\hline & SD & 77 & 68 & 92 & 90 & 97 & 71 \\
\hline \multirow[t]{2}{*}{12} & Mean & 762 & 685 & 667 & 703 & 687 & 696 \\
\hline & SD & 82 & 68 & 97 & 91 & 99 & 74 \\
\hline \multirow[t]{2}{*}{13} & Mean & 696 & 614 & 629 & 653 & 664 & 632 \\
\hline & SD & 82 & 63 & 104 & 98 & 107 & 60 \\
\hline \multirow[t]{2}{*}{14} & Mean & 670 & 616 & 623 & 630 & 624 & 609 \\
\hline & SD & 73 & 60 & 94 & 90 & 103 & 66 \\
\hline \multirow[t]{2}{*}{15} & Mean & 681 & 616 & 600 & 635 & 635 & 616 \\
\hline & SD & 76 & 62 & 58 & 93 & 103 & 65 \\
\hline \multirow[t]{2}{*}{16} & Mean & 694 & 618 & 614 & 640 & 644 & 628 \\
\hline & SD & 78 & 58 & 54 & 97 & 108 & 69 \\
\hline \multirow[t]{2}{*}{17} & Mean & 715 & 631 & 628 & 657 & 664 & 645 \\
\hline & SD & 78 & 59 & 57 & 98 & 114 & 72 \\
\hline
\end{tabular}




\begin{tabular}{clllllll}
\hline & & \multicolumn{6}{c}{ Versuchsgruppe } \\
\cline { 3 - 8 } Versuchswoche & & nonORX & ORX & SARMT & SARMP & TestT & \multirow{2}{*}{ TestP } \\
\hline \multirow{2}{*}{18} & Mean & 724 & 635 & 632 & 666 & 679 & 659 \\
& SD & 75 & 65 & 68 & 99 & 109 & 75 \\
\hline Gesamte & Mean & $731^{*}$ & 667 & 664 & 682 & 679 & 662 \\
Versuchszeit & SD & 30 & 34 & 34 & 31 & 26 & 31 \\
\hline
\end{tabular}

Tabelle 11: Durchschnittliche Muskelgewichte (Mean) und Standardabweichungen (SD) der Mm. levatores anorum (MLA), Mm. gastrocnemii (MGA) und Mm. solei (MSO) der Versuchstiere in Gramm (Dunn's Multiple Comparison Test: * signifikant erhöht gegenüber ORX, TestT und TestP; + signifikant erniedrigt gegenüber SARMT und SARMP)

\begin{tabular}{llllllll}
\hline & & \multicolumn{5}{c}{ Versuchsgruppe } \\
\cline { 3 - 8 } Muskel & & nonORX & ORX & SARMT & SARMP & TestT & TestP \\
\hline \multirow{2}{*}{ MLA } & Mean & $0,60^{*}$ & $0,26+$ & 0,56 & 0,63 & 0,31 & 0,21 \\
& SD & 0,24 & 0,07 & 0,07 & 0,12 & 0,04 & 0,10 \\
\multirow{2}{*}{ MAG } & Mean & 3,18 & 2,77 & 3,13 & 2,87 & 2,99 & 2,85 \\
\multirow{2}{*}{ MSO } & SD & 0,44 & 0,44 & 0,38 & 0,55 & 0,52 & 0,56 \\
& Mean & 0,29 & 0,27 & 0,30 & 0,26 & 0,27 & 0,26 \\
& SD & 0,05 & 0,04 & 0,03 & 0,05 & 0,03 & 0,06 \\
\hline
\end{tabular}

Tabelle 12: Durchschnittliche Prostatagewichte (Mean) der Versuchstiere und Standardabweichungen (SD) in Gramm (Dunn's Multiple Comparison Test: * signifikant erhöht gegenüber ORX, SARMT, TestT und TestP; * signifikant erniedrigt gegenüber SARMP; ${ }^{\circ}$ signifikant erhöht gegenüber TestT)

\begin{tabular}{lllllll}
\hline & \multicolumn{5}{c}{ Versuchsgruppe } \\
\cline { 2 - 6 } & nonORX & ORX & SARMT & SARMP & TestT & TestP \\
\hline & & & & & \\
Mean & $1,22^{*}$ & $0,18^{*}$ & 0,39 & $0,62^{\circ}$ & 0,19 & 0,33 \\
SD & 0,30 & 0,07 & 0,08 & 0,13 & 0,07 & 0,13 \\
\hline
\end{tabular}




\subsubsection{Kapillardichte}

Tabelle 13: Durchschnittliche Anzahl Kapillare / Anzahl Muskelzellen (Mean) und Standardabweichungen (SD) im 0,5 mm² Muskelquerschnitt der Mm. longissimi (MLO), Mm. gastrocnemii (MGA) und Mm. solei (MSO) der Versuchstiere

\begin{tabular}{llllllll}
\hline & & \multicolumn{7}{c}{ Versuchsgruppe } \\
\cline { 3 - 8 } Muskel & & nonORX & ORX & SARMT & SARMP & TestT & TestP \\
\hline \multirow{2}{*}{ MLO } & Mean & 2,04 & 1,76 & 1,97 & 1,80 & 2,01 & 1,81 \\
& SD & 0,14 & 0,18 & 0,43 & 0,13 & 0,40 & 0,29 \\
\multirow{2}{*}{ MAG } & Mean & 1,98 & 1,76 & 1,80 & 1,83 & 1,76 & 1,80 \\
& SD & 0,26 & 0,22 & 0,29 & 0,35 & 0,22 & 0,28 \\
& Mean & 1,65 & 1,68 & 1,64 & 1,74 & 1,72 & 1,57 \\
& SD & 0,20 & 0,25 & 0,10 & 0,23 & 0,30 & 0,29 \\
\hline
\end{tabular}

\subsubsection{Muskelzellquerschnittsflächen und Muskelzell-}

\section{Äquivalentdurchmesser}

Tabelle 14: Durchschnittliche Muskelzellquerschnittsflächen (Mean) und Standardabweichungen (SD), Typ-1 und Typ-2 der Mm. longissimi der Versuchstiere in Quadratmikrometern sowie durchschnittliche Muskelzellquerschnittsflächen (Mean) / Körpergewichte (KG) der Versuchstiere in Gramm

\begin{tabular}{llllllll}
\hline & & \multicolumn{5}{c}{ Versuchsgruppe } \\
\cline { 3 - 8 } & & nonORX & ORX & SARMT & SARMP & TestT & TestP \\
\hline \multirow{2}{*}{ Typ-1 } & Mean & 3107 & 3373 & 3248 & 2844 & 3240 & 3000 \\
& SD & 755 & 1446 & 640 & 317 & 745 & 828 \\
& Mean/KG & 4,34 & 5,23 & 5,19 & 4,35 & 4,77 & 4,52 \\
& SD & 1,21 & 2,00 & 0,94 & 0,77 & 0,55 & 0,99 \\
Typ-2 & Mean & 7609 & 6534 & 7232 & 6274 & 7157 & 6350 \\
& SD & 2111 & 1205 & 1626 & 1022 & 1516 & 1448 \\
& Mean/KG & 10,62 & 10,26 & 11,49 & 9,62 & 10,52 & 9,61 \\
& SD & 3,32 & 2,20 & 1,99 & 2,28 & 0,63 & 1,59 \\
\hline
\end{tabular}


Tabelle 15: Durchschnittliche Muskelzell-Äquivalentdurchmesser (Mean) und Standardabweichungen (SD), Typ-1 und Typ-2 der Mm. longissimi der Versuchstiere in Mikrometern sowie durchschnittliche Muskelzell-Äquivalentdurchmesser (Mean) / Körpergewichte (KG) der Versuchstiere in Gramm

\begin{tabular}{llllllll}
\hline & & \multicolumn{5}{c}{ Versuchsgruppe } \\
\cline { 3 - 7 } & & nonORX & ORX & SARMT & SARMP & TestT & TestP \\
\hline \multirow{2}{*}{ Typ-1 } & Mean & 61,4 & 63,2 & 62,9 & 59,2 & 63,0 & 60,6 \\
& SD & 7,2 & 12,6 & 5,8 & 3,3 & 6,8 & 8,9 \\
& Mean /KG & 0,09 & 0,10 & 0,10 & 0,09 & 0,09 & 0,09 \\
& SD & 0,01 & 0,02 & 0,01 & 0,01 & 0,01 & 0,01 \\
Typ-2 & Mean & 96,9 & 90,1 & 94,9 & 88,6 & 94,5 & 88,9 \\
& SD & 12,4 & 8,3 & 10,3 & 7,2 & 9,8 & 10,4 \\
& Mean/KG & 0,13 & 0,14 & 0,15 & 0,14 & 0,14 & 0,14 \\
& SD & 0,02 & 0,02 & 0,02 & 0,02 & 0,01 & 0,01 \\
\hline
\end{tabular}

Tabelle 16: Durchschnittliche Muskelzellquerschnittsflächen (Mean) und Standardabweichungen (SD), Typ-1 und Typ-2 der Mm. gastrocnemii der Versuchstiere in Quadratmikrometern sowie durchschnittliche Muskelzellquerschnittsflächen (Mean) / Körpergewichte (KG) bzw. Muskelgewichte (MG) der Versuchstiere in Gramm ( ${ }^{*}$ in Quadratmillimeter / Gramm)

\begin{tabular}{|c|c|c|c|c|c|c|c|}
\hline & & \multicolumn{6}{|c|}{ Versuchsgruppe } \\
\hline & & nonORX & ORX & SARMT & SARMP & TestT & TestP \\
\hline \multirow[t]{6}{*}{ Тур-1 } & Mean & 2425 & 2082 & 2539 & 2640 & 2701 & 2220 \\
\hline & SD & 509 & 478 & 622 & 725 & 292 & 589 \\
\hline & Mean /KG & 3,35 & 3,26 & 4,05 & 3,97 & 4,11 & 3,38 \\
\hline & SD & 0,63 & 0,83 & 0,88 & 0,95 & 0,95 & 0,61 \\
\hline & Mean $/ \mathrm{MG}^{*}$ & 0,77 & 0,76 & 0,83 & 0,91 & 0,92 & 0,75 \\
\hline & $\mathrm{SD}^{*}$ & 0,16 & 0,27 & 0,25 & 0,13 & 0,14 & 0,09 \\
\hline \multirow[t]{6}{*}{ Тур-2 } & Mean & 4432 & 3849 & 4382 & 4600 & 4483 & 4146 \\
\hline & SD & 804 & 607 & 739 & 1413 & 1423 & 1085 \\
\hline & Mean /KG & 6,16 & 6,01 & 7,05 & 6,93 & 6,83 & 6,33 \\
\hline & SD & 1,29 & 0,87 & 1,41 & 1,80 & 2,55 & 1,00 \\
\hline & Mean $/ \mathrm{MG}^{*}$ & 1,40 & 1,37 & 1,43 & 1,60 & 1,50 & 1,41 \\
\hline & $\mathrm{SD}^{*}$ & 0,19 & 0,26 & 0,31 & 0,26 & 0,36 & 0,19 \\
\hline
\end{tabular}


Tabelle 17: Durchschnittliche Muskelzell-Äquivalentdurchmesser (Mean) und Standardabweichungen (SD), Typ-1 und Typ-2 der Mm. gastrocnemii der Versuchstiere in Mikrometern sowie durchschnittliche Muskelzell-Äquivalentdurchmesser (Mean) / Körpergewichte (KG) bzw. Muskelgewichte (MG) der Versuchstiere in Gramm ( ${ }^{*}$ in Quadratmillimeter / Gramm)

\begin{tabular}{|c|c|c|c|c|c|c|c|}
\hline & & \multicolumn{6}{|c|}{ Versuchsgruppe } \\
\hline & & nonORX & ORX & SARMT & SARMP & TestT & TestF \\
\hline \multirow[t]{6}{*}{ Typ-1 } & Mean & 54,6 & 50,5 & 55,9 & 56,6 & 58,0 & 52,2 \\
\hline & SD & 5,6 & 6,3 & 6,3 & 7,6 & 3,1 & 6,9 \\
\hline & Mean /KG & 0,08 & 0,08 & 0,09 & 0,09 & 0,09 & 0,08 \\
\hline & SD & 0,01 & 0,01 & 0,01 & 0,01 & 0,02 & 0,01 \\
\hline & Mean $/ \mathrm{MG}^{*}$ & 0,017 & 0,019 & 0,018 & 0,020 & 0,020 & 0,018 \\
\hline & $\mathrm{SD}^{*}$ & 0,003 & 0,005 & 0,004 & 0,002 & 0,003 & 0,002 \\
\hline \multirow[t]{6}{*}{ Тур-2 } & Mean & 74,2 & 69,2 & 73,9 & 75,1 & 74,2 & 71,5 \\
\hline & SD & 6,6 & 5,6 & 6,1 & 11,0 & 11,2 & 8,7 \\
\hline & Mean /KG & 0,10 & 0,11 & 0,12 & 0,11 & 0,11 & 0,11 \\
\hline & SD & 0,01 & 0,01 & 0,02 & 0,02 & 0,03 & 0,01 \\
\hline & Mean $/ \mathrm{MG}^{*}$ & 0,024 & 0,025 & 0,024 & 0,027 & 0,025 & 0,025 \\
\hline & $\mathrm{SD}^{*}$ & 0,003 & 0,004 & 0,004 & 0,004 & 0,004 & 0,004 \\
\hline
\end{tabular}

Tabelle 18: Durchschnittliche Muskelzellquerschnittsflächen (Mean) und Standardabweichungen (SD), Typ-1 der Mm. solei der Versuchstiere in Quadratmikrometern sowie durchschnittliche Muskelzellquerschnittsflächen (Mean) / Körpergewichte (KG) bzw. Muskelgewichte (MG) der Versuchstiere in Gramm ( ${ }^{*}$ in Quadratmillimeter / Gramm)

\begin{tabular}{llllllll}
\hline & & \multicolumn{5}{c}{ Versuchsgruppe } \\
\cline { 3 - 8 } & & nonORX & ORX & SARMT & SARMP & TestT & TestP \\
\hline \multirow{2}{*}{ Typ-1 } & Mean & 3852 & 4124 & 4397 & 3382 & 4367 & 3731 \\
& SD & 647 & 615 & 549 & 925 & 689 & 1086 \\
& Mean/KG & 5,40 & 6,44 & 7,09 & 5,25 & 6,54 & 5,71 \\
& SD & 1,29 & 0,78 & 1,32 & 2,12 & 1,21 & 1,61 \\
& Mean/MG* & 13,71 & 15,30 & 15,04 & 13,06 & 16,40 & 14,68 \\
& SD* & 2,75 & 2,53 & 3,04 & 3,06 & 1,47 & 3,25 \\
\hline
\end{tabular}


Tabelle 19: Durchschnittliche Muskelzell-Äquivalentdurchmesser (Mean) und Standardabweichungen (SD), Typ-1 der Mm. solei der Versuchstiere in Mikrometern sowie durchschnittliche Muskelzell-Äquivalentdurchmesser (Mean) / Körpergewichte (KG) bzw. Muskelgewichte (MG) der Versuchstiere in Gramm ( ${ }^{*}$ in Quadratmillimeter / Gramm)

\begin{tabular}{llllllll}
\hline & & \multicolumn{5}{c}{ Versuchsgruppe } \\
\cline { 3 - 8 } & & nonORX & ORX & SARMT & SARMP & TestT & TestP \\
\hline \multirow{2}{*}{ Typ-1 } & Mean & 69,2 & 71,5 & 73,9 & 64,3 & 73,8 & 67,7 \\
& SD & 6,1 & 5,3 & 4,5 & 8,0 & 5,7 & 9,8 \\
& Mean/KG & 0,10 & 0,11 & 0,12 & 0,10 & 0,11 & 0,10 \\
& SD & 0,02 & 0,01 & 0,02 & 0,02 & 0,02 & 0,02 \\
& Mean/MG* & 0,245 & 0,267 & 0,252 & 0,252 & 0,279 & 0,272 \\
& SD* & 0,042 & 0,041 & 0,039 & 0,052 & 0,018 & 0,057 \\
\hline
\end{tabular}

\subsubsection{Verhältnis der Muskelzelltypen des M. Iongissimus}

Tabelle 20: Verhältnisse (Mean) der Muskelzellanzahl von Typ-1 und Typ-2 zur Gesamtmuskelzellanzahl in $1 \mathrm{~mm}^{2}$ Muskelquerschnitt der $\mathrm{Mm}$. Iongissimi der Versuchstiere in Prozent

\begin{tabular}{llllllll}
\hline & \multicolumn{7}{c}{ Versuchsgruppe } \\
\cline { 3 - 8 } & & nonORX & ORX & SARMT & SARMP & TestT & TestP \\
\hline \multirow{2}{*}{ Typ-1 } & Mean & 40,6 & 41,1 & 41,7 & 38,6 & 34,2 & 37,2 \\
& SD & 4,5 & 4,8 & 5,7 & 5,5 & 10,1 & 6,9 \\
Typ-2 & Mean & 59,4 & 58,9 & 58,3 & 61,4 & 65,8 & 64,2 \\
& SD & 4,5 & 4,8 & 5,7 & 5,5 & 10,1 & 7,4 \\
\hline
\end{tabular}




\subsubsection{Serum-Kreatinkinase-Werte}

Tabelle 21: Durchschnittliche Serum-Kreatinkinase-Werte (Mean) und Standardabweichungen (SD) der Versuchsgruppen in Units/Liter

\begin{tabular}{lllllll}
\hline & \multicolumn{5}{c}{ Versuchsgruppe } \\
\cline { 2 - 6 } & nonORX & ORX & SARMT & SARMP & TestT & TestP \\
\hline & & & & & \\
Mean & 6563 & 5120 & 6048 & 6873 & 5214 & 7788 \\
SD & 2066 & 1785 & 3670 & 3610 & 533 & 2012 \\
\hline
\end{tabular}




\section{Literaturverzeichnis}

Adachi JD, Adami S, Gehlbach S, Anderson FA, Boonen S, Chapurlat RD, Compston JE, Cooper C, Delmas P, Adolfo D-P, et al. (2010): Impact of prevalent fractures on quality of life: baseline results from the global longitudinal study of osteoporosis in women. Mayo Clin Proc $\underline{85}$, 806-813

Adler RA (2014): Osteoporosis in men: a review. Bone Res $\underline{2}, 1-7$

Aitman TJ, Critser JK, Cuppen E, Dominiczak A, Fernandez-Suarez XM, Flint J, Gauguier D, Geurts AM, Gould M, Harris PC, et al. (2008): Progress and prospects in rat genetics: a community view. Nat Genet $\underline{40}, 516-522$

Ambrose C (2015): Muscle weakness during aging: a deficiency state involving declining angiogenesis. Ageing Res Rev $\underline{23}, 139-153$

Ammon J-C: Auswirkung der vertikalen Ganzkörpervibration unterschiedlicher Frequenzen auf die Muskulatur im osteoporotischen Rattenmodell. Med. Diss. Göttingen 2015

Anawalt BD, Yeap BB (2018): Conclusions about testosterone therapy and cardiovascular risk. Asian J Androl 20, 152-153

Andersen P (1975): Capillary density in skeletal muscle of man. Acta Physiol Scand $\underline{95}$, 203-205

Armstrong RB, Phelps RO (1984): Muscle fiber type composition of the rat hindlimb. Dev Dyn 171, 259-272

Badr I, Brown MD, Egginton S, Hudlická O, Milkiewicz M, Verhaeg J (2003): Differences in local environment determine the site of physiological angiogenesis in rat skeletal muscle. Exp Physiol $\underline{88}, 565-568$

Basaria S, Coviello AD, Travison TG, Storer TW, Farwell WR, Jette AM, Eder R, Tennstedt S, Ulloor J, Zhang A, et al. (2010): Adverse events associated with testosterone administration. N Engl J Med $\underline{363}, 109-122$

Basaria S, Collins L, Dillon EL, Orwoll K, Storer TW, Miciek R, Ulloor J, Zhang A, Eder R, Zientek H, et al. (2013): The safety, pharmacokinetics, and effects of LGD-4033, a novel nonsteroidal oral, selective androgen receptor modulator, in healthy young men. J Gerontol A Biol Sci Med Sci $\underline{68}$, 87-95

Bassil N, Alkaade S, Morley JE (2009): The benefits and risks of testosterone replacement therapy: a review. Ther Clin Risk Manag $\underline{5}, 427-448$

Baum S (2008): The PAS Reaction for Staining Cell Walls. Cold Spring Harb Protoc $\underline{3}, 1-3$ 
Baumgartner R, Waters D, Gallagher D, Morley J, Garry P (1999): Predictors of skeletal muscle mass in elderly men and women. Mech Ageing Dev 107, 123-136

Beeton C, Garcia A, Chandy KG (2007): Drawing blood from rats through the saphenous vein and by cardiac puncture. J Vis Exp $\underline{7}, 266$

Behm B, Stollman N (2003): Postoperative ileus: etiologies and interventions. Clin Gastroenterol Hepatol 1, 71-80

Berg BN, Harmison CR (1957): Growth, disease, and aging in the rat. J Gerontol $\underline{12}, 370-377$

Bhasin S, Jasuja R (2009): Selective androgen receptor modulators as function promoting therapies. Curr Opin Clin Nutr Metab Care 12, 232-240

Binkley N, Krueger D, Buehring B (2013): What's in a name revisited: should osteoporosis and sarcopenia be considered components of "dysmobility syndrome?”. Osteoporos Int 24 2955-2959

Blanqué R, Lepescheux L, Auberval M, Minet D, Merciris D, Cottereaux C, Clément-Lacroix P, Delerive P, Namour F (2014): Characterization of GLPG0492, a selective androgen receptor modulator, in a mouse model of hindlimb immobilization. BMC Musculoskelet Disord 15, 291

Bleibler F, Konnopka A, Benzinger P, Rapp K, König H-H (2013): The health burden and costs of incident fractures attributable to osteoporosis from 2010 to 2050 in Germany-a demographic simulation model. Osteoporos Int $\underline{24}, 835-847$

Blouin S, Libouban H, Moreau MF, Chappard D (2008): Orchidectomy models of osteoporosis. Methods Mol Biol Clifton NJ $\underline{455}$, 125-134

Borst SE, Conover CF (2006): Orchiectomized Fischer 344 male rat models body composition in hypogonadal state. Life Sci $\underline{79}, 411-415$

Borst SE, Conover CF, Carter CS, Gregory CM, Marzetti E, Leeuwenburgh C, Vandenborne K, Wronski TJ (2007): Anabolic effects of testosterone are preserved during inhibition of 5 -reductase. AJP Endocrinol Metab $\underline{293}$, 507-514

Brooke MH, Kaiser KK (1970): Muscle fiber types: how many and what kind? Arch Neurol 23, 369-379

Brown M, Fisher JS, Hasser EM (2001): Gonadectomy and reduced physical activity: Effects on skeletal muscle. Arch Phys Med Rehabil 2, 93-97

Budhia S, Mikyas Y, Tang M, Badamgarav E (2012): Osteoporotic fractures: a systematic review of U.S. healthcare costs and resource utilization. Pharmacoeconomics $\underline{30}, 147-170$

Carstens JC, Hoffmann DB, Lehmann W, Schilling AF, Krischek C, Sehmisch S, Komrakova M (2018): Die Wirkungen des selektiven 
Androgenrezeptormodulators „Ligandrol“ auf die Muskulatur im ovarektomierten Rattenmodell. Zitiert nach Postervorstellung (23.-26.10.2018) in: Deutscher Kongress für Orthopädie und Unfallchirurgie (DKOU 2018), Berlin 2018, Programm und Inhaltsangaben; o. Hrsg., o. Verl., o.O. 2018

Chen Y, Fu L, Han Y, Teng Y, Sun J, Xie R, Cao J (2012): Testosterone replacement therapy promotes angiogenesis after acute myocardial infarction by enhancing expression of cytokines HIF-1a, SDF-1a and VEGF. Eur J Pharmacol $\underline{684}$, 116124

Ciciliot S, Rossi AC, Dyar KA, Blaauw B, Schiaffino S (2013): Muscle type and fiber type specificity in muscle wasting. Int J Biochem Cell Biol $\underline{45}$, 2191-2199

Cilotti A, Falchetti A (2009): Male osteoporosis and androgenic therapy: from testosterone to SARMs. Clin Cases Min Bone Metab $\underline{6}$, 229-233

Cistulli PA, Grunstein RR, Sullivan CE (1994): Effect of testosterone administration on upper airway collapsibility during sleep. Am J Respir Crit Care Med 149, 530-532

Clark RV, Walker AC, O'Conner-Semmes RL, Leonard MS, Miller RR, Stimpson SA, Turner SM, Ravussin E, Cefalu WT, Hellerstein MK, Evans WJ (2014): Total body skeletal muscle mass: estimation by creatine (methyl-d3) dilution in humans. J Appl Physiol 116, 1605-1613

Clark RV, Walker AC, Andrews S, Turnbull P, Wald JA, Magee MH (2017): Safety, pharmacokinetics and pharmacological effects of the selective androgen receptor modulator, GSK2881078, in healthy men and postmenopausal women. Br J Clin Pharmacol 83, 2179-2194

Commission of Editors of Biochemical Journal (1965): Enzyme nomenclature. Report on the recommendations (1964) of the International Union of Biochemistry on Nomenclature and Classification of Enzymes. Science 150, 719-721

Consensus Development Conference (1993): Consensus development conference: diagnosis, prophylaxis, and treatment of osteoporosis. Am J Med $\underline{94}, 646-$ 650

Costa AG, Wyman A, Siris ES, Watts NB, Silverman S, Saag KG, Roux C, Rossini M, Pfeilschifter J, Nieves JW, et al. (2013): When, Where and How OsteoporosisAssociated Fractures Occur: An Analysis from the Global Longitudinal Study of Osteoporosis in Women (GLOW). PLoS One $\underline{8}$, e83306

Cozzoli A, Capogrosso RF, Sblendorio VT, Dinardo MM, Jagerschmidt C, Namour F, Camerino GM, De Luca A (2013): GLPG0492, a novel selective androgen receptor modulator, improves muscle performance in the exercised-mdx mouse model of muscular dystrophy. Pharmacol Res $\underline{72}, 9-24$ 
Crawford J, Prado CMM, Johnston MA, Gralla RJ, Taylor RP, Hancock ML, Dalton JT (2016): Study Design and Rationale for the Phase 3 Clinical Development Program of Enobosarm, a Selective Androgen Receptor Modulator, for the Prevention and Treatment of Muscle Wasting in Cancer Patients (POWER Trials). Curr Oncol Rep 18, 36-37

Cruz-Jentoft AJ, Baeyens JP, Bauer JM, Boirie Y, Cederholm T, Landi F, Martin FC, Michel J-P, Rolland Y, Schneider SM, et al. (2010): Sarcopenia: European consensus on definition and diagnosis: Report of the European Working Group on Sarcopenia in Older People. Age Ageing $\underline{39}, 412-423$

Cruz-Jentoft A (2013): Sarcopenia: a clinical review. Rev Clin Gerontol $\underline{23}$, 267274

Cruz-Jentoft AJ, Landi F, Schneider SM, Zuniga C, Arai H, Boirie Y, Chen L-K, Fielding RA, Martin FC, Michel J-P, et al. (2014): Prevalence of and interventions for sarcopenia in ageing adults: a systematic review. Report of the International Sarcopenia Initiative (EWGSOP and IWGS). Age Ageing 43, 748-759

Cruz-Jentoft AJ, Bahat G, Bauer J, Boirie $Y$, Bruyère $\mathrm{O}$, Cederholm T, Cooper $\mathrm{C}$, Landi F, Rolland Y, Sayer AA, et al. (2019): Sarcopenia: revised European consensus on definition and diagnosis. Age Ageing $\underline{48}, 16-31$

Dalbo VJ, Roberts MD, Mobley CB, Ballmann C, Kephart WC, Fox CD, Santucci VA, Conover CF, Beggs LA, Balaez A, et al. (2017): Testosterone and trenbolone enanthate increase mature myostatin protein expression despite increasing skeletal muscle hypertrophy and satellite cell number in rodent muscle. Andrologia $\underline{49}, 1-11$

Dalton JT, Barnette KG, Bohl CE, Hancock ML, Rodriguez D, Dodson ST, Morton RA, Steiner MS (2011): The selective androgen receptor modulator GTx-024 (enobosarm) improves lean body mass and physical function in healthy elderly men and postmenopausal women: results of a double-blind, placebo-controlled phase II trial. J Cachexia Sarcopenia Muscle 2, 153-161

Dalton JT (2017): The long and winding road for selective androgen receptor modulators. Br J Clin Pharmacol 83, 2131-2133

DGEM-Leitlinie 2013 Terminologie in der klinischen Ernährung. Deutsche Gesellschaft für Ernährungsmedizin, o.O. 2014

Dobs AS, Boccia RV, Croot CC, Gabrail NY, Dalton JT, Hancock ML, Johnston MA, Steiner MS (2013): Effects of enobosarm on muscle wasting and physical function in patients with cancer: a double-blind, randomised controlled phase 2 trial. Lancet Oncol $\underline{14}$, 335-345

Drenckhahn D: Makroskopische Anatomie, Histologie, Embryologie, Zellbiologie. Band 1; 17. Auflage; Elsevier, München 2008 
Drescher C, Konishi M, Ebner N, Springer J (2015): Loss of muscle mass: current developments in cachexia and sarcopenia focused on biomarkers and treatment. J Cachexia Sarcopenia Muscle $\underline{6}$, 303-311

Drey M, Sieber C, Bauer J, Uter W, Dahinden P, Fariello R, Vrijbloed J (2013): Cterminal Agrin Fragment as a potential marker for sarcopenia caused by degeneration of the neuromuscular junction. Exp Gerontol $\underline{48}$, 76-80

Dubois V, Simitsidellis I, Laurent MR, Jardi F, Saunders PTK, Vanderschueren D, Claessens F (2015): Enobosarm (GTx-024) Modulates Adult Skeletal Muscle Mass Independently of the Androgen Receptor in the Satellite Cell Lineage. Endocrinology 156, 4522-4533

DVO-Leitlinie 2014 zur Prophylaxe, Diagnostik und Therapie der Osteoporose bei Männern ab dem 60. Lebensjahr und bei postmenopausalen Frauen. Dachverband Osteologie e.V., o.O. 2014

Egginton S (2011): Physiological factors influencing capillary growth. Acta Physiol Oxf Engl 202, 225-239

Eisenberg E, Gordan GS (1950): The levator ani muscle of the rat as an index of myotrophic activity of steroidal hormones. J Pharmacol Exp Ther 99, 38-44

Estrada M, Espinosa A, ller M, Jaimovich E (2003): Testosterone stimulates intracellular calcium release and mitogen-activated protein kinases via a $\mathrm{G}$ protein-coupled receptor in skeletal muscle cells. Endocrinology 144, 3586-3597

Evans WJ, Morley JE, Argilés J, Bales C, Baracos V, Guttridge D, Jatoi A, Kamyar K-Z, Lochs H, Mantovani G, et al. (2008): Cachexia: a new definition. Clin Nutr 27, 793-799

Farrar RP, Martin TP, Ardies CM (1981): The interaction of aging and endurance exercise upon the mitochondrial function of skeletal muscle. J Gerontol $\underline{36}, 642-$ 647

Fearon K, Argiles JM, Baracos VE, Bernabei R, Coats A, Crawford J, Deutz NE, Doehner W, Evans WJ, Ferrucci L, et al. (2015): Request for regulatory guidance for cancer cachexia intervention trials. J Cachexia Sarcopenia Muscle $\underline{6}$, 272-274

Fielding RA, Vellas B, Evans WJ, Bhasin S, Morley JE, Newman AB, van Kan G, Andrieu S, Bauer J, Breuille D, et al. (2011): Sarcopenia: an undiagnosed condition in older adults. Current consensus definition: prevalence, etiology, and consequences. International working group on sarcopenia. J Am Med Dir Assoc 12, $249-256$

Furrer R, Handschin C (2019): Muscle Wasting Diseases: Novel Targets and Treatments. Annu Rev Pharmacol Toxicol $\underline{59}$, 315-339 
Freitas SS, Barrett-Connor E, Ensrud KE, Fink HA, Bauer DC, Cawthon PM, Lambert LC, Orwoll ES (2008): Rate and circumstances of clinical vertebral fractures in older men. Osteoporos Int $\underline{19}, 615-623$

Frese S, Velders M, Schleipen B, Schänzer W, Bloch W, Diel P (2011): Myosin heavy chain expression pattern as a marker for anabolic potency: desoxymethyltestosterone (madol), norandrostendione and testosterone repress MHC-IIb expression and stimulate MHC-IId/x expression in orchiectomized rat gastrocnemius muscle. Arch Toxicol $\underline{85}, 635-643$

Freyberger A, Ellinger-Ziegelbauer H, Krötlinger F (2007): Evaluation of the rodent Hershberger bioassay: testing of coded chemicals and supplementary molecular-biological and biochemical investigations. Toxicology 239, 77-88

Fridén J, Lieber RL (2001): Serum creatine kinase level is a poor predictor of muscle function after injury. Scand J Med Sci Sports 11, 126-127

Frost HM (1987): Bone „mass“ and the „mechanostat“: a proposal. Anat Rec $\underline{219}$, $1-9$

Frost HM (2003): Bone's mechanostat: A 2003 update. Anat Rec 275A, 10811101

Gagliano-Jucá T, Basaria S (2019): Testosterone replacement therapy and cardiovascular risk. Nat Rev Cardiol 16, 555-574

Garber K (2016): No longer going to waste. Nat Biotechnol 포, 458-461

Gemoll W, Vretska K, Kronasser H: Gemoll Griechisch-Deutsches Schul- und Handwörterbuch. 9. Auflage; Oldenburg Schulbuchverlag, München 2000

Girgis C (2015): Integrated Therapies for Osteoporosis and Sarcopenia: From Signaling Pathways to Clinical Trials. Calcif Tissue Int 96, 243-255

Gonçalves L, de Souza RR, Maifrino LBM, Caperuto ÉC, Carbone PO, Rodrigues B, Gama EF (2014): Resistance exercise and testosterone treatment alters the proportion of numerical density of capillaries of the left ventricle of aging Wistar rats. Aging Male $\underline{17}, 243-247$

Goodpaster B, Chomentowski P (2008): Effects of physical activity on strength and skeletal muscle fat infiltration in older adults: a randomized controlled trial. J Appl Physiol 105, 1498-1503

Gruenewald DA, Matsumoto AM (2003): Testosterone supplementation therapy for older men: potential benefits and risks. J Am Geriatr Soc 51, 101-115

Hem A, Smith AJ, Solberg P (1998): Saphenous vein puncture for blood sampling of the mouse, rat, hamster, gerbil, guinea pig, ferret and mink. Lab Anim $\underline{32}$, 364368 
Hershberger LG, Shipley EG, Meyer RK (1953): Myotrophic Activity of 19Nortestosterone and Other Steroids Determined by Modified Levator Ani Muscle Method. Proc Soc Exp Biol Med 3ㅜ, 175-180

Holloszy JO, Chen M, Cartee GD, Young JC (1991): Skeletal muscle atrophy in old rats: differential changes in the three fiber types. Mech Ageing Dev $\underline{60}, 199-213$

Holmäng A, Svedberg J, Jennische E, Björntorp P (1990): Effects of testosterone on muscle insulin sensitivity and morphology in female rats. Am J Physiol $\underline{259}$, $555-560$

Holyoak JD, Crawford ED, Meacham RB (2008): Testosterone and the prostate: implications for the treatment of hypogonadal men. Curr Urol Rep $\underline{9}, 500-505$

Horák V (1983): A successive histochemical staining for succinate dehydrogenase and „reversed“-ATPase in a single section for the skeletal muscle fibre typing. Histochemistry $\underline{78}, 545-553$

Hudlická (1985): Development and adaptability of microvasculature in skeletal muscle. J Exp Biol 115, 215-228

Iannaccone PM, Jacob HJ (2009): Rats! Dis Model Mech $\underline{2}$, 206-210

Izumi Y, Sugiyama F, Sugiyama Y, Yagami K (1993): Comparison between the blood from orbital sinus and heart in analizing plasma biochemical values-increase of plasma enzyme values in the blood from orbital sinus. Jikken Dobutsu $\underline{42}, 99-102$

Jacob HJ (1999): Functional genomics and rat models. Genome Res $\underline{9}$, 1013-1016

Jahelka B, Dorner T, Terkula R, Quittan M, Bröll H, Erlacher L (2009): Healthrelated quality of life in patients with osteopenia or osteoporosis with and without fractures in a geriatric rehabilitation department. Wien Med Wochenschr $\underline{159}, 235-240$

Jekl V, Hauptman K, Jeklová E, Knotek Z (2005): Blood sampling from the cranial vena cava in the Norway rat (Rattus norvegicus). Lab Anim 푸, 236-239

Kanis J, EV M, Johansson H, Oden A, Ström O, Borgström F (2010): Development and use of FRAX in osteoporosis. Osteoporos Int 21, 407-413

Kicman AT (2008): Pharmacology of anabolic steroids. Br J Pharmacol 154, 502521

Kim J, Wu D, Hwang D, Miller D, Dalton J (2005): The para substituent of S-3(phenoxy)-2-hydroxy-2-methyl-N-(4-nitro-3-trifluoromethyl-phenyl)-propionamides is a major structural determinant of in vivo disposition. J Pharmacol Exp Ther $\underline{315}, 230-239$ 
Kim J, Wang R, Veverka KA, Dalton JT (2013): Absorption, distribution, metabolism and excretion of the novel SARM GTx-024 [(S)-N-(4-cyano-3-(trifluoromethyl)phenyl)-3-(4-cyanophenoxy)-2-hydroxy-2-methylpropanamide] in rats. Xenobiotica $\underline{43}$, 993-1009

Kling JH: Einfluss des Lipoxygenaseinhibitors Baicalein in unterschiedlicher Dosierung auf den Skelettmuskel der ovariektomierten Ratte. Med. Diss. Göttingen 2015

Komrakova M, Werner C, Wicke M, Nguyen B, Sehmisch S, Tezval M, Stuermer K, Stuermer E (2009): Effect of daidzein, 4-methylbenzylidene camphor or estrogen on gastrocnemius muscle of osteoporotic rats undergoing tibia healing period. J Endocrinol 201, 253-262

Komrakova M, Krischek C, Wicke M, Sehmisch S, Tezval M, Rohrberg M, Brandsch T, Stuermer K, Stuermer E (2011): Influence of intermittent administration of parathyroid hormone on muscle tissue and bone healing in orchiectomized rats or controls. J Endocrinol 209, 9-19

Komrakova M, Hoffmann DB, Nuehnen V, Stueber H, Wassmann M, Wicke M, Tezval M, Stuermer K, Sehmisch S (2016): The Effect of Vibration Treatments Combined with Teriparatide or Strontium Ranelate on Bone Healing and Muscle in Ovariectomized Rats. Calcif Tissue Int $\underline{99}$, 408-422

Korenchevsky V, Dennison M, Eldridge M (1937): The prolonged treatment of castrated and ovariectomized rats with testosterone propionate. Biochem J $\underline{31}$, 475

Kovanen V, Suominen H (1987): Effects of age and life-time physical training on fibre composition of slow and fast skeletal muscle in rats. Pflugers Arch $\underline{408}$, $543-551$

Lang F: Nervensystem, Muskel, Sinne. In: Silbernagel S, Lang F: Taschenatlas Pathophysiologie. 4. Auflage; Gerorg Thieme Verlag, Stuttgart 2013, 324-387

Larsson L, Biral D, Campione M, Schiaffino S (1993): An age-related type IIB to IIX myosin heavy chain switching in rat skeletal muscle. Acta Physiol Scand 147, $227-234$

Lauretani F, Russo CR, Bandinelli S, Bartali B, Cavazzini C, Iorio A, Corsi AM, Rantanen T, Guralnik JM, Ferrucci L (2003): Age-associated changes in skeletal muscles and their effect on mobility: an operational diagnosis of sarcopenia. J Appl Physiol 95, 1851-1860

Lefebvre HP, Jaeg JP, Rico AG, Toutain PL, Braun JP (1992): Variations of plasma creatine kinase in rabbits following repetitive blood sampling effects of pretreatment with acepromazine, carazolol and dantrolene. Eur J Clin Chem Clin Biochem $\underline{30}, 425-428$ 
Leitlinie Osteoporose s. DVO-Leitlinie 2014

Leitlinie Terminologie in der klinische Ernährung s. DGEM-Leitlinie 2013

Lexell J (1995): Human aging, muscle mass, and fiber type composition. J Gerontol $\underline{50}, 11-16$

Lightfoot AP, Rachel M, Nye GA, Anne M (2014): Mechanisms of skeletal muscle ageing; avenues for therapeutic intervention. Curr Opin Pharmacol 16, 116-121

Lindsey JR, Baker HJ: Historical foundations. In: Suckow M, Weisbroth S, Franklin C (Hrsg.): The laboratory rat. 2. Auflage; Academic Press, New York 2005, 152

Lubischer JL, Bebinger DM (1999): Regulation of terminal Schwann cell number at the adult neuromuscular junction. J Neurosci $\underline{19}, 46$

Lüllmann-Rauch R, Asan E: Histologie. In: Asan E, Lüllmann-Rauch R (Hrsg.): Muskelgewebe. 5. Auflage; Thieme, Stuttgart 2015, 238-266

Magal M, Dumke CL, Urbiztondo ZG, Cavill MJ, Triplett NT, Quindry JC, McBride JM, Epstein Y (2010): Relationship between serum creatine kinase activity following exercise-induced muscle damage and muscle fibre composition. J Sports Sci $28,257-266$

Marks LS, Mazer NA, Mostaghel E, Hess DL, Dorey FJ, Epstein JI, Veltri RW, Makarov DV, Partin AW, Bostwick DG, et al. (2006): Effect of testosterone replacement therapy on prostate tissue in men with late-onset hypogonadism: a randomized controlled trial. JAMA 296, 2351-2361

McGregor RA, Cameron-Smith D, Poppitt SD (2014): It is not just muscle mass: a review of muscle quality, composition and metabolism during ageing as determinants of muscle function and mobility in later life. Longev Heal $\underline{3}, 9$

Meijer AE (1970): Histochemical method for the demonstration of myosin adenosine triphosphatase in muscle tissues. Histochemie $\underline{22}, 51-58$

Miescher K, Wettstein A, Tschopp E (1936): The activation of the male sex hormones. II. Biochem J 30, 1977-1990

Moline SW, Glenner GG (1964): Ultrarapid tissue freezing in liquid Nitrogen. J Histochem Cytochem 12, 777-783

Monaco M, Vallero F, Monaco R, Tappero R (2011): Prevalence of sarcopenia and its association with osteoporosis in 313 older women following a hip fracture. Arch Gerontol Geriatr $\underline{52}, 71-74$

Moore KL, Vidhya T, Persaud N: Embryologie. In: Moore KL, Vidhya T, Persaud N: Muskulatur. 5. Auflage; Urban \& Fischer, München 2007, 443-446 
Moreau MF, Libouban H, Legrand E, Baslé MF, Audran M, Chappard D (2001): Lean, fat and bone masses are influenced by orchidectomy in the rat. A densitometric X-ray absorptiometric study. J Musculoskelet Neuronal Interact 1 , 209213

Morley JE, Abbatecola AM, Argiles JM, Baracos V, Bauer J, Bhasin S, Cederholm T, Coats AJ, Cummings SR, Evans WJ, et al. (2011): Sarcopenia with limited mobility: an international consensus. J Am Med Dir Assoc 12, 403-409

Morton DB, Abbot D, Barclay R (1993): Removal of blood from laboratory mammals and birds. First report of the BVA/FRAME/RSPCA/UFAW Joint Working Group on Refinement. Lab Anim 27, 1-22

Moslen MT, Kanz MF, Bhatia J, Catarau EM (1988): Two cannula method for parenteral infusion and serial blood sampling in the freely moving rat. J Parenter Enteral Nutr 12, 633-637

Muscaritoli M, Anker S, Argilés J, Aversa Z, Bauer J, Biolo G, Boirie Y, Bosaeus I, Cederholm T, Costelli P, et al. (2010): Consensus definition of sarcopenia, cachexia and pre-cachexia: joint document elaborated by Special Interest Groups (SIG) „cachexia-anorexia in chronic wasting diseases“ and „nutrition in geriatrics“. Clin Nutr $\underline{29}, 154-159$

Narayanan R, Mohler ML, Bohl CE, Miller DD, Dalton JT (2008): Selective androgen receptor modulators in preclinical and clinical development. Nucl Recept Signal $\underline{6}$, e010

Narayanan R, Coss CC, Dalton JT (2018): Development of selective androgen receptor modulators (SARMs). Mol Cell Endocrinol 465, 134-142

Nedergaard A, Karsdal MA, Sun S, Henriksen K (2013): Serological muscle loss biomarkers: an overview of current concepts and future possibilities. J Cachexia Sarcopenia Muscle $\underline{4}, 1-17$

Negro-Vilar A (1999): Selective androgen receptor modulators (SARMs): a novel approach to androgen therapy for the new millennium. J Clin Endocrinol Metab 84, 3459-3462

Neil D, Clark RV, Magee M, Billiard J, Chan A, Xue Z, Russell A (2018): GSK2881078, a SARM, Produces Dose-Dependent Increases in Lean Mass in Healthy Older Men and Women. J Clin Endocrinol Metab 103, 3215-3224

Omwancha J, Brown TR (2006): Selective androgen receptor modulators: in pursuit of tissue-selective androgens. Curr Opin Investig Drugs $\underline{7}$, 873-881

Osterberg EC, Bernie AM, Ramasamy R (2014): Risks of testosterone replacement therapy in men. Indian J Urol $\underline{30}, 2-7$

Papanicolaou D, Ather S, Zhu H, Zhou Y, Lutkiewicz J, Scott B, Chandler J (2013): A phase IIA randomized, placebo-controlled clinical trial to study the efficacy 
and safety of the selective androgen receptor modulator (SARM), MK-0773 in female participants with sarcopenia. J Nutr Health Aging $\underline{17}$, 533-43

Pechersky AV, Mazurov VI, Semiglazov VF, Karpischenko AI, Mikhailichenko VV, Udintsev AV (2002): Androgen administration in middle-aged and ageing men: effects of oral testosterone undecanoate on dihydrotestosterone, oestra-

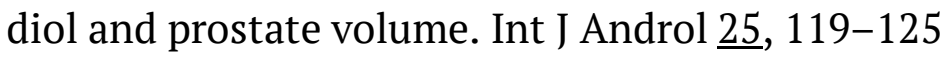

Peter JB, Barnard RJ, Edgerton VR, Gillespie CA, Stempel KE (1972): Metabolic profiles of three fiber types of skeletal muscle in guinea pigs and rabbits. Biochemistry (Moscow) 11, 2627-2633

Rechholz CHM: Der Einfluss von vertikaler Ganzkörpervibration, Alendronat und 8-Prenylnaringenin auf die Muskulatur der ovariektomierten Ratte. Med. Diss. Göttingen 2017

Reiss J, Iglseder B, Kreutzer M, Weilbuchner I, Treschnitzer W, Kässmann H, Pirich C, Reiter R (2016): Case finding for sarcopenia in geriatric inpatients: performance of bioimpedance analysis in comparison to dual X-ray absorptiometry. BMC Geriatr $\underline{16}, 52$

Roddam AW, Allen NE, Appleby P, Key TJ (2008): Endogenous sex hormones and prostate cancer: a collaborative analysis of 18 prospective studies. J Natl Cancer Inst $\underline{100}, 170-183$

Rogers MA, Evans WJ (1993): Changes in skeletal muscle with aging: effects of exercise training. Exerc Sport Sci Rev 21, 65-102

Rosenberg IH (1989): Summary comments. Am J Clin Nutr 므, 1231-1233

Roubenoff R, Hughes V (2000): Sarcopenia: current concepts. J Gerontol Biol Sci Med Sci $\underline{55}$, M716-24

Ryu SJ, Ryu DS, Kim JY, Park JY, Kim KH, Chin DK, Kim KS, Cho YE, Kuh SU (2015): Bone Mineral Density Changes after Orchiectomy using a Scrotal Approach in Rats. Korean J Spine 12, 55-59

Scanlon TC, Fragala MS, Stout JR, Emerson NS, Beyer KS, Oliveira LP, Hoffman JR (2014): Muscle architecture and strength: Adaptations to short term resistance training in older adults. $\underline{49}, 584-592$

Segal S, Narayanan R, Dalton JT (2006): Therapeutic potential of the SARMs: revisiting the androgen receptor for drug discovery. Expert Opin Investig Drugs $\underline{15}$, 377-387

Scheidt-Nave C, Banzer D, Abendroth K (1997): Schlussbericht Multizentrische Studie zu Verteilung, Determination und prädiktivem Wert der Knochendichte in der deutschen Bevölkerung. Förderprojekt Bundesminist für Forschung und Technologie. Förderkennzeichen 01KM 93040, 1-45 
Seidlová-Wuttke D, Stürmer KM, Stürmer EK, Sehmisch S, Wuttke W (2006): Contrasting effects of estradiol, testosterone and of a black cohosh extract on density, mechanical properties and expression of several genes in the metaphysis of the tibia and on fat tissue of orchidectomized rats. Maturitas $\underline{55}, 64-74$

Sergi G, De Rui M, Veronese N, Bolzetta F, Berton L, Carraro S, Bano G, Coin A, Manzato E, Perissinotto E (2015): Assessing appendicular skeletal muscle mass with bioelectrical impedance analysis in free-living Caucasian older adults. Clin Nutr Edinb Scotl $\underline{34}, 667-673$

Shang Y, Myers M, Brown M (2002): Formation of the androgen receptor transcription complex. Mol Cell $\underline{9}, 601-610$

Sinert R, Kohl L, Rainone T, Scalea T (1994): Exercise-induced rhabdomyolysis. Ann Emerg Med 233, 1301-1306

Sinha-Hikim I, Artaza J, Woodhouse L, Gonzalez-Cadavid N, Singh AB, Lee MI, Storer TW, Casaburi R, Shen R, Bhasin S (2002): Testosterone-induced increase in muscle size in healthy young men is associated with muscle fiber hypertrophy. Am J Physiol 283, e154-e164

Sinnesael M, Callewaert F, Morreels M, Kumar N, Sitruk-Ware R, Van Proeyen K, Hespel P, Boonen S, Claessens F, Vanderschueren D (2011): 7 $\alpha$-methyl-19nortestosterone vs. testosterone implants for hypogonadal osteoporosis: a preclinical study in the aged male orchidectomized rat model: Hypogonadal Osteoporosis. Int J Androl 노, e601-e611

Siparsky PN, Kirkendall DT, Garrett WE (2014): Muscle changes in aging: understanding sarcopenia. Sports Health $\underline{6}, 36-40$

Sjöblom S, Suuronen J, Rikkonen T, Honkanen R (2013): Relationship between postmenopausal osteoporosis and the components of clinical sarcopenia. Maturitas $\underline{75}, 175-180$

Snyder P, Peachey H, Hannoush P, Berlin J, Loh L, Lenrow D, Holmes J, Dlewati A, Santanna J, Rosen C, Strom B (1999): Effect of testosterone treatment on body composition and muscle strength in men over 65 years of age. J Clin Endocrinol Metab 4ㅗ $2647-2653$

Srinath R, Dobs A (2014): Enobosarm (GTx-024, S-22): a potential treatment for cachexia. Future Oncol $\underline{10}, 187-194$

Stürmer EK, Seidlová-Wuttke D, Sehmisch S, Rack T, Wille J, Frosch KH, Wuttke W, Stürmer KM (2005): Standardized Bending and Breaking Test for the Normal and Osteoporotic Metaphyseal Tibias of the Rat: Effect of Estradiol, Testosterone, and Raloxifene. J Bone Miner Res 21, 89-96

Stuermer E, Sehmisch S, Tezval M, Tezval H, Rack T, Boekhoff J, Wuttke W, Herrmann T, D S-W, Stuermer K (2009): Effect of testosterone, raloxifene and 
estrogen replacement on the microstructure and biomechanics of metaphyseal osteoporotic bones in orchiectomized male rats. World J Urol 27, 547-555

Tarantino U, Baldi J, Celi M, Rao C, Liuni FM, Iundusi R, Gasbarra E (2013): Osteoporosis and sarcopenia: the connections. Aging Clin Exp Res 225, 93-95

Terracciano C, Celi M, Lecce D, Baldi J, Rastelli E, Lena E, Massa R, Tarantino U (2013): Differential features of muscle fiber atrophy in osteoporosis and osteoarthritis. Osteoporos Int $\underline{24}, 1095-1100$

Thompson IM, Pauler DK, Goodman PJ, Tangen CM, Lucia MS, Parnes HL, Minasian LM, Ford LG, Lippman SM, Crawford ED et al. (2004): Prevalence of prostate cancer among men with a prostate-specific antigen level $<$ or $=4.0 \mathrm{ng}$ per milliliter. N Engl J Med 350, 2239-2246

Turner RT, Hannon KS, Demers LM, Buchanan J, Bell NH (1989): Differential effects of gonadal function on bone histomorphometry in male and female rats. J Bone Miner Res $\underline{4}, 557-563$

Vanderschueren D, Vandenput L, Boonen S, Van Herck E, Swinnen JV, Bouillon $R$ (2000): An aged rat model of partial androgen deficiency: prevention of both loss of bone and lean body mass by low-dose androgen replacement. Endocrinology $\underline{141}, 1642-1647$

Vellas B, Fielding RA, Bens C, Bernabei R, Cawthon PM, Cederholm T, Cruz-Jentoft AJ, Del Signore S, Donahue S, Morley J, et al. (2018): Implications of ICD-10 for Sarcopenia Clinical Practice and Clinical Trials: Report by the International Conference on Frailty and Sarcopenia Research Task Force. J Frailty Aging 7 , 29

Verschueren S, Gielen E, TW O, Pye S, Adams J, Ward K, Wu F, Szulc P, Laurent M, Claessens F (2013): Sarcopenia and its relationship with bone mineral density in middle-aged and elderly European men. Osteoporos Int 24, 87-98

Wang H, Listrat A, Meunier B, Gueugneau M, Cécile C-G, Combaret L, Taillandier D, Polge C, Attaix D, Lethias C, et al. (2014): Apoptosis in capillary endothelial cells in ageing skeletal muscle. Aging Cell $\underline{13}, 254-262$

Welsch U, Deller T: Lehrbuch der Histologie. In: Deller T, Welsch U (Hrsg.): Muskelgewebe. 3. Auflage; Urban \& Fischer Verlag, München 2010, 152-167

Westaby D, Ogle SJ, Paradinas FJ, Randell JB, Murray-Lyon IM (1977): Liver damage from long-term methyltestosterone. Lancet $\underline{2}$, 262-263

Wigston DJ, English AW (1992): Fiber-type proportions in mammalian soleus muscle during postnatal development. J Neurobiol $\underline{23}, 61-70$

Wink CS, Felts WJ (1980): Effects of castration on the bone structure of male rats: a model of osteoporosis. Calcif Tissue Int $\underline{32}, 77-82$ 
Yarrow JF, McCoy SC, Borst SE (2010): Tissue selectivity and potential clinical applications of trenbolone (17beta-hydroxyestra-4,9,11-trien-3-one): A potent anabolic steroid with reduced androgenic and estrogenic activity. Steroids $\underline{75}$, 377-389

Yu J-G, Bonnerud P, Eriksson A, Stål PS, Tegner Y, Malm C (2014): Effects of long term supplementation of anabolic androgen steroids on human skeletal muscle. PloS One $\underline{9}$, e105330

Zilbermint MF, Dobs AS (2009): Nonsteroidal selective androgen receptor modulator Ostarine in cancer cachexia. Future Oncol $\underline{5}, 1211-1220$

Zur B: Laborchemische Referenzbereiche für Wistarratten und C57BL/6-Mäuse. Med. Diss. Düsseldorf 2005 


\section{Danksagung}

Zunächst danke ich dem ehemaligen Abteilungsleiter Herrn Prof. Dr. med. K. M. Stürmer und dem Abteilungsleiter Herrn Prof. Dr. med. W. Lehmann, sowie der Deutschen Forschungsgemeinschaft (SE 1966/6-1, KO 4646/3-1) für die Ermöglichung und Förderung dieser Arbeit.

Ein beachtlicher Dank gilt meinem Doktorvater Prof. Dr. med. S. Sehmisch für die ruhige und zielführende Unterstützung von Anfang bis Ende meiner Dissertation.

Mein besonderer Dank richtet sich an Dr. rer. nat. Marina Komrakova für ihre überaus gute Betreuung und allgegenwärtige unterstützende Präsenz.

Herzlich danke ich Frau Ramona Castro-Machgut und Frau Annette Witt für ihre tatkräftige Unterstützung in Labor und OP sowie ihre erfahrene und herzliche Unterstützung.

Ferner danke ich Frau Ruth Wiggert, Mitarbeiterin des Departments für Nutztierwissenschaften der Georg-August Universität Göttingen, für ihre freundliche Hilfe. 